\title{
A model of stress distribution and cracking in cohesive soils produced by simple tillage implements
}

\author{
by \\ Sandra Y. Ibarra \\ A thesis submitted to the Faculty of Graduate Studies and Research in Partial fulfilment \\ of the requirements for the degree of Doctor of Philosophy.
}

August 2001

Department of Agricultural \& Biosystems Engineering Macdonald Campus, McGill University

Montreal, Canada

(c) Sandra Y. Ibarra, 2001 
National Library of Canada

Acquisitions and Bibliographic Services

395 Wellington Street Ottawa ON K1A ON4 Canada
Bibliothèque nationale du Canada

Acquisitions et services bibliographiques

395, rue Wellington Ottawa ON KIA ON4 Canada
Your the Votre refterence

Our the Notre reiterence
The author has granted a nonexclusive licence allowing the National Library of Canada to reproduce, loan, distribute or sell copies of this thesis in microform, paper or electronic formats.

The author retains ownership of the copyright in this thesis. Neither the thesis nor substantial extracts from it may be printed or otherwise reproduced without the author's permission.
L'auteur a accordé une licence non exclusive permettant à la Bibliothèque nationale du Canada de reproduire, prêter, distribuer ou vendre des copies de cette thèse sous la forme de microfiche/film, de reproduction sur papier ou sur format électronique.

L'auteur conserve la propriété du droit d'auteur qui protège cette thèse. Ni la thèse ni des extraits substantiels de celle-ci ne doivent être imprimés ou autrement reproduits sans son autorisation. 


\begin{abstract}
The objective of this research was to further understand the behavior of the soil under the action of a tillage tool, with the purpose of finding a relation between the tool geometry and the resultant soil seed bed. Thus the problem consisted of understanding the mechanics of producing soil break up and to find a logical method of analyzing it.

The problem was solved using fundamental principles of soil mechanics and force equilibrium analyzis. As a result, a mathematical model was developed which describes three failure zones within the cut soil volume. The model can be programmed into a computer to generate maps of normal and shear stresses to visualize the three failure zones.
\end{abstract}

The failure zones are the shear failure zone, the tensile fracturing zone and the no failure zone. The tensile fracturing zone is delimited by the tensile stress reaching the tensile strength of the soil at the given soil moisture content and soil density. The tensile strength of the soil was measured using an apparatus and method designed in this research.

The mathematical model gives an explanation of the mechanics of crumbling and the shape of the failed volume, but it does not give information concerning soil aggregate quality and arrangement within the soil furrow. Then, a method of analyzing the formed aggregates was developed which considers some soil physical properties of aggregates.

The study concluded that the smaller tool width and the smaller tool rake angle, among the ones used in this research, produced the most efficient geometry in producing the largest amount of soil break up, the most uniform aggregate formation and the most stable aggregate arrangement. The same tool geometry requires less energy per unit volume of soil disturbed. The best performance is produced at the lowest soil water content among those tested.

Keywords: stress analysis, tensile fracture, shear strength, tensile strength, soil seed bed, swelling factor, uniformity coefficient. 


\section{Résumé}

L'objectif principal de cette recherche fut d'approfondir nos connaissances face au comportement des sols lors de leur travail, afin d'établir une relation entre la géométrie des instruments aratoires et la préparation du sol pour l'ensemencement. De fait il s'agissait de mieux comprendre le processus de désagrégation du sol et d'établir un protocole expérimental pouvant l'étudier.

Pour parvenir au but, l'étude s'est basée sur les principes fondamentaux de mécanique des sols, et sur l'analyse de l'équilibre des forces. Ainsi, un modèle mathématique a été développé afin de décrire les trois zones de rupture d'un volume extrait du sol. Le modèle développé peut être programmé à l'ordinateur pour générer des graphiques des contraintes normales et des forces de cisaillement, permettant de visualiser les trois zones de rupture, soit la zone de rupture par cisaillement, la zone de rupture à la traction, et la zone sans rupture. La zone de rupture à la traction est délimitée par la contrainte de traction au moment d'atteindre la charge de rupture du sol pour un taux d'humidité et une densité du sol donnés. La charge de rupture à la traction du sol a été mesurée grâce à un instrument et une méthode élaborés lors de cette étude.

Le modèle mathématique donne un bon aperçu du phénomène de la désagrégation et de la forme du volume en rupture, mais il ne donne pas d'information quant à la qualité des agrégats du sol et à leur arrangement à l'intérieur du sillon. Ainsi, une méthodologie fut développée afin d'analyser la formation des agrégats tout en prenant en considération des propriétés physiques du sol.

L'étude a démontré que, pour les instruments de travail du sol étudiés, la plus petite largeur et le plus petit angle d'inclinaison offraient la géométrie produisant le plus de désagrégation du sol, la formation la plus uniforme de petits agrégats, et le meilleur arrangement des particules. De plus, cette même géométrie d'outil du travail du sol s'avère être le plus efficace dans sa consommation d'énergie. La meilleure performance fut produite au taux d'humidité le plus bas testé.

Mots clés: analyse des contraintes, rupture de traction, résistance au cisaillement, charge de rupture, lit de semence, indice de gonflement, coefficient d'uniformité. 


\section{ACKNOWLEDGMENTS}

I am very grateful to Dr. Edward McKyes for being patient during the discussions of ideas and the thesis supervision.

Special appreciation is extended to the thesis co-supervisor Dr. Robert S. Broughton and Mr. Ray Cassidy. The research could not be done without their continuos support and encouragement.

I would like to acknowledge The Canadian Natural Science and Engineering Research Council NSERC and The Department of Agricultural and Biosystems Engineering of McGill University for providing the funding for the study.

I also thank fellow students David Romero and Venkatesh Sosle for their support and positive attitude.

Special thanks to my dad Dr. Rodolfo Ibarra, my mom Mrs. Luisa Gonzalez, and my daughter Sandra Yalina for being supportive, patient and understanding. 


\section{TABLE OF CONTENTS}

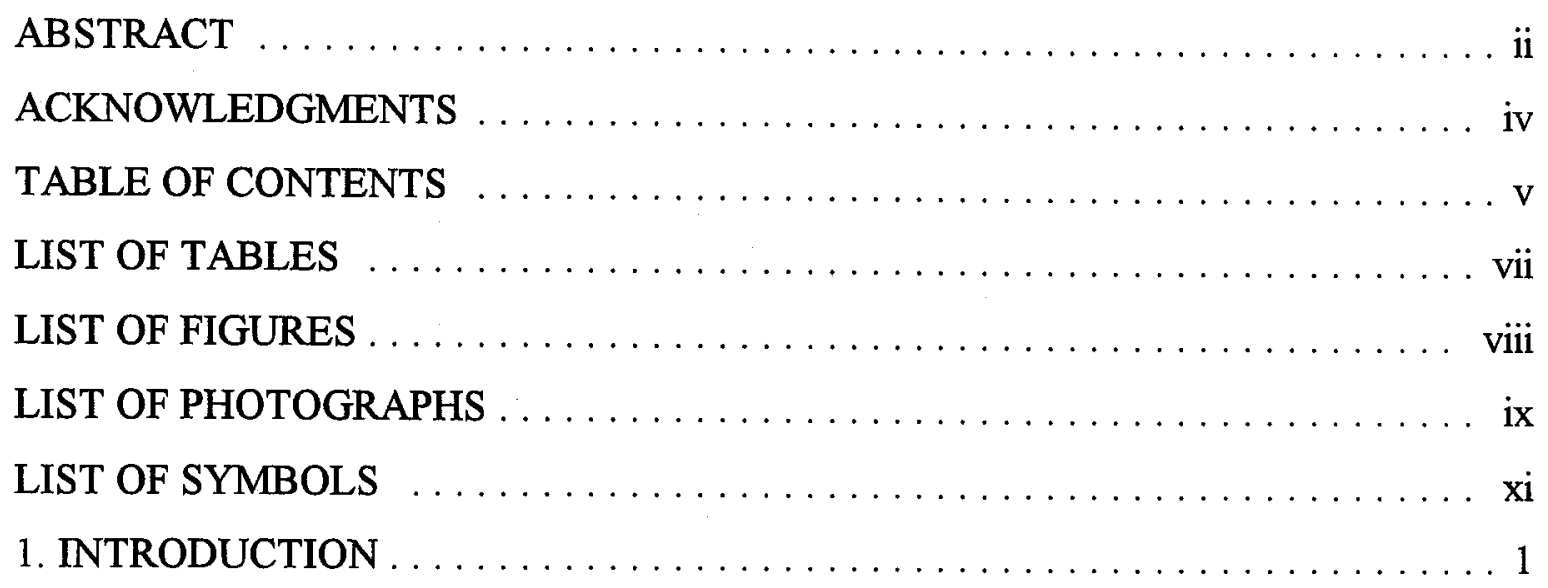

1.1 Soil Strength and Deformation Produced by Simple Tillage Implements . . . 1

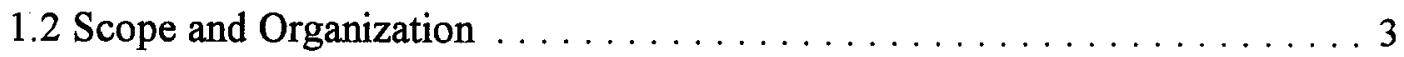

1.3 Research Objectives $\ldots \ldots \ldots \ldots \ldots \ldots \ldots \ldots \ldots \ldots \ldots \ldots$

2. LITERATURE REVIEW $\ldots \ldots \ldots \ldots \ldots \ldots \ldots \ldots \ldots \ldots \ldots$

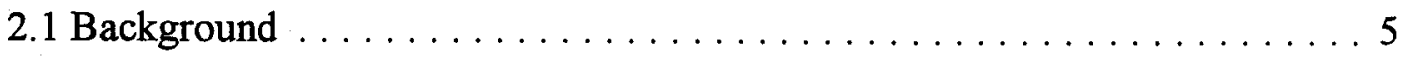

2.2 Measurement of Tensile Strength of Soil Aggregates $\ldots \ldots \ldots \ldots \ldots 7$

2.3 Soil Response to Tillage . . . . . . . . . . . . . . . . . . . . 17

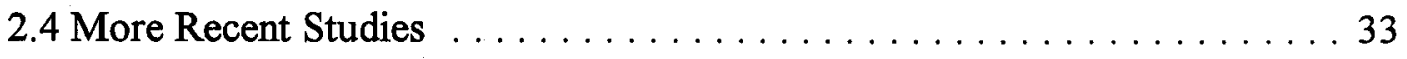

2.5 Summary of Literature Review . . . . . . . . . . . . . . . . . 35

3. THEORETICAL STRESS DISTRIBUTION MODEL $\ldots \ldots \ldots \ldots \ldots \ldots . \ldots 37$

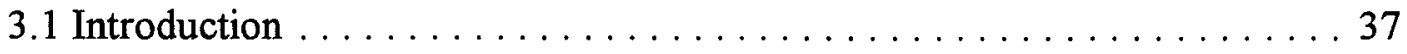

3.2 Problem Statement $\ldots \ldots \ldots \ldots \ldots \ldots \ldots \ldots \ldots \ldots \ldots \ldots \ldots \ldots$

3.3 Theoretical Approach for the Mathematical Model ............. 40

3.4 Mathematical Model Development . . . . . . . . . . . . . . . 44

3.5 Maximum Radial Distance from the Center of the Blade . . . . . . . . . 54

3.6 Shear Failure Criterion . . . . . . . . . . . . . . . . . . 54

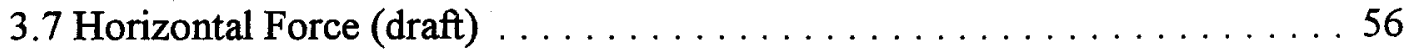

3.8 Maximum Radius measured from the edge of the blade . . . . . . . . 57

4. TENSILE STRENGTH TEST OF COHESIVE SOILS $\ldots \ldots \ldots \ldots \ldots \ldots .58$ 


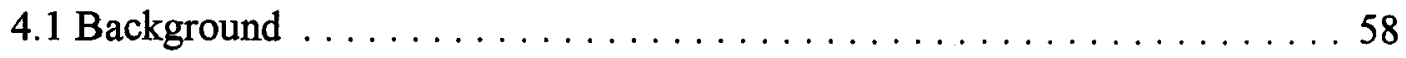

4.2 Tensile Strength Apparatus $\ldots \ldots \ldots \ldots \ldots \ldots \ldots \ldots \ldots \ldots$

4.3 Preliminary Performance Observations of the Tensile Strength Test . . . . 59

5. TENSION FAILURE CRITERIA $\ldots \ldots \ldots \ldots \ldots \ldots \ldots \ldots \ldots \ldots \ldots \ldots$

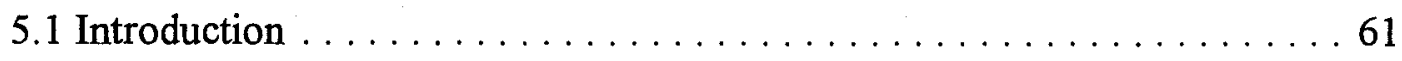

5.2 Criteria for Failure in Tension . . . . . . . . . . . . . . . . 62

5.3 Minimum Value of Normal and Shear Stresses at Tension Failure . . . . . . 63

5.4 Failure Interpretation $\ldots \ldots \ldots \ldots \ldots \ldots \ldots \ldots \ldots \ldots \ldots \ldots \ldots \ldots \ldots \ldots$

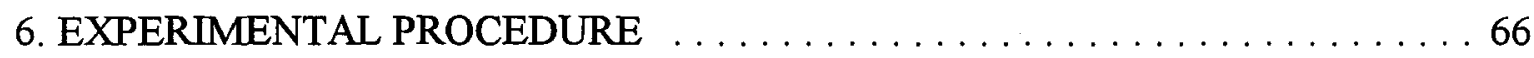

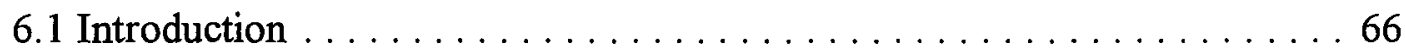

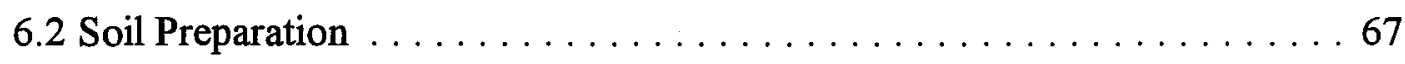

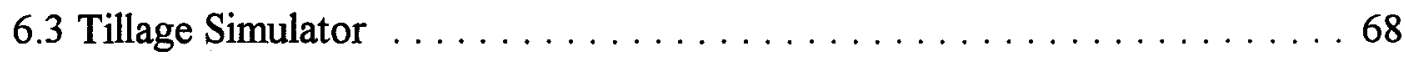

6.4 Sampling for Initial Bulk Density and Moisture Content . . . . . . . . 69

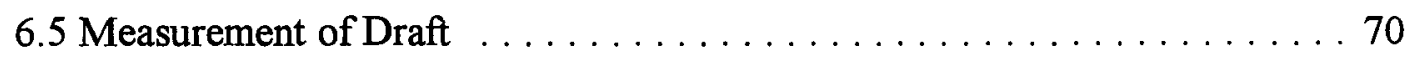

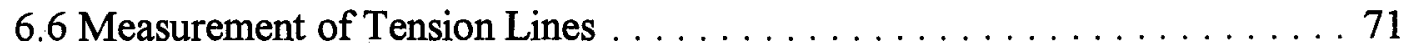

6.7 Quantity of Loosening $\ldots \ldots \ldots \ldots \ldots \ldots \ldots \ldots \ldots \ldots \ldots \ldots$

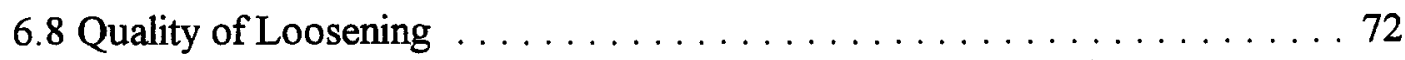

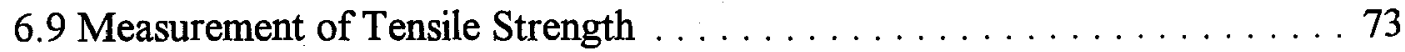

7. RESULTS FROM THE EXPERIMENTAL STUDY $\ldots \ldots \ldots \ldots \ldots \ldots \ldots 77$

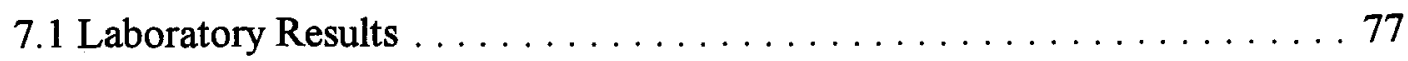

7.2 Theoretical Predictions . . . . . . . . . . . . . . . . . . 87

8. ANALYSIS AND CONCLUSIONS $\ldots \ldots \ldots \ldots \ldots \ldots \ldots \ldots \ldots$

8.1 Introduction $\ldots \ldots \ldots \ldots \ldots \ldots \ldots \ldots \ldots \ldots \ldots \ldots \ldots \ldots \ldots \ldots$

8.2 Analysis . . . . . . . . . . . . . . . . . . . . . 93

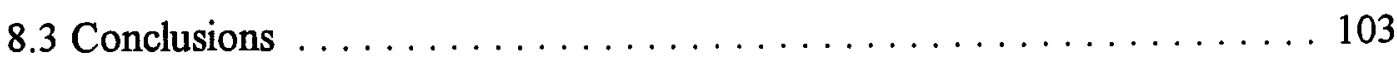

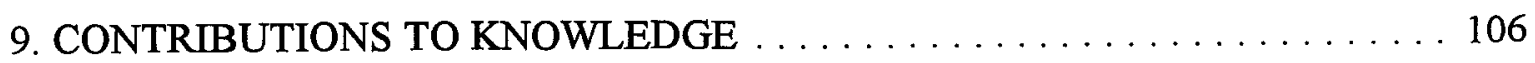

10. RECOMMENDATIONS FOR FURTHER RESEARCH $\ldots \ldots \ldots \ldots \ldots \ldots 108$

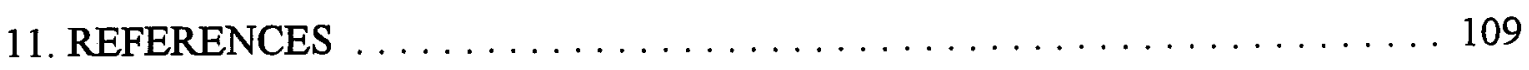

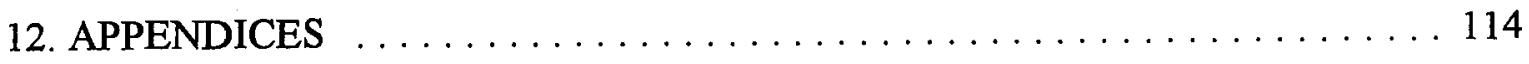




\section{LIST OF TABLES}

Table 7.1: Average values of soil density and moisture content $\ldots \ldots \ldots \ldots 78$

Table 7.2: Cohesion, and Friction angle at different soil moisture . . . . . . . 79

Table 7.3: $\quad$ Measured values of tensile strength, $\mathrm{T}$, in $\mathrm{kPa} \ldots \ldots \ldots \ldots \ldots$

Table 7.4: Best fit values used for the mathematical model validation $\ldots \ldots \ldots 81$

Table 7.5: Identification of the performed tests $\ldots \ldots \ldots \ldots \ldots \ldots \ldots$

Table 7.6: $\quad$ Measured draft force in N, maximum angle of soil fractures

$\left(\theta_{\max }{ }^{\circ}\right)$, width $(\mathrm{mm})$ and depth $(\mathrm{mm})$ of the empty furrow, and seed bed properties: aggregate density $\left(\mathrm{Mg} / \mathrm{m}^{3}\right)$ and mean weight diameter of aggregates (MWD) $\ldots \ldots \ldots \ldots \ldots .85$

Table 7.7: $\quad$ Maximum angle $\left(\theta_{\max }{ }^{\circ}\right)$ which defines the tensile fracturing zone, theoretical width of the disturbed cross section, and the circular portions of shear failure $\ldots \ldots \ldots \ldots \ldots \ldots \ldots$

Table 7.8: Predicted radius of the circular portion of the soil segment at the depth of $5 \mathrm{~mm}$ (surface soil slice) and at depth of 50 $\mathrm{mm}$ correspondent to the middle soil slice. Horizontal force applied by the tool at the surface soil slice $(z=5 \mathrm{~mm})$, middle soil slice $(\mathrm{z}=50 \mathrm{~mm})$ and bottom of the soil segment $(z=d=100 \mathrm{~mm})$ which correspond to the bottom of the blade. 92

Table 8.1: Useful coefficients for the analysis of the seed bed quality 


\section{LIST OF FIGURES}

Figure 3.1: $\quad$ Step (1) Force applied to a semi-infinite medium . . . . . . . . . . 39

Figure 3.2a: Step (2) Side view of the shear failed soil segment . . . . . . . . 39

Figure 3.2b: Step (2) Top view of the shear failed soil segment $\ldots \ldots \ldots \ldots 39$

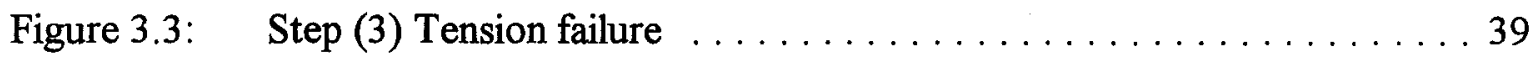

Figure 3.4: Top view of failed soil segment after cracking $\ldots \ldots \ldots \ldots \ldots 1$

Figure 3.5a: Boundary stresses produced by $\mathrm{H} \ldots \ldots \ldots \ldots \ldots \ldots \ldots \ldots$

Figure 3.5b: External force $\mathrm{H}$, and total reaction force $\mathrm{H} \ldots \ldots \ldots \ldots \ldots$

Figure 3.5c: Boundary reaction produced by the reaction force $H \ldots \ldots \ldots \ldots 42$

Figure 3.6: Superposition of reaction stresses $\ldots \ldots \ldots \ldots \ldots \ldots \ldots \ldots$

Figure 3.7: Final system for the analysis $\ldots \ldots \ldots \ldots \ldots \ldots \ldots \ldots \ldots$

Figure 3.8: Final system for the analysis of internal points $\ldots \ldots \ldots \ldots \ldots 44$

Figure 3.9: Forces acting on a soil segment $\ldots \ldots \ldots \ldots \ldots \ldots \ldots \ldots \ldots 45$

Figure 3.10: Free Boundary distributed forces $\ldots \ldots \ldots \ldots \ldots \ldots \ldots \ldots$

Figure 3.11a: Free Boundary stresses in $\mathrm{x} \ldots \ldots \ldots \ldots \ldots \ldots \ldots \ldots \ldots$

Figure 3.11b: Free Boundary stresses in $\mathrm{y} \ldots \ldots \ldots \ldots \ldots \ldots \ldots \ldots \ldots$

Figure 4.1: Diagram of Tensile Strength Apparatus for Soil Samples . . . . . . . . 59

Figure 5.1: $\quad$ Tension Failure criteria $\ldots \ldots \ldots \ldots \ldots \ldots \ldots \ldots \ldots \ldots \ldots \ldots \ldots \ldots$

Figure 5.2: Minimum values of stresses for tension failure $\ldots \ldots \ldots \ldots \ldots 63$

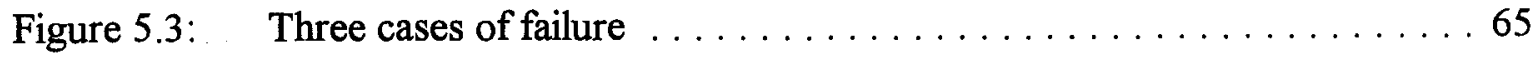

Figure 7.1: Best fit values of cohesion, friction angle and tensile strength for different values of moisture content $\ldots \ldots \ldots \ldots \ldots .81$

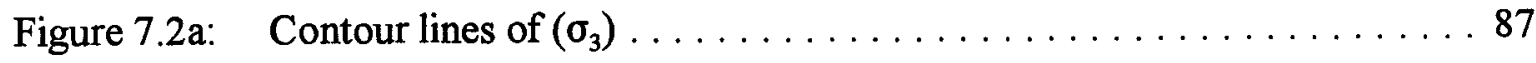

Figure 7.2b: Example of shear stress distribution in $\mathrm{kPa} \ldots \ldots \ldots \ldots \ldots \ldots 87$

Figure 7.3: Failure zones $\ldots \ldots \ldots \ldots \ldots \ldots \ldots \ldots \ldots \ldots \ldots \ldots$

Figure 8.1a: Failure zones at surface $\ldots \ldots \ldots \ldots \ldots \ldots \ldots \ldots \ldots \ldots$

Figure 8.1b: Failure zones at deeper soil slice $\ldots \ldots \ldots \ldots \ldots \ldots \ldots \ldots \ldots 9$

Figure 8.2a: Contour of minor normal stress $\ldots \ldots \ldots \ldots \ldots \ldots \ldots \ldots \ldots$

Figure $8.2 \mathrm{~b}$ : Tensile fracturing zone $\ldots \ldots \ldots \ldots \ldots \ldots \ldots \ldots \ldots \ldots \ldots \ldots \ldots \ldots \ldots$ 


\section{LIST OF PHOTOGRAPHS}

Photo 4.1: Tensile strength apparatus for soil samples . . . . . . . . . . . . 59

Photo 6.1a: Set of wooden boxes placed together for soil filling $\ldots \ldots \ldots \ldots$

Photo 6.1b: Filling of soil, the photo shows the steel fence which will be filled up with soil $\ldots \ldots \ldots \ldots$. . . . . . . . . . . 68

Photo $6.1 \mathrm{c}: \quad$ Compaction of the soil using the lawn roller $\ldots \ldots \ldots \ldots \ldots \ldots$

Photo 6.2a: Tillage simulator. The blade is half way of the length of the soil bin . . . . . . . . . . . . . . . . . . . . . . . . . . . . . . 69

Photo $6.2 \mathrm{~b}: \quad$ An example of the tillage blade $\ldots \ldots \ldots \ldots \ldots \ldots$

Photo 6.3a: Set of steel cores, $15 \mathrm{~mm}$ diameter and $30 \mathrm{~mm}, 20 \mathrm{~mm}$ and

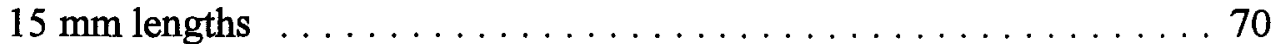

Photo 6.3b: Taking the soil samples using a especial core driver which can be used at different depths without disturbing the

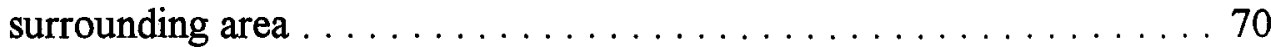

Photo 6.3c: Sample of the holes after the soil has been sampled. Note that there is no visible disturbance around the holes $\ldots \ldots \ldots \ldots 70$

Photo 6.4: A set of pictures from different tillage treatments $\ldots \ldots \ldots \ldots \ldots 71$

Photo 6.5a: Measurement of the soil profile after the tillage operation . . . . . . 72

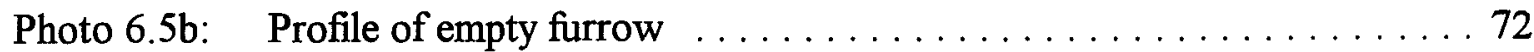

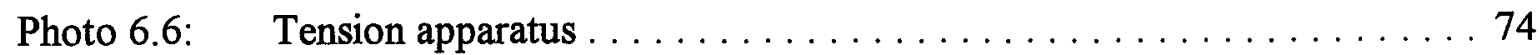

Photo 6.7: Calibration of the tension apparatus $\ldots \ldots \ldots \ldots \ldots \ldots$

Photo 6.8: $\quad$ Steel core for soil specimen preparation and steel weights

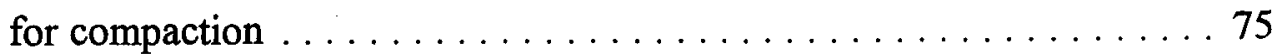

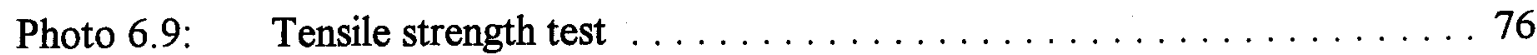

Photos 7.1 a and 7.1b: Show that aggregation produced at the surface of the soil volume keeps its pattern along the way of the tillage tool $\ldots \ldots \ldots \ldots \ldots$

Photo $7.2 \mathrm{a}: \quad$ Initial fracturing of the soil $\ldots \ldots \ldots \ldots \ldots \ldots \ldots \ldots \ldots \ldots$ 
Photo 7.2b: A more advance stage of the fracturing $\ldots \ldots \ldots \ldots \ldots \ldots \ldots$

Photo 7.3: Shows the empty furrow $\ldots \ldots \ldots \ldots \ldots \ldots \ldots \ldots \ldots \ldots$

Photo 8.1a: Front view of test $601-100 \ldots \ldots \ldots \ldots \ldots \ldots \ldots \ldots \ldots$

Photo 8.1b: Measured maximum theta for the test $601-100 \ldots \ldots \ldots \ldots . \ldots 97$ 


\section{LIST OF SYMBOLS}

$\mathrm{P}=\mathrm{P}_{1}+2 \mathrm{P}_{2}=$ total force on the tool

$P_{1}=$ total force acting on the centre soil wedge.

$\mathrm{P}_{2}=$ total force acting on each side soil crescent.

$\mathrm{P}_{3}=$ normal force acting on the sides of the centre wedge.

$\mathrm{P}_{\mathrm{A}}=$ force acting on a retaining wall for the active case.

$P_{P}=$ force acting on a retaining wall for the passive case.

$\mathrm{R} \cos \phi=$ normal force acting on the rupture plane

$\gamma=$ total soil density

$\mathrm{d}=$ tool working depth below the soil surface

$\mathrm{w}=$ tool width

$\mathrm{d} / \mathrm{w}=$ aspect ratio

$\mathrm{K}_{\mathrm{a}}=$ Coefficient of active earth pressure.

$\mathrm{K}_{\mathrm{P}}=$ Coefficient of passive earth pressure.

$\mathrm{K}_{\mathrm{o}}=$ Coefficient of earth pressure at rest.

$q=$ surcharge pressure vertically acting on the soil surface

$\mathrm{N}_{\gamma}, \mathrm{N}_{\mathrm{c}}, \mathrm{N}_{\mathrm{q}}$, = factors which depend on soil friction strength, tool geometry, tool to soil strength properties.

$\sigma=$ normal stress

$\sigma_{1}=$ major principle stress

$\sigma_{3}=$ minor principle stress

$\sigma_{\mathrm{f}}=$ normal stress at failure

$\sigma_{\mathrm{f}}=$ radial stress

$\sigma_{\theta}=$ angular stress

$\theta=$ horizontal angle from the centre of the cross section

$r=$ radial distance measured from the centre of the blade

$r_{\text {max }}=$ maximum radial distance measured from the edge of the blade. It describe the circular portion of the cross section of the soil volume 
$\tau=$ shear stress

$\tau_{\mathrm{f}}=$ shear stress at failure

$\alpha=$ rake angle with the horizontal

$\beta=\quad$ angle between an horizontal plane at the bottom of a retaining wall and the wall, or, angle of forward failure surface.

$\delta=$ angle of friction between soil and tool material

$\tan \delta=$ coefficient of friction between the soil and tool materials

$\mathrm{c}=$ soil cohesion strength

$c_{a}=$ soil to tool adhesion strength, independent of normal pressure

$\phi=$ angle of internal friction

$\tan \phi=$ coefficient of internal sliding friction

$\mathrm{H}=$ draft force

$\mathrm{H}_{\mathrm{t}}=$ horizontal force that causes tension failure.

$\mathrm{V}=$ total tool vertical force

$\mathrm{N}_{\mathrm{o}}=$ normal load on the inclined tool

$\mathrm{W}=$ weight of the soil segment

$\mathrm{N}_{1}=$ normal load on the forward failure surface

$\mathrm{v}_{\mathrm{o}}=$ velocity of the tool 


\section{INTRODUCTION}

\subsection{Strength and Deformation produced by Simple Tillage Implements:}

Tillage tools are mechanical devices used for applying forces to the soil to cause one or more of cutting, movement, fracturing, loosening, overturning and pulverization of the soil to prepare a seed bed. Friction between soil bodies, cohesion between the soil particles and friction between soil and tool's material are the most important elements in the mechanical study of the tilled soil body. These are the major effects that the external force has to overcome to break the soil into smaller aggregates.

Some studies have been useful in calculating the force that the tool will have to apply to the soil to cut and to determine the shape and volume of soil cut. These models have shown the relation between the tool geometry, force requirements and the total cut soil volume. They also have shown that energy requirements increase with tool width at a fixed depth, and specific energy efficiency for cutting alone increases with tool width.

A few studies have shown the distribution of stresses on the blade produced by the total soil reaction forces. However, most of these studies do not show the distribution of stresses that the external force produces into the soil mass. The distribution of stresses in the soil is responsible for the failure in tension or compression of the different portions of soil within the soil mass.

A considerable number of studies exist on the stress-strain behavior of soils under the application of external forces. Most of these studies consider soil failure, but with the material remaining in a continuous structure. Tillage operations apply external forces that develop normal and shear stresses in the soil mass, often causing fracture and extensive changes in the soil structure. From the failure conditions a prediction of soil break-up and soil loosening could be estimated.

Some studies have determined the tensile strength of soil aggregates. The results of these studies show the tensile strength as a function of geometrical and structural parameters of the samples. 
This thesis presents a combination of soil mechanic theories, and a superposition method of force analysis with logical assumptions in a finite element approach to develop a mathematical model which describe the stresses produced by the tillage operation in the volume of soil being cut. In this model, the volume of soil predicted by models of soil cutting is divided into sections of thickness $t$. The resultant stresses can be represented on a map for easier visualization.

Assuming that the soil behaves according to Mohr-Coulomb shear failure criterion, it is possible to determine the failure conditions in any part of the soil volume, which could give an idea of aggregate arrangement and aggregate strength.

To quantify the tension fracturing criterion, a method of measuring the tensile strength was also developed in this study. This method for cohesive soils is a preliminary study, which, uses a non-standard laboratory instrumentation. The results of the tests give an independent constant value of soil tensile strength for each density and moisture content.

The thesis also presents a modification of the traditional thin wall tube core utensils for taking relatively undisturbed soil samples. A set of cores and a core driver adapted to the conditions of the research set-up were designed and built, to get information useful in the analysis of the quantity and quality of the soil aggregation.

In the present research an approach of analysing seed bed stability and resistance of aggregates to erosion is also introduced. The method considers a combination of factors used for earth moving calculations, together with a uniformity coefficient derived from the mean weight aggregate diameter calculations.

The important assumptions made in this study were that the soil is a homogeneous mass, and that the soil behaves in a brittle manner, which has been shown by Fryman's (1964) model to give good results.

This study permits further understanding of soil behaviour under compression and tensile stresses, and the prediction and optimization of tool geometry for pulverizing the soil and preparation of the seed bed. 


\subsection{Scope and Organization:}

This thesis is divided into of two main parts: theory and laboratory work. The theory is described in Chapters 2 to 5, and the laboratory experimentation in Chapters 6 and 7.

In Chapter 2 published reports starting with Coulomb's analytical solution of active earth pressure on retaining walls (1776) to the present are summarized. Chapter 3 presents a theoretical model which predicts the distribution of normal and shear stresses due to the external force (draft) applied by a tillage tool on the soil volume. Using logical manipulation of the expressions for stresses, the soil segment can be divided into different failure zones.

A preliminary method of measuring tensile strength of cohesive soils, and a nonstandard design of a tensile strength apparatus for testing soil specimens are proposed in Chapter 4 . The failure criteria used in this research, which is derived from the general Mohr-Coulomb theory, is explained in Chapter 5.

The description of the equipment and methods used for soil sampling and testing the mathematical model are explained in Chapter 6 .

The predictions from the theoretical model and the measurements from laboratory experiments are presented in Chapter 7. The evaluation of the performance of the mathematical predictions are presented in Chapter 8 .

The final three chapters deal with the new addition to the understanding of the tillage process and soil behaviour under tensile stresses, suggestions for further studies and a list of references. 


\subsection{Research Objectives:}

\subsubsection{General objective}

The main objective of this study was to develop a workable model which predicts the stress distribution in the volume of soil cut by a simple tillage tool. A model of this type would allow the theoretical determination of tool efficiency in loosening and pulverizing the soil.

\subsubsection{Specific objectives}

1) To analyze the stress distribution in tilled soil using an elastic approximation.

2) To analyze the tool efficiency in soil loosening and pulverization as a function of tool geometry, soil type and soil moisture conditions.

3) To study the resulting soil aggregate density and strength as a function of the tool geometry, and the aggregate arrangement in the seed bed. 


\section{LITERATURE REVIEW}

\subsection{Background:}

The problem considered in this proposal is an extension of that studied by Coulomb (1736-1806). In 1776 Coulomb published the first analytical solution of active earth pressure against retaining walls. He considered the strength parameters cohesion, $(c)$, and angle of internal friction, $(\phi)$. He also considered the possibility of internal sliding on a curved surface. However, he limited his analysis to a plane failure surface for simplicity of calculations. Coulomb proposed that the force acting on the retaining wall for the active case is given by:

$$
P_{A}=\frac{1}{2}\left(\gamma H^{2} K_{a}\right)
$$

Terzaghi (1941) formulated Coulomb's concept as follows.

$$
K_{a}=\left[\frac{\csc \beta \sin (\beta-\phi)}{\sqrt{\sin (\beta+\delta)}+\sqrt{\sin (\phi+\delta) \sin (\phi-i) / \sin (\beta+i)}}\right]^{2}
$$

where $\gamma=$ is the soil density, $H=$ draft force, $K_{a}=$ coefficient of active earth pressure, $\beta$ is the angle between the bottom of a retaining wall and the horizontal, $\phi=$ soil friction angle, $\delta=$ friction angle between the soil and the tool material and $i=$ is the angle between the ground surface and the horizontal.

In 1968 Harr cited the solution obtained in 1906 by Muller - Breslau. Breslau prepared a set of nomograms that gives the solution for $\mathrm{K}_{\mathrm{a}}$ for granular soils where $c=0$. Although the solution of this problem does not provide information about the location of the force $\mathbf{P}$, like Coulomb he assumed it to act at one third of the height of the wall.

The solution for the passive case (soil moving upwards) was presented by Harr (1968). In this analysis, a plane wall was considered with a horizontal soil surface (backfill), and equation (2.1) can be expressed as: 


$$
P_{P}=\frac{\gamma H^{2}}{2 \cos \delta}\left[\frac{1}{(1 / \cos \phi)-\sqrt{\tan ^{2} \varphi+\tan \varphi \tan \delta}}\right]^{2}
$$

Equation (2.3) does not give any information about the distribution of stresses. Although soil is not an elastic material, a stress analysis cannot be undertaken easily without using the fundamentals of elasticity theory. Frocht (1941 and 1948) examined a large number of problems of stress patterns using steel, aluminum, bakelite and celluloid. He presented the analysis in both mathematical and photo-elastic forms.

Chapter 2 of Frocht (1948) is an analysis of the radial stresses in a semi-infinite plate. He stated that "when a concentrated load acts on the straight edge of a semi-infinite plate, the stress distribution is purely radial". The general expression for these stresses is:

$$
\sigma_{r}=\frac{A \cos \theta}{r}
$$

in which $\theta$ and $r$ are polar coordinates, and $A$ is a constant.

Frocht defined a semi-infinite plate as any portion of an infinite plate separated by a transverse plane section. Frocht (1948) presented Flamant's solution of the stresses produced by a concentrated load $(P)$ acting on the edge of a semi-infinite plate of uniform thickness, $t$, on the straight boundary where the load is acting (Flamant 1886). The radial stresses are given by:

$$
\sigma_{r}=\frac{2 P \cos \theta}{\pi t r}
$$

Since the stress system is radial, the isoclinics are also radial, and the principal stress trajectories form a system of concentric circles with centres at the point of application of the load. The maximum shear trajectories are always inclined $45^{\circ}$ to the direction of the principal stresses. Therefore, the shear trajectories can be readily determined as:

$$
r=C e^{\theta}
$$


which are logarithmic spirals curves.

Chapter 4 of Frocht (1948) presents the analysis of stresses in a circular disk. The disk can be treated as a finite portion of a semi-infinite plate. The problem is solved by superposition of the system of radial stresses for a semi-infinite plate produced by an external load, and a system of radial traction stresses opposite to the radial stresses acting at the boundary. The simplest boundary system is a uniform distribution of radial traction, and for this case Frocht found that the whole disk forms an isotropic region of the same stress intensity equal to the stress acting at the boundary. For the external load system, he analysed the problem of concentrated loads acting along the diameter, and also acting along a chord. In his study, Frocht demonstrated that the stress distribution is independent of the material properties, and his analysis did not consider stressdeformation relationships.

Most relationships used in practice for the characterization of the stressdeformation and strength properties of soils are empirical and based on phenomenological descriptions of soil behaviour. The Mohr-Coulomb equation and the method of stress characteristics are the most widely used for representing the state of stress or strain at a point in a soil body which is failing in shear. Coulomb's equation states that:

$$
\begin{aligned}
& \tau_{f f}=c+\sigma_{f f} \tan \phi \\
& \tau_{f f}=c^{\prime}+\sigma_{f f}^{\prime} \tan \phi^{\prime}
\end{aligned}
$$

where $\tau_{\mathrm{ff}}$ is shear stress at failure on the failure plane, $c$ is a cohesion intercept, $\sigma_{\mathrm{ff}}$ is the normal stress on the failure plane, and $\phi$ is a friction angle. $\sigma_{\mathrm{ff}}^{\prime}$ defines an effective stress (total stress minus internal fluid pressure), and $c^{\prime}$ and $\phi^{\prime}$ are effective stress parameters.

\subsection{Measurement of Tensile Strength of Soil Aggregates:}

The basic factors responsible for soil compressive strength are cohesional and frictional resistance between soil particles in contact. The magnitude of this resistance depends on the effective stress and the tendency to change in volume (Mitchell, 1993).

Tensile strength is important in determining the degree of soil breakup or 
"crumbling" produced by a tillage implement and it can be measured by direct and indirect techniques.

Direct measurements involve the direct application of tensile stress. Most direct methods involve grasping a sample of material at the ends or along its sides, and pulling until failure occurs. Tensile strength is then calculated as the ratio of the pulling force to the cross sectional area of the fracture plane. In pulling tests, great care must be taken to avoid bending moments and stress concentrations, which could cause underestimation of the true tensile strength.

Another direct technique is centrifugation, wherein a sample is rotated in a centrifuge. The angular velocity of the centrifuge is increased until the sample fails. The tensile strength is calculated from the centripetal force applied across the failure plane. This technique eliminates the bending moments, however the rotation could induce redistribution of water within the sample and thus influence results.

Indirect measurements consist of indirectly induced failure by applying compressive forces or bending moments which generate tensile stresses within the sample. The sample will fail in tension along a plane different than that of the applied stress. The relationships between applied stress and tensile stress at failure are calculated from the geometrical and elastic properties of the samples.

A common indirect method is the flexure or "modulus of rupture" technique. Richards (1953) used the modulus of rupture to measure the breaking strength of briquets $1 \times 3.5 \times 7 \mathrm{~cm}$. Breaking strength is the maximum fibre stress that the material will withstand without breaking. The maximum fibre stress is calculated by

$$
s=\frac{3 F L}{2 b d^{2}}
$$

where $s$ is the modulus of rupture, $F$ is the compression breaking force, $L$ is the distance between the two lower supports, $b$ is the width of the briquet and $d$ is the depth or thickness of the briquet. Richards adapted this technique to the evaluation of soil surface crust strength. 
Another method to estimate tensile strength from a compressive force required to cause fracture of samples roughly spherical in shape was used by Rogowski et al. (1968). They considered air-dry aggregates as approximate spheres. Aggregates of nine surface soils containing from 7 to $53 \%$ clay were tested. The objective of the study was to introduce three rupture parameters: rupture stress, rupture strain and rupture modulus. Values of rupture stress are calculated by the change in polar diameter at rupture $(\Delta d)$ per unit length of the original polar diameter $(d)$.

$$
\varepsilon=\frac{\Delta d}{d}
$$

The rupture stress $R$, is defined as the load $F$ per unit cross sectional area $A$

$$
R=\frac{F}{A}
$$

and the ratio of rupture stress/rupture strain defined as the rupture modulus $(m)$ is analogous to Young's modulus of elasticity

$$
m=\frac{R}{\varepsilon}
$$

Experimental stress-strain curves indicated that Hooke's law was valid up to rupture.

Both methods, the flexure (modulus of rupture) and compression tests, assume linear stress-strain relationships, and that the modulus of elasticity of a soil is the same in tension as in compression. These assumptions often do not hold true in soils. Also it is assumed that the sample will fail in tension before it fails in any other manner. This assumption is usually true for relatively dry soil and brittle samples. However, softer moist soils will often fail in shear before they fail in tension (Snyder and Miller, 1985).

The Brazilian test is an indirect method which has been used for concrete and other brittle materials. Frydman (1964) used the Brazilian test in soil samples that may deform appreciably at the loading points. He modified the stress analysis that Frocht (1948) developed for a circular disk under external forces applied at one cord of the disk. 
It is convenient to use small cylindrical specimens $(2.5 \mathrm{~cm}$ diameter by $5.0 \mathrm{~cm}$ length) for soil strength testing. Elasticity is assumed throughout, since the plastic behaviour causing flattening takes place only in a region near the load points where a large compressive stress exists, and not at the centre of the specimen, which is the point of critical tensile stress. The theory presented is applicable only to those soils which fail in a brittle manner, and takes no account of soils which undergo overall plastic failure. The study concluded that:

The calculated tensile stress acting at the centre of a deformed specimen is given by

$$
\begin{aligned}
& \sigma_{x}=\left(\frac{2 P}{\pi d t}\right) g\left(\sigma_{x}\right) \\
& g\left(\sigma_{x}\right)=\left(\frac{-d}{2 a}\right)\left\{\frac{2 f-\sin 2 f-2 y_{1}}{d \log \tan \left(\frac{\pi}{4}+\frac{f}{2}\right)}\right\}
\end{aligned}
$$

where $d$ is the specimen diameter and $t$ is the thickness of the cylindrical sample. $P$ is the load distributed over the flattened portion of the specimen and $2 a$ is the length of the flattened portion. $y_{1}$ is the is the vertical distance between the flattened portion and the centre of the specimen and $f=\arctan \left(\alpha / y_{y}\right) \cdot g\left(\sigma_{x}\right)$ decreases as the ratio of the width of the flattened portion of the specimen to the distance between flattened portions increases.

A simplified formula $\sigma_{\mathrm{x}}=2 P / \pi d t$ gives good accuracy for samples with $g\left(\sigma_{\mathrm{x}}\right)>$ 0.9. This means that the ratio of the width of the flattened portion of the specimen to the distance between flattened portions at failure must not exceed $0.27\left(a / y_{1}<0.27\right)$.

The soils examined were kaolin, kaolin with $10 \%$ cement and montmorillonite clay. The samples were examined at different moisture contents, and for most soils $g\left(\sigma_{\mathfrak{x}}\right)$ $>0.9$. In practice it would therefore be likely that the simplified formula is valid for 
indirect tension tests for soils.

Dexter (1975) used the crushing force to calculate the tensile strength of aggregate materials. He used ideal brittle tilths, made from synthetic aggregates, and compressed them uniaxially. Tilths are arrangements of soil aggregates, crumbs or clods occurring near the soil surface, and may be a product of tillage or weathering. Therefore, tilths are not homogeneous soils. Dexter followed the approach of Rowgoski et al. (1968) (parallel plates), and Rowgoski et al. (1968) used the results of Sternberg and Rosenthal (1952) for the compressive stress $(Z) . Z$ acts normally across the centre of the equatorial plane of a spherical aggregate loaded at its poles by a force $\mathrm{F}$.

$$
|Z|=\left(\frac{6 F}{\pi d^{2}}\right)\left[\frac{(14+5 \mu)}{(7+5 \mu)}\right]
$$

where $d$ is the aggregate diameter and $\mu$ is the Poisson ratio. For an incompressible elastic body, $\mu$ is equal to 0.5 and equation (2.14) reduces to

$$
|Z|=3.317\left(\frac{F}{d^{2}}\right)
$$

The maximum tensile strength $(\mathrm{T})$ occurs at the centre of the sphere. The results of Frocht and Guernsey (1952) for the centre of the sphere are:

$$
\begin{aligned}
& Z=3.30\left(\frac{F}{d^{2}}\right) \\
& T=0.573\left(\frac{F}{d^{2}}\right)
\end{aligned}
$$

which yield the ratio of

$$
T=-0.1737^{*} Z
$$

if $\mathrm{L}$ is the value of the diametric loading force $\mathrm{F}$, at failure and $\mathrm{Y}$ is the tensile yield strength of the material which is the value of $\mathrm{T}$ at failure, then a combination of equations 
(2.16) and (2.17) gives

$$
Y=0.5762\left(\frac{L}{d^{2}}\right)
$$

The height of each sample, before and after compression was used to calculate changes in packing density (D), with stress (S). Subsequent excavation of the compressed samples showed that most of the large void spaces disappeared and that only approximately half of the aggregates had been broken. This observation led to the idea of plastic flow of material from broken aggregates into the remaining voids. Two hypotheses were required to represent this process statistically. One is that as a brittle tilth is compressed, aggregates fracture randomly. The second is that the material from broken aggregates flows plastically into the interstices of the remaining aggregates.

The process of the first hypothesis can be described by the Gaussian error function, while the second hypothesis is a steady process that can be described by an exponential function, and has been found in real soils. The compression of brittle tilths is described by

$$
D-D_{i}=\left(D-D_{f}\right)\left(1-e^{k s}\right) \phi\left(\frac{S}{Y}\right)
$$

where $D_{i}$ and $D_{f}$ are the initial and final values of the tilth packing density. $k$ is an exponent to be determined experimentally.

In 1979, Braunack et al. compared the crushing strength of aggregates of five soils from South Australia and Queensland with a statistical theory. The crushing strength was calculated with equation (2.19), and the statistical theory that they developed can be expressed by

$$
\log _{e} s=-\left(\frac{1}{\alpha}\right) \log _{e} V+\log _{e}\left[s_{0} V_{0}^{1 / \alpha} \Gamma\left(1+\frac{1}{\alpha}\right)\right]
$$

where $\mathrm{s}$ is the mean critical stress, $\mathrm{V}_{\mathrm{o}}$ is the volume element, $\mathrm{V}$ is the total volume, $\alpha$ and 
$\mathrm{s}_{\mathrm{o}}$ are parameters of the material $\mathrm{s}_{\mathrm{o}}$ is the strength of the solid, $\alpha$ is the fracture parameter and $\Gamma$ is the tabulated gamma function.

The values of mean tensile strength, $s$, and the equation that describe the compaction behaviour of Braunack and Dexter (1978) were used to investigate the change in structure of compacted beds. The empirical equation of compaction behaviour is

$$
\frac{H}{H_{i}}=0.4+0.6 \exp \left[0.017\left(\frac{P}{S}\right)-0.38\left(\frac{P}{S}\right)^{1 / 2}\right]
$$

where $\mathrm{H}$ and $\mathrm{H}_{\mathrm{i}}$ are the height at stress $P$ and the initial height at stress $P=0$ of the aggregate bed respectively. The compacted bed was analysed using a paraffin wax technique described by Dexter (1976).

Braunack et al. concluded that the correlation coefficient for equation (2.19) and (2.21) is 0.97 . The fracture parameter $\alpha$ is a measure of the dispersion of crack strength distribution. For soil aggregates, $\alpha$ appears to be in the range 1 to 4 . The water content of the aggregates strongly affects the mean yield stress. This factor increases ten fold for a change of water potential from $-100 \mathrm{kPa}$ to $-153 \mathrm{MPa}$. The beds of smaller aggregates would be less easily compacted than beds of larger aggregates at the same water content.

Utomo and Dexter (1981) studied the effect of wetting and drying cycles, freezing and thawing cycles and phosphoric acid treatment on the friability of Urrbrae soil. The tensile strength was calculated using equation (2.19), and equation (2.21) was used for prediction of mean tensile strength. They identified the value of $1 / \alpha$ as the parameter $k$, which is the soil friability and a measure of the dispersion of the strength of the microcracks and flaws within the clods or aggregates. Bodman (1949) defined soil friability as the tendency of a mass of unconfined soil in bulk to crumble and break down under applied stress into smaller fragments, aggregates and individual soil particles. Large values of friability indicate that the larger clods have a much smaller strength than the smaller clods or aggregates, and may thus be more readily fragmented into smaller stronger units. A small value of $\mathrm{k}$ indicates that the strength of large clods does not differ much from that of any smaller fragments. These findings are in agreement with 
Braunack's findings on the brittle fracture study. McKyes et al. (1993) found that brittle soil has a large shear strength at relatively small deformation.

The maximum value of friability $k$ occurs at a gravimetric water content close to the plastic limit. At this same water content, the maximum fragmentation occurs during tillage.

Utomo and Dexter (1981) characterized soils for their friability as follows:

$\mathrm{k}<0.05 \quad$ not friable

$0.05<\mathrm{k}<0.1 \quad$ slightly friable

$0.1<\mathrm{k}<0.25 \quad$ friable

$0.25<\mathrm{k}<0.4 \quad$ very friable

$\mathrm{k}>0.4 \quad$ mechanically unstable

Snyder and Miller (1985) studied the problem of tensile failure of uncemented soils. They combined Aitchison's extension of the classic Haines-Fisher model of capillary cohesion with Griffith's theory of the fracture of cracked elastic solids.

The criterion for soil tensile failure given by Haines (1927) and Fisher (1926) was that the critical applied tensile stress necessary to induce failure must be just great enough to overcome the cohesive stress due to the pore fluids. This was equivalent to stating that at failure the effective stress is zero. Aitchison (1961) assumed that a real soil could be considered a composite of ideal soils of different particle radii. The frequency distribution of these ideal elements was estimated from a moisture desorption curve for the whole soil.

Griffith's theory (1924) of fracture of cracked elastic solids state that the maximum tensile stress $\left(\sigma_{m}\right)$ occurs along the sharpest edges of the crack, in a two dimensional analysis because the sharpest edges are points of stress concentration. He postulated that tensile failure initiates at these points of stress concentration once $\sigma_{\mathrm{m}}$ reaches a certain critical value, which is a material constant. Another important result of Griffith's two-dimensional analysis is that the ratio $\sigma_{\mathrm{m}} / \sigma$ is only a function of crack geometry and is independent of either crack size or the material elastic constants. Sadowsky and Sternberg (1949) studied the three-dimensional case, and they found very similar results. The ratio of $\sigma_{m} / \sigma$ was found to be almost an exclusive function of flaw 
geometry, being only slightly dependent on the Poisson ratio (v) of the material and totally independent of the size of the flaw or the material elastic modulus.

In 1970 Timoshenko and Goodier gave a relation of the lowest possible value of $\sigma_{\mathrm{m}} / \sigma$ for flawed elastic materials. This value occurs at the edge of spherical flows, and is given by

$$
\frac{\sigma_{m}}{\sigma}=\frac{27-15 v}{7-5 v}
$$

Snyder and Miller (1985) linked the above theories in an indirect method which involves the assumption of linear stress-strain relations in soils, but does not require that the modulus of elasticity be the same in tension and compression. This method is based on the principle that the state of stress in an unsaturated soil of a given geometrical configuration is highly dependent on the effective stresses. Thus, it is important that tensile strength measurements be accompanied by measurements of pore-air pressure, pore-water pressure and the degree of pore saturation. Snyder and Miller combine the above theories in a unique relationship between tensile strength, pore-water pressure deficiency and degree of pore saturation for a given soil to find the parameters $\sigma_{\mathrm{m}} / \sigma$ and $X$. As in the case of an elastic solid, the tensile failure of the second system will occur when the stress $\sigma_{\mathrm{m}}=\left(\sigma-u_{a}\right)_{\mathrm{m}}$ reaches a certain critical value. However, for elastic solids, the critical $\left(\sigma-u_{a}\right)_{\mathrm{m}}$ is a material constant, whereas in unsaturated soils it is conditioned by the requirement that effective stresses at the crack edges must be zero. Therefore, the value of $\left(\sigma-u_{a}\right)_{m}$ at rupture in the second system is determined by

$$
\frac{\sigma_{m}}{\sigma}=\frac{\left(\sigma-u_{a}\right)_{m}}{\left(\sigma-u_{a}\right)}=\frac{1}{f(\theta)}
$$

and

$$
X=\frac{-\left(\sigma-u_{a}\right)_{m}}{\left(u_{a}-u_{w}\right)}
$$


This criterion for failure can be related to the applied stress $\left(\sigma-u_{a}\right)$ by

$$
\frac{X}{f(\theta)}=-\frac{\sigma-u_{a}}{u_{a}-u_{w}}
$$

$\left(u_{a}-u_{w}\right)$ is the pore water pressure.

Equation (2.26) predicts that for a group of cracked soils of similar pore-space configurations, the ratio of tensile strength to the pore-water pressure deficiency should be a constant at a given degree of pore saturation. To verify the theory, values of tensile strength from different studies were used. These studies were in soils with particle sizes in the range of loams, silts, fine sands and aggregates. The values of aggregate strength tended to be lower than the predicted values.

A review of measurement methods of shear strength was done by Johnson et al. (1987). They stated that the role of displacement in shearing strength measurements is largely dependent on the state of compactness of the soil. This dependence is exhibited for three soil conditions: cemented, dense and loose. Shearing displacement may be important when soils are not cemented. Based on observation of loose soil conditions, an empirical expression of shearing stress, $\tau$, as a function of shearing displacement, $j$, along the controlled failure surface is

$$
\tau=\tau_{m}\left(1-e^{-j / k}\right)
$$

which also can be expressed as

$$
\tau=(c+\sigma \tan \phi)\left(1-e^{-j / k}\right)
$$

where $\mathrm{k}$ is a coefficient that is assumed not to be a function of $\sigma$.

Equations (2.27) and (2.28) have been useful for initially loose soils, but may be misleading in compacted soil conditions when excessive displacement may result from tension cracks beneath the displacement measuring device.

In 1993, Causarano used a similar approach to that of Dexter and Kroesberger (1985), followed by Hadas and Lennard (1988), to study the effect of water content, organic matter content, and aggregate size on the tensile strength of natural soil 
aggregates. He concluded that the tensile strength depends mainly on water content.

The methods of calculating tensile stress described above are based on the breaking force applied to laboratory samples of small sizes and regular shapes. Most of the methods depend on the magnitude of the compressive force and the geometry of the sample. There is no method reported to determine the tensile strength of soils directly and to measure the effect of compressive forces on the soil properties as in the case of soil tillage.

\subsection{Soil Response to Tillage:}

\subsubsection{Soehne (1953 - 1956) Inclined tools, taken from Gill (1967)}

Soehne developed an equilibrium equation for the soil segment, taking into consideration the acceleration forces as follows:

$$
\mathrm{W}=\mathrm{N}_{0}(\cos \alpha-\tan \delta \sin \alpha)-\mathrm{N}_{1}(\cos \beta-\tan \phi \sin \beta)+\left(\mathrm{cF}_{1}+\mathrm{B}\right) \sin \beta=0
$$

$\mathrm{B}=$ acceleration force of the soil

$\mathrm{F}_{1}=\mathrm{bd} / \sin \beta=$ area of shear

$\mathrm{B}=(\gamma / \mathrm{g}) \mathrm{bdv}_{\mathrm{o}}^{2}[\sin \alpha / \sin (\alpha+\beta)]$

$\beta=$ angle of forward failure surface to the horizontal.

The calculated values from equation (2.29) were $18 \%$ higher than measured values, possibly for the following reasons expressed by Gill (1967):

- $\quad$ edge and supporting standard effects were not considered on the model

- $\quad \mathrm{N}_{0}$ and $\mathrm{N}_{1}$ were considered constant along the respective surfaces on which they act, which may not be true.

- $\quad$ the pure cutting resistance of the tool bottom edge was assumed to be negligible

\subsubsection{Payne (1956) Vertical tools.}

Based in the passive earth pressure theory of Rankine, Payne was able to develop a mechanics theory to represent the tillage action. In narrow tools the side effect can no be ignored. Payne reasoned that shear failure surfaces must exist which pass along the sides 
of the tool as well as the bottom of the tool. He described the formation of the sheared block of soil as follows: As a narrow tool advances, it pushes forward and upward a triangular wedge-shaped block of soil. The wedge pushes sideways and upward two blocks of soil on each side of the centre line of the tool in the direction of travel. A description of the forces acting on the wedge is sufficient to determine the forces acting on the tool, since, the wedge is the only block in contact with the tool.

By using force equilibrium equations he found the following relations to calculate the draft and the vertical forces.

$$
\begin{aligned}
& H=B_{c} \cos \beta+B_{R} \sin (\phi+\beta)+T \cos \left(\theta_{m}\right)+2\left[S_{R} \cos \theta \sin (\alpha+\lambda)+S_{c} \cos \beta \cos \lambda\right] \\
& V=T \sin \left(\theta_{m}\right)+B_{R} \cos (\phi+\beta)+2\left[S_{R} \sin \theta+S_{c} \sin \beta\right]-B_{c} \sin \beta-D_{A}-W
\end{aligned}
$$

$\lambda=$ angle between the direction of travel and sides of the wedge in a horizontal plane

$\theta_{\mathrm{m}}=$ average angle between the force $\mathrm{T}$ and the direction of travel

$\theta=$ angle between $S_{R}$ and the direction of travel.

$\beta=$ angle between $S_{c}$ and the direction of travel.

$T=$ force resulting from the shear failure of the two fronts of the crescent that acts on the leading edge of the wedge.

$D_{A}=$ adhesion force

$\mathrm{B}_{\mathrm{c}}=$ cohesive forces $=(\mathrm{cw} / 2)[\mathrm{w} /(2 \tan \lambda \cos \beta)]=\left(\mathrm{cw}^{2}\right) /(4 \tan \lambda \cos \beta)$

$S_{R}=$ resultant of the normal and frictional force acting on the side of the wedge

$S_{c}=$ cohesive force on the side of the wedge

$\mathrm{S}_{\mathrm{c}}=\left[\left(\mathrm{c}_{\mathrm{r}} \mathrm{w}\right) / 2 \sin \lambda\right][1-(\mathrm{w} \tan \beta) /(4 \tan \lambda)]$

Payne reasoned that because of the vertical relative movement of the soil, the sides of the wedge were considered to be 'old' failure surfaces so that residual cohesion $\left(c_{r}\right)$ rather than failure cohesion would be acting. Payne also observed that equations (2.32) and (2.33) may be used to predict the draft of a narrow vertical tool at the instant of failure of the shear surfaces. Hence, the predicted draft value will be at maximum. As the tool continues to advance, the draft should be at some lower value until another failure 
state has been built up. An analysis of the results showed that the draft could be assumed to be nearly proportioned to the cohesion. Since cohesion ranged from a low $c_{r}$ to a high of $c$, an estimate of the minimum draft could be calculated from the relation:

$$
H_{\min }=H_{\max }\left(c_{r} / c\right)
$$

$\mathrm{H}_{\max }=$ maximum draft as determined from equations (2.32) and (2.33)

$\mathrm{H}_{\min }=$ minimum draft forces

The measured draft that fell within the predicted range varied from 6 to 78 percent for different tests. The apparent discrepancy between the measured and calculated values does not prove or disprove the validity of the mechanics.

\subsubsection{Kostritsyn (1956), taken from Gill (1967)}

The effects on soil cutting of the degree of soil vertical confinement was demonstrated by Kostritsyn (1956). He studied thin vertical cutters, and he noted that near the surface, soil would rupture or move upward, but at deeper depths, the movement was parallel to the direction of travel of the cutter. There is a critical depth below which there is a linear relation between draft and depth. The critical depth generally coincided with the depth where the soil movement becomes horizontal. Kostritsyn reported that the critical depth was 200 to $250 \mathrm{~mm}$ for cutters approximately $30 \mathrm{~mm}$ wide. Thus, the deeper depth confinements of the soil causes pure cutting and horizontal soil movement, whereas at shallower depths other types of soil failure also may occur.

\subsubsection{Reece (1965) Universal earth-moving equation}

Reece's equation is based in Rankine passive earth failure theory and it applies to all forms of soil failure where deformation takes place slowly, so that inertia forces due to velocity effects can be neglected:

$$
\mathrm{P}=\gamma \mathrm{z}^{2} \mathrm{~N}_{\mathrm{\gamma}}+\mathrm{czN} \mathrm{N}_{\mathrm{c}}+\mathrm{c}_{\mathrm{a}} \mathrm{zN}_{\mathrm{a}}+q \mathrm{qN}_{\mathrm{q}}
$$

$z=$ operation depth and $N_{\gamma}, N_{c}, N_{a}, N_{q}$ factors which depend on the soil frictional strength, tool geometry and tool to soil strength. 
The $\mathrm{N}$ factors of this equation are supposed to be valid only if they are independent of the main variables $\gamma, c, c_{a}$, and $q$. Later it was demonstrated by Hettiaratchi et al.(1966) that the failure surface is influenced by these variables. Therefore the $\mathrm{N}$ factors cannot be independent of them.

\subsubsection{Hettiaratchi et al. (1966- 1974) Passive pressure and soil resistance (wide blades)}

Hettiaratchi et al. (1966) reviewed Reece's equation and presented a set of charts with computed values of N. From 1967 to 1974, Hettiaratchi and Reece extended the analysis to three-dimensional soil failure. They restricted their analysis to infinitely wide vertical interface and finite wide vertical interface. Their method considered a perfectly smooth interface $(\delta=0)$; and a perfectly rough interface $(\delta=\phi)$.

They elaborated a set of charts for the solution of symmetrical three dimensional soil failure problems describing the failure geometry. The charts are restricted to: 1) the plane symmetrical interface in which the forces normal to the interface lie in planes containing the direction of motion of the interface; 2) the calculation of passive forces, although all the arguments will apply equally well to the active case; 3) the rake angle $\alpha$ between the interface and the horizontal free can be any value $\leq 90^{\circ}$ forward from the vertical.

The failure surface is assumed to be linear from the edge of the interface with an angle $\psi$ between the failure surface and the plane containing the width of the interface. These two horizontal failure planes will form a wedge of triangular shape. This centre wedge is similar to the one presented by Payne (1956). From the geometry of the wedge formation, there is a critical depth of the tool, $z^{\prime}$, at which the wedge first becomes fully formed. Under these circumstances the critical aspect ratio $\left(k=z^{\prime} / w\right)$ at which the wedge is fully formed can be obtained from:

$$
\mathrm{k}=\tan \psi \sin (\alpha+\beta) / 2 \sin \beta
$$

When $d<k w$ the wedge is not fully formed. If $d \geq k w$ the effective width is equal to the width of the blade, $w$. 
Assuming that the vertical failure in front of a loaded interface extends the full width and depth of the interface, the force $P_{f}$ on the interface due to this component of failure can be obtained directly from the Reece's universal earthmoving equation, and the $\mathrm{N}$ factors worked out by Hettiaratchi and Reece (1966). These expressions work well for interfaces inclined from the vertical.

Since it is assumed that soil is incompressible, it follows that the vertical wedge would be required to displace the soil sideways and backwards into the trench. The failure geometry is a logarithmic spiral centred at the bottom edge of the tool. To calculate the stresses, an elemental cube located at depth, s, from the horizontal free surface was represented by the Mohr-Coulomb diagram.

The method considered a) a smooth interface and b) a rough interface.

Smooth interface: The total force $\mathrm{P}_{\mathrm{s}}$, is given by:

$$
\mathrm{P}_{\mathrm{s}}=\gamma b \mathrm{~b}^{2} \mathrm{~N}_{\mathrm{sy}}+\operatorname{cbdN}_{\mathrm{sc}}
$$

Where the $\mathrm{N}$ factors are given by :

$$
\begin{aligned}
& \mathrm{N}_{\mathrm{s \gamma}}=\sin ^{2} \psi(1+\tan \phi \tan \psi) \\
& \mathrm{N}_{\mathrm{sc}}=2 \sin ^{2} \psi \tan \psi+\cot \phi
\end{aligned}
$$

Rough interface: The total force is the sum of cohesive, gravitational and surcharge forces:

$$
\mathrm{P}_{\mathrm{s}}=\gamma(\mathrm{d}+\mathrm{q} / \gamma)^{2} \mathrm{wN}_{\mathrm{s \gamma}}+\mathrm{cwdN}_{\mathrm{sc}}
$$

The same equations can be used for inclined interfaces multiplied by an inclination factor. The inclination factor is tabulated as a function of $\alpha$ and $\phi$.

\subsubsection{Three dimensional models}

\subsubsection{Godwin and Spoor (1977) narrow tines}

Goodwin and Spoor (1977) proposed a mathematical model to estimate the forces and the position of the critical depth for a wide range of tine aspect ratios, $d / w$. Their study was carried out using a glass-sided box to observe the soil failure pattern in the vertical plane containing the centre line of the tine. 
A compacted soil wedge was observed on the front of each tine at all tine widths and rake angles tested. With tines of small aspect ratio $(d / w)$, the soil ahead of the wedge moved forwards and upwards over the entire working depth, with a distinct shear plane being developed from the tine base (crescent failure). As the tine aspect ratio increased, the soil below a certain depth (the critical depth) appeared to move forwards and sideways only, with no distinct shear plane being formed (lateral failure). The soil failure mechanism below the critical depth was considered to be purely two-dimensional in a horizontal plane.

The force prediction model is based upon the assumptions that the soil worked by the tines obeys the Mohr-Coulomb shear failure criterion, that the soil is homogeneous and isotropic, and that inertial forces can be neglected.

A simple passive failure was considered to occur in the top crescent failure area. The magnitude of the resultant passive force was estimated from the equation for plane failure in front of wide cutting blades, given by Hettiaratchi et al. $(1966,1974)$ equation (2.39).

The crescent itself comprises a linear section immediately ahead of the tine with a width equal to the tine width, flanked by two curved sections of constant radius, and a circular failure pattern.

The passive force per unit width of the linear portion of soil which acts at an angle $\delta$ to the normal to the tine face, can be determined using equation (2.39). The angle $\rho^{\prime}$ between the direction of travel and the termination of the curved section of the crescent is given by:

$$
\rho^{\prime}=\cos ^{-1}(\cot \alpha / m)
$$

where:

$$
\mathrm{m}=\mathrm{r} / \mathrm{d}_{\mathrm{c}}
$$

$\mathrm{m}=$ rupture distance to depth ratio.

The passive force $\mathrm{dP}$ necessary to cause shear of a volumetric element contained in the sector $d \rho$ radiating from the edges of the tine to the crescent boundary is given by equation (2.43). This force acts at a horizontal angle $\rho$ to the direction of travel and at a 
vertical angle $\delta$ to the normal to the tine face.

$$
\mathrm{dP}=\left(\gamma \mathrm{d}_{\mathrm{c}}{ }^{2} \mathrm{~N}_{\gamma}+\mathrm{cd}_{\mathrm{c}} \mathrm{N}_{\mathrm{c}}+\mathrm{qd}_{\mathrm{c}} \mathrm{N}_{\mathrm{q}}\right) \mathrm{rd} \rho / 2
$$

It is assumed that $\mathrm{rd \rho} / 2$ is the effective width of the element. In practice, $\mathrm{rd} \rho / 2$ may be an under or over estimate of the mean width of the shear plane, depending whether the shear plane is convex or concave. The adhesive component in the radial zone is neglected because its width at the tine is infinitely small. It is assumed, for all rake angles, that the element is vertical and radiates at an angle $\rho$ to the direction of travel at all depths, (this is the case for the $90^{\circ}$ rake angle tines). The horizontal and vertical force components of $\mathrm{dP}$ are given by:

$$
\begin{aligned}
& \mathrm{dH}_{\mathrm{p}}=\mathrm{dP} \sin (\alpha+\delta) \\
& \mathrm{dV}_{\mathrm{p}}=-\mathrm{dP} \cos (\alpha+\delta)
\end{aligned}
$$

Upwards forces are considered positive. The component of $\mathrm{dH}_{\mathrm{p}}$ in the direction of travel is :

$$
\mathrm{dH}=\mathrm{F}(\mathrm{r} / 2) \sin (\alpha+\delta) \cos (\rho) \mathrm{d} \rho
$$

integrating (2.48) between the limits $\rho=0$ and $\rho=\rho^{\prime}$ gives the horizontal force component for one curved section.

The total horizontal force component in the direction of travel and above the critical depth is given by:

$$
\mathrm{H}_{\mathrm{T}}=\mathrm{Pw} \sin (\alpha+\delta)+2 \mathrm{H}+\mathrm{c}_{\mathrm{a}} \mathrm{wd}_{\mathrm{c}} \cos \alpha
$$

the term $c_{a} w_{c} \cos \alpha$, is the friction force acting parallel to the blade.

Following the same procedure, the total vertical force for one curved section is:

$$
\mathrm{V}=-\mathrm{dP} \cos ^{-1}[(\cot \alpha) / \mathrm{m}](\pi / 180) \cos (\alpha+\delta)
$$

and the total vertical force above the critical depth:

$$
\mathrm{V}_{\mathrm{T}}=\mathrm{Pw} \cos (\alpha+\delta)+2 \mathrm{~V}+\mathrm{c}_{\mathrm{a}} \mathrm{wd}_{\mathrm{c}} \sin \alpha
$$

The soil below the critical depth is considered to fail in a two dimensional manner in a horizontal plane regardless of the tine rake angle. The logarithmic spiral boundaries extend beyond the plane containing the face of the tine. Studies have shown that the resultant force on a footing is relatively insensitive to the degree of mobilization of shear 
stresses along the face parallel to the width of the tool; therefore, shear stresses on this face are neglected. To meet this condition, the angle $\eta$ must be $\left(45^{\circ}-\phi / 2\right)$. For narrow tines it appears that the failure mechanism extends through undisturbed soil only, and the angle $\beta$ must be equal to the angle of shearing resistance $\phi$.

This model gives useful agreement for compacted soil conditions. The technique is useful in the determination of the critical depth.

\subsubsection{McKyes and Ali (1977) The cutting of soil by narrow blades.}

McKyes and Ali (1977) proposed a three-dimensional model assuming that the surface side failure crescent is circular, and straight line failure planes in the soil can be used to predict both the draft forces and the volume of soil disturbed in front of a narrow blade.

The forward distance of the failure crescent, $r$, is given by:

$$
r=d(\cot \alpha+\cot \beta)
$$

where $d=$ tool working depth, $\alpha=$ the blade rake angle and $\beta=$ the slope of the lowest soil shear plane.

Applying the mechanics of equilibrium and impending soil failure on the boundaries of the three dimensional soil segments ahead of the blade, they developed an expression for the draft force:

$$
\mathrm{H}=\left(\gamma \mathrm{d}^{2} \mathrm{~N}_{\gamma}+\mathrm{cd} \mathrm{N}_{\mathrm{c}}+q \mathrm{qd} \mathrm{N}_{\mathrm{q}}\right) \mathrm{w} \sin (\alpha+\delta)
$$

This expression is of the same form as Reece's equation, with the following $\mathrm{N}$ factors:

$$
\begin{aligned}
& N_{\gamma}=\left[(r / 2 d)\left[1+(2 \mathrm{rd} / 3 \mathrm{dw}) \sin \rho^{\prime}\right]\{1 /[\cot (\alpha+\delta)+\cot (\beta+\phi)\}\right. \\
& \mathrm{N}_{\mathrm{c}}=[1+\cot \beta \cot (\beta+\phi)]\left[1+(\mathrm{rd} / \mathrm{dw}) \sin \rho^{\prime}\right]\{1 /[\cot (\alpha+\delta)+\cot (\beta+\phi)\} \\
& \mathrm{N}_{\mathrm{q}}=\mathrm{r} / \mathrm{d}\left[1+(\mathrm{rd} / \mathrm{dw}) \sin \rho^{\prime}\right]\{1 /[\cot (\alpha+\delta)+\cot (\beta+\phi)\}
\end{aligned}
$$

where $\rho^{\prime}=$ the maximum horizontal angle of the side failure crescent.

The failure plane angle $\beta$ is determined by minimizing the $N_{\gamma}$ with respect to $\beta$.

Graphical and tabulated values of $\mathrm{N}$ factors are presented in the publication. Predicted 
values of $\mathrm{N}$ factors are compared with values obtained using log spiral analyses and both methods gives very close results for low blade rake angles, and a difference of $10 \%$ or less at intermediate rake angles. However, for a high angle of soil to metal friction, the model overestimates the force factors considerably at rake angles greater than $90^{\circ}$. A closer approximation can be achieved by establishing the base of the wedge on the blade that makes an angle of $(\delta+45+\phi / 2)$ with the blade surface. This model permits a straightforward calculation of draft force and volume of soil disturbed by the blade.

\subsubsection{Yong and Hanna (1977)}

Yong and Hanna (1977) developed a finite element method (FEM) solution for determining soil performance under the actions of a cutting blade. The model takes into account the effect of progressive and continuous cutting of kaolin clay soil at the tip of the blade, with the possible development of failure zones in the soil whenever the shear strength of the soil is exceeded. They provided a theoretical solution for the two dimensional soil cutting phenomenon, and an evaluation of the model with actual experimental results obtained for cutting tests in a clay soil.

In the experiments, they used a cutting blade $10 \mathrm{~cm}$ wide $\times 20 \mathrm{~cm}$ long, travelling through a soil contained in a bin with transparent acrylic side walls. The internal dimensions of the bin allowed for two dimensional motion with a minimum blade travel of at least $50 \mathrm{~cm}$. Continuous photographs of the deforming grid during the cutting process permitted an evaluation of the deformation phenomenon. Subsequent plotting and superposition of the sequential photographs provided the history of the deformation process over a range of blade movement.

The soil was compacted in place to a bulk density of $1.6 \mathrm{Mg} / \mathrm{m}^{3}$. The friction angle $(\phi)$ of the soil was equal to 0 . The measured parameters were vertical and horizontal forces, and the blade horizontal displacement. The blades movement was at a rate of $2.5 \mathrm{~cm} / \mathrm{min}$. Blade inclinations $(\alpha)$ with $10^{\circ}, 20^{\circ}, 40^{\circ}$ and $50^{\circ}$ from the vertical.

The following assumptions were used in the modelling procedure: uniform movement of the blade in the soil, blades were considered rigid, self weight of the soil 
was considered, uniform horizontal rigid displacements were applied at all interface nodes, and the displacements were increased in ten equal increments of $0.25 \mathrm{~cm}$ for a total displacement of $2.5 \mathrm{~cm}$.

In their FEM technique applied to the soil cutting problem, the soil mass was divided into small elements with each element connected to its neighbouring elements at their nodal points. Approximate displacement functions were defined for each element. These functions were in accord with the constraints and requirements of the problem being analysed.

Their observations showed that there are two zones of soil displacement. One, the zone above the cutting plane, where the soil is moved forward and upward relative to the original blade position. These motions indicate that shear distortions occurred throughout the zone. Two, the zone below the cutting plane is shown to experience very little deformation.

A certain amount of slip occurred between the blade surface and the adjacent soil. The amount of slip for $10^{\circ}$ inclination of the blade decreased with depth, having the minimum value at the bottom tip of the blade. The slip distribution seemed to be more uniform for a $50^{\circ}$ inclination.

The results also indicated:

1- $\quad$ Stress concentrations at the tip of the blades were characterized by a singular behaviour where differences in the magnitudes, and in some instances in the directions of the stresses above and below the blade tippoint, were obtained.

2- The effect of the cutting element's plane on the horizontal stress distribution is to divide the stress field into two differently stressed regions:

a) The upper field, where the compressive stresses are high near the blade surface and decrease with distance from that surface, b) the lower field, where lower stresses, partly tensile and partly compressive, are developed. The compressive stresses develop in 
the soil below the blade tip.

3- $\quad$ The vertical stress, $\sigma_{y}$, distributions showed the existence of a zero vertical stress contour in the upper part of the soil mass for both $10^{\circ}$ and $50^{\circ}$ blade inclinations. The soil below the cutting plane experienced a change from tensile stress below the blade tip to compressive stress away from the blade.

4- The shear stress $(\tau)$ contours indicated a zone in front of the blade tip with high levels of shear stress. Shear stresses in this zone were positive. Thus the shearing is a clockwise shearing action as would be expected. These zones could be termed the "active" shear zones. There existed also zero shear stress contours with negative shear stresses. These zones were seen to expand with larger negative values in the $1.3 \mathrm{~cm}$ diagrams, indicating an upward action that explains the formation of a surface surcharge. In their model, the specifications of the finite elements mesh recognized the continuity of the masses, and hence did not require separate interpolations for extension to other points. To arrive at the displacement functions at the nodal points, they examined the basic energy principles for a body in equilibrium.

\subsubsection{Gupta and Larson (1982)}

Gupta and Larson (1982) presented models for predicting soil mechanical behaviour during tillage operations. They defined soil mechanical behaviour in terms of soil breakup and soil compaction. One of their experiments was to determine the change in the total porosity of soil as influenced by water content and applied stress. They developed a relationship between the parameters developed by Larson et al. (1980) and the particle size analysis. The Larson et al. equation is:

$$
\gamma=\left[\gamma_{\mathrm{k}}+\Delta_{\mathrm{T}}\left(\mathrm{S}_{1}-\mathrm{S}_{\mathrm{k}}\right)\right]+\mathrm{C} \log \left(\sigma_{\mathrm{a}} / \sigma_{\mathrm{k}}\right)
$$

where:

$\gamma, \gamma_{\mathrm{k}}=$ compacted bulk density corresponding to an applied stress, $\sigma_{\mathrm{a}}$, and bulk 
density, at known stress, $\sigma_{\mathbf{k}}$.

$\Delta_{\mathrm{T}}=$ slope of the curve: bulk density vs. degree of water saturation curve at $\sigma_{\mathrm{k}}$.

$\mathrm{S}_{1}=$ desired degree of saturation at $\sigma_{\mathrm{k}}$.

$S_{k}=$ degree of saturation corresponding to $\rho_{k}$ and $\sigma_{k}$.

$\mathrm{C}=$ compression index (slope of the linear portion of the compression curve)

The estimation of $\gamma_{\mathrm{k}}$, was done by regression of the curve $\Delta_{\mathrm{T}}$ vs. percent of clay, the same way that estimation of $\mathrm{C}$ was done by regression analysis of penetration resistance vs. bulk density

\subsubsection{Perumpral et al. (1983) Three-dimensional soil-tool model}

The objective of Perumpral et al. (1983) was to develop a generalized mathematical model and to examine its validity for predicting narrow tillage tool performance in soils. The model is similar to that developed by Ura and Yamamoto (1978) for predicting the behaviour of anchors in sand. One difference is that the cohesive and adhesive forces are included in the tillage model. The soil-tool model was based on the following assumptions: 1) The soil has cohesional and frictional characteristics, and it is isotropic and homogeneous. 2) The rupture surface is plane. 3) The frictional and cohesional forces are uniformly distributed on the surfaces of the wedge. 4) The tool face is frictional, and the soil-metal friction angle, ( $\delta)$, is a function of tool angle. 5) The Mohr-Coulomb failure criterion describes the soil shear failure. 6) The soil density is not affected by the tool displacement. 7) Acceleration forces on the tool are zero. 8) The width of the centre wedge is the same as the tool width.

The model considers a crescent formation in front of the tool, divided in a centre and two side crescents. Also the curved sliding surface was assumed to be straight, similarly to McKyes and Ali (1977) model. The difference is that in this model they replaced the two side crescents by a horizontal force acting on either side of the centre wedge.

By force equilibrium equations they derived the following final equations: 
$\mathrm{H}=\mathrm{P}_{1} \sin (\alpha+\delta)$

$\mathrm{V}=\mathrm{P}_{1} \cos (\alpha+\delta)$

$\mathrm{P}=[1 / \sin (\alpha+\phi+\beta+\delta)]\left\{-\mathrm{ADF} \cos (\alpha+\phi+\beta)+2 \mathrm{SF}_{2} \cos \phi+\mathrm{W} \sin (\phi+\beta)+\right.$

$\left.2 \mathrm{CF}_{2} \cos \phi+\mathrm{CF}_{1} \cos \phi\right\}$

where:

$\mathrm{SF}=$ frictional forces on the sides abc, def and the rupture plane of the centre wedge

$\mathrm{CF}=\mathrm{cwd}=$ cohessional forces on the sides abc, def and the rupture plane

$\mathrm{CF}_{1}=\mathrm{cwd} / \mathrm{sin} \beta$

$\mathrm{SF}_{1}=\mathrm{Q} \tan \phi=\mathrm{R} \sin \phi$

$\mathrm{CF}_{2}=\mathrm{c} \times \mathrm{A}$

$\mathrm{SF}_{2}=\mathrm{P}_{3} \tan \phi$

$A=$ Area of each side surface of the centre wedge

$\mathrm{ADF}=\mathrm{adw}(1+\mathrm{h} / \mathrm{d}) \sin \alpha=\mathrm{P}_{1} \sin \delta=$ adhesion force (soil-tool)

$\mathrm{Q}=\mathrm{R} \cos \phi=$ normal force acting on the rupture plane

Statistical analyses of the model gave a correlation coefficient of 0.96 , which means that the model predicted well $96 \%$ of the measured draft forces.

\subsubsection{McKyes (1985)}

McKyes presented different applications of the method of stress characteristics (Mohr circle of stresses, together with Coulomb's strength law) in combination with the universal earthmoving equation proposed by Reece in 1965 to analyze stress distribution in bodies of soil.

McKyes, (1985), derived an equation which described the shape of failure surfaces in a weightless soil for the characteristic failure lines, $\eta$ and $\xi$ :

$$
\mathrm{r}=\mathrm{C}_{3} \mathrm{e}^{-\mathrm{\theta tan} \phi}
$$

where $\mathrm{C}_{3}$ is constant of integration to be evaluated at a boundary.

\section{Smooth, vertical wide blade}


Since there is no friction, the major principle stress, $\sigma_{1}$, is horizontal all along the area of contact between the blade and the soil. Assuming uniform surcharge , $q$, the minor principle stress $\sigma_{3}=q$. Therefore, $d \theta=d \beta=d \mu=0$.

Manipulating the Mohr-Coulomb's strength equations for the boundary conditions, McKyes shows that the universal earth moving equation represented accurately the smooth vertical blade conditions.

\section{Raked wide blade in a cohesive soil}

The smooth blade is raked at angle $\alpha$ to the horizontal. The boundary conditions are similar to the vertical blade, except, that the major principle stress, $\sigma_{1}$, is not horizontal, it is inclined from the horizontal at an angle $\theta=\alpha-\pi / 2$. The assumption that $\mathrm{d} \theta=0$ is no longer acceptable.

To simplify the analysis, the cohesive forces are assumed to be much larger than the frictional forces.

Expressing the Coulomb's strength law in differential form and integrating, the total tool force per unit width, $(\mathrm{P} / \mathrm{w})$, can be calculated from:

$$
P=\mathrm{cdN}_{\mathrm{c}}+\mathrm{qdN}_{\mathrm{q}}
$$

where the $N$ values are exponential functions of $\phi$ and $\alpha$.

For the rough blade, the major principle stress, $\sigma_{1}$, will be acting at an angle $\delta$ clockwise from the direction perpendicular to the blade. Therefore, there is an upward shear strength, $\tau_{b}$, acting on the blade at failure, and the soil to blade normal pressure is, $\sigma_{b}$. Assuming that the adhesive strength is equal to the soil's internal strength, the upward shear force can be expressed as

$$
\tau_{\mathrm{b}}=\mathrm{c}+\sigma_{\mathrm{b}} \tan \phi
$$

The total tool force for a rough blade can be calculated from equation (2.62), but the $\mathrm{N}$ values are exponential functions of $\phi, \alpha$ and $\mu$.

\section{Boundary conditions between very rough and smooth}


From practical experience, the soil to tool friction angle, $\delta$, ranged from $1 / 2$ to $7 / 8$ of the soil internal friction angle, $\phi$, for steel and around $7 / 8$ of $\phi$ for concrete, (Tennessee Valley Authority, 1952; Desir, 1981).

The normal and shear stresses on the blade surface $\sigma_{b}$, and $\tau_{b}$, appear on the Mohr's circle of stresses where the tool to soil stress envelope $\left(s=c_{a}+\sigma_{n} \tan \delta\right)$, intersects the circle on the right hand side. Thus $\sigma_{1}$, is neither perpendicular nor at angle $\mu$ to the blade as in the rough blade in cohesive soil.

The total force, $\mathrm{P}$, can be calculated from an equation similar to (2.62), where the $\mathrm{N}$ values are exponential functions of $\theta$ and $\phi$.

\subsubsection{Swick and Perumpral (1988) Soil-tool interaction (Dynamic conditions)}

They present a modification of an available model for slow-moving narrow tillage tools, Perumpral et al. (1983). The model is based on the hypothesis that a large portion of the increase in tool forces due to increasing tool speed can be attributed to the following two phenomena: 1) Soil shear strength and soil-metal friction increase with increasing shear rate; and 2) The force required to accelerate soil from a state of rest to a certain velocity depends on tool speed and soil failure geometry.

A three-step procedure was employed to test the above hypothesis for tines working in an artificial soil. First, a series of laboratory tests was conducted to determine the effect of shear rate on soil shear strength and soil-metal friction parameters. Second, a soil-tillage tool interaction model developed for slow-moving tools was modified to include the shear rate effects and accelerational force effects. Third, the model was verified experimentally under laboratory conditions.

A conventional direct shear box was used to determine the effect of shear rate on soil strength and soil-metal friction parameters. For the dynamic model, they chose the model developed by Perumpral et al. (1983), equation (2.60). A major step in the modification was the incorporation of terms that account for acceleration force. The acceleration force used in the model was developed by Soehne (1956), equation (2.30).

The verification of the model was conducted under laboratory conditions, in a soil bin facility using artificial soil of unit weight equal to Florida Zircon sand. Mineral oil 
was used to similate moisture. The conclusions of the study are: 1) The angle of internal friction, soil-metal friction angle, cohesion and adhesion were found to be independent of shear rate for an artificial soil tested. 2) A soil-tillage tool interaction model developed for quasi-static soil failure was modified to include dynamic effects. The model gave reasonable predictions of tool forces encountered by narrow flat tools. 3) The model demonstrated that terms including accelerational force effects can account for a large portion of the increase in tool force observed to occur with an increase in tool speed.

\subsubsection{Chi and Kushwaha (1989) Finite element analysis of forces on a plane soil blade.}

Chi and Kushwaha (1989) developed a nonlinear 3-D element model to predict the soil forces on a tillage tool. They used the weighted residual method to formulate the FEM, using the equations of equilibrium in matrix form:

$$
D^{\mathrm{T}} \mathrm{S}-\mathrm{f}=0
$$

Where $\mathbf{D}=$ differential operator matrix

$$
\begin{aligned}
& S=\text { stress tensor }\left\{\sigma_{x}, \sigma_{y}, \sigma_{z}, \tau_{x y}, \tau_{y z}, \tau_{x z}\right\}^{T} \\
& f=\text { body force vector }\{0,0,-\gamma\}
\end{aligned}
$$

The incremental method was used in which the change in displacement is still very small in each small increment. The difference in strain at each increment can be considered as infinitesimal strain. Therefore, for each increment a linear relationship between strain and displacement is considered but with stiffness varying with total strain.

The stress-strain relationship of the soil (C) used was expressed:

$$
C=\left(E_{t}\right) /[(1+v)(1-2 v)]
$$

where $v=$ Poisson's ratio

$\mathrm{E}_{\mathrm{t}}=$ tangent modulus

The tangent modulus equation $\left(\mathrm{E}_{\mathrm{t}}\right)$ was developed by Duncan and Chang (1970) based upon Kondner's model (1963).

The soil properties used to compare the FEM results are: 
$\mathrm{c}=10 \mathrm{kPa} ; \phi=30^{\circ}$; Soil density $\gamma=15 \mathrm{kN} / \mathrm{m}^{3}$; External friction $\delta=0$ smooth blade; Poisson's ratio $v=0.48 ; \mathrm{R}_{\mathrm{f}}=0.90 ; \mathrm{K}=40 ; \mathrm{n}=0.4 ;$ Rake angle $\alpha=45^{\circ}, 60^{\circ}, 90^{\circ}$; Tool depth $\mathrm{d}=10,20 \mathrm{~cm}$; Tool width $\mathrm{w}=5 \mathrm{~cm}$

The element was considered to have failed when its deviatoric stress exceeded the soil strength. The stresses of each element were examined with the Mohr-Coulomb soil failure theory. The draft force of the model was calculated using the procedure described by McKyes and Ali (1977) and Perumpral et al. (1983).

The results of draft were compared with the values obtained by McKyes and Ali (1977) and Perumpral et al. (1983) and they seems to be in reasonable agreement.

\subsection{More Recent Studies:}

Recent studies related to the subject of this thesis that have been published are summarised in this section. Although the topics are related to tensile strength and tillage, the material presented in those recent publications is not very useful for the present research. Thus, they are very briefly explain in the following paragraphs.

Abebe and Koolen (1995) used the concept of fracture to investigate the behavior of cohesive soil crumbling. The study is based on Griffith's theory (1921) which postulates that tensile failure initiates at pre-existing flaws and micro-cracks, or defects in the material. They concluded that the structural conditions (pore distribution, moisture content, flaws, etc.) seem to determine the fracture behavior of cohesive soils.

Aluko and Seig (2000) studied the conditions and characteristics of brittle fracture in three different soil types (sandy loam, clay loam and cemented soil). The results showed that under the tillage compressive stresses, the soil segment can be cut by brittle fracturing and shear failure at the bottom of the blade. In their study the soil was confined to a glass box.

Sharifat and Kushwaha (2000) developed a mathematical model of the horizontal movement of soil particles using the general equation of radial stress distribution in a semi-infinite medium presented in Frocht (1948).

Dexter and Bird (2001) developed methods for predicting the optimum water content at which a tillage operation is satisfactory. The soil samples used in their study 
were soil compositions with a range of fine material between 26 and $32 \%$ by mass. The method explains soil break-up in terms of zones of weakness in the soil which are identified by relatively large air-filled pores. 


\subsection{Summary of the Literature Review:}

Frocht (1948) proposed mathematical and photoelastic analyses of stress distributions produced by external compressive forces. He used steel, aluminum and Bakelite, concluding the stress distribution does not depend on material properties. In 1964, Frydman used the Frocht approach in soil samples of cylindrical shape, following the Brazilian Test procedure. Frydman concluded that this model gives good results for soil which fails in brittle manner.

For soil loosening which consist of soil separation, it is necessary to find the maximum tensile stress which represents the maximum stress that the material can experience without separation. Tensile stress can be measured by direct or indirect techniques. Direct methods have the disadvantage that they can not be performed in-situ. Indirect methods can be performed in the lab or in-situ. They consist of applying compressive forces or bending moments and determining the tensile stress using geometrical relationships together with material properties.

The literature presents different approaches for measuring tensile strength using soil samples of different shapes (cylindrical, spherical or square), but, there is no study done using irregular shapes or performed in the field.

Some studies have been useful for determination of the compressive forces applied by tillage tools of different geometries. The same studies can be used for determination of shape and volume of soil. These studies are based on the Reece's earth moving equation for the passive soil failure zone. They show different zones of soil displacement and relative soil distortion among the different zones. Calculations are simple if the models give graphical representations of the factors used in the developed equations.

A few studies have been done to determine of normal stress distributions on a tillage blade, produced by the soil resistance. These models are computer models using incremental differences and stress-strain relationships. The resultant forces predicted by the computer models are then compared with forces calculated by theoretical models which calculate total compressive forces. These computer models are not simple to use. 
There is no reliable method of calculating stress distributions within the soil mass, or comprehensive models of soil behaviour under compressive forces, which is the case during tillage. A study like this would be useful to determine the tool efficiency in causing tension to pulverize the soil, and the strength of the resultant soil aggregates. 


\section{THEORETICAL STRESS DISTRIBUTION MODEL}

\subsection{Introduction:}

The model presented in this chapter combines general soil mechanics principles and empirical models of soil behaviour with optical observations and an essential force equilibrium analysis in a finite slices approach. As a result, a mathematical model was developed which can be used to predict stress distribution and soil failure within a finite segment of soil cut by a tillage blade.

The performance of the mathematical model can be tested using a physical experiment of the actual tillage process.

\subsection{Problem Statement:}

From visual observations of soil tillage processes, it can be stated that the soil cutting and fracturing process consists of three distinct steps:

1) First, compressive forces are applied by the blade to a semi-infinite soil medium (Figure 3.1). In this process only compressive stresses are developed in a radial manner $\left(\sigma_{\mathrm{r}}\right)$, and vertically $\left(\sigma_{z z}\right)$ due to the soil weight. The compressive pressure increases from a minimum at the surface of the soil and increases with depth.

2) Subsequently, the shear failure plane starts at the bottom of the blade (Figure 3.2) when the shear strength of the soil is reached. The soil fails in shear according to the Rankine passive theory in a log-spiral shape (side view, Figure 3.2a) and approximately a semi-circular plan shape from the edge of the blade (top view, Figure 3.2b). The sheared segment becomes a finite mass, acted upon by the external forces from the blade and the rest of the soil.

3) The continuous action of the forces produces reaction forces around the border of the soil segment. Then, there is development of tensile stresses within the soil segment producing breaking of the soil in a radial manner 


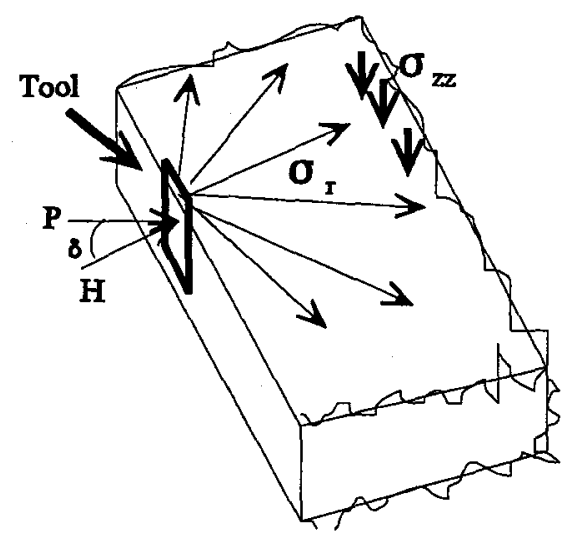

Figure 3.1: Step (1) Force applied to a semi-infinite medium

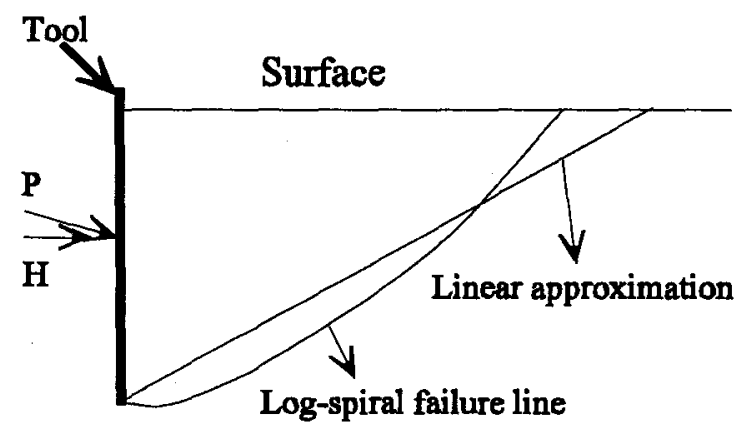

Figure 3.2a: Step 2, Side view of the shear failed soil segment.

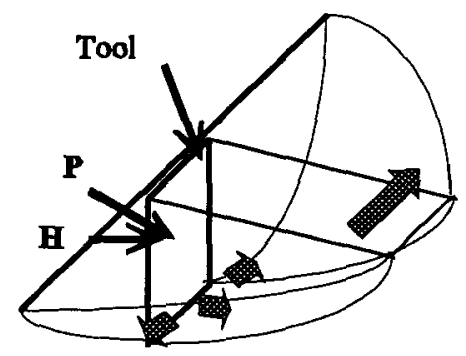

Figure 3.2b: Step 2, Oblique view of shear failed soil segment

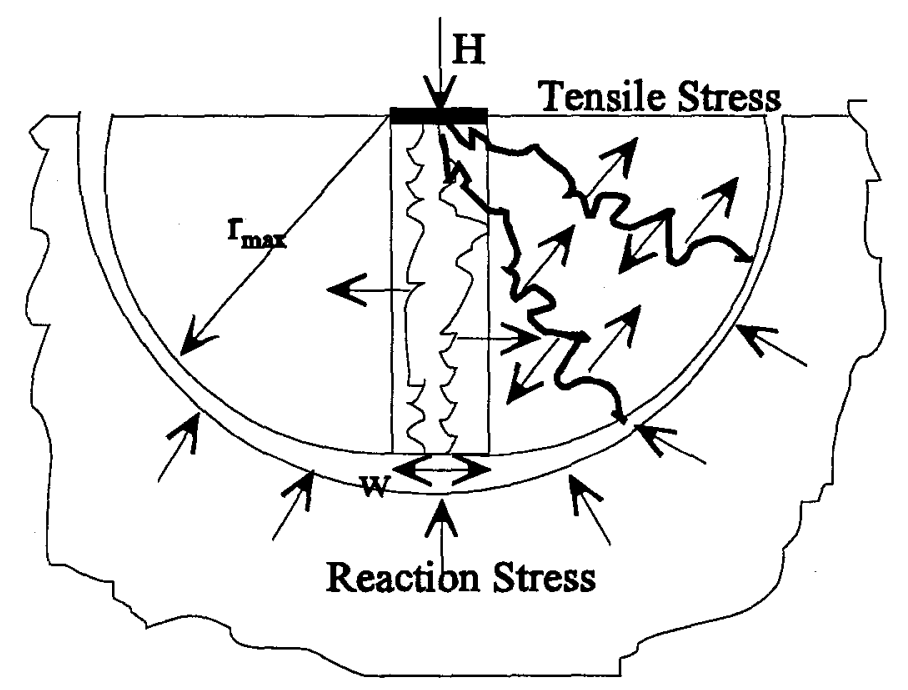

Figure 3.3: Step 3, Tension Failure. 


\subsection{Theoretical Approach for the Mathematical Model:}

\subsubsection{Background}

There are different problem solutions in soil mechanics publications based on a general equation presented by Frocht (1948), Sokolovski (1956) and Harr (1966) which predicts radial stresses produced by a concentrated load acting on a semi-infinite plate. Frocht (1948) experimented with point and equally distributed forces applied on different symmetrical shapes of bakelite. He validated his findings using a photo-elastic approach. In Frocht's experiments with bakelite, he found that a unique value of tensile stress always acted at the centre of the different bodies. Frocht's approach was used by Frydman (1964) in a study of the tensile strength of soil samples.

The samples used in Frydman's research were cylinders of dry soil. The samples were placed between plates (Brazilian test), which is not the case in tillage. In the present research another application of the general equation used by Frocht in 1948 is developed. Some assumptions are made for simplification of the problem.

\subsubsection{Assumptions}

Three main assumptions in the development of the mathematical model are:

1) The soil is a homogeneous and isotropic mass.

2) The soil behaves in a linearly elastic manner until shear or tension failure.

3) The initial shape of the sheared soil volume has one free straight edge perpendicular to the line of action of the draft force, $\mathrm{H}$, (Figure 3.4).

Sign convention: The convention used for the force analysis is that compressive stress is positive and tensile stress is negative. 
from the centre of the cross section (Figure 3.3).

Models to predict processes 1 and 2 have been developed by various researchers, as explained in the literature review. There is no model which predicts the distribution of stresses accurately within the failed soil volume. Therefore there is no model for calculating the tensile stresses which cause the cracking of the soil volume at the centre, or at any other location within the soil volume disturbed by the tillage tool. It is the tensile failure that causes the soil segment to crumble and loosen. Thus, a model which predicts the distribution of stresses within the soil segment is proposed in the following section. 


\subsubsection{Reasoning for the theoretical approach}

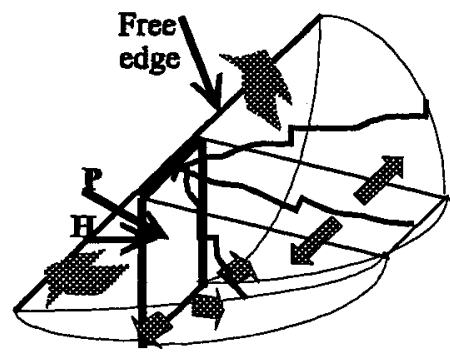

Figure 3.4: Top view failed soil segment after cracking

After the soil has failed in shear (Figure 3.2), there are forces that constrain the soil to move outwards from the centre along the free edges on the side of the blade (Figure 3.4). The reasoning used to find the stress distribution within the soil segment is

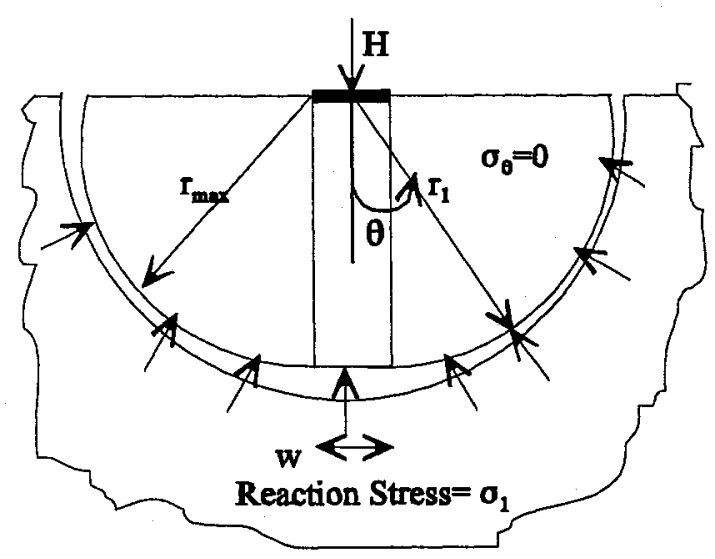

Figure 3.5a: Boundary stresses

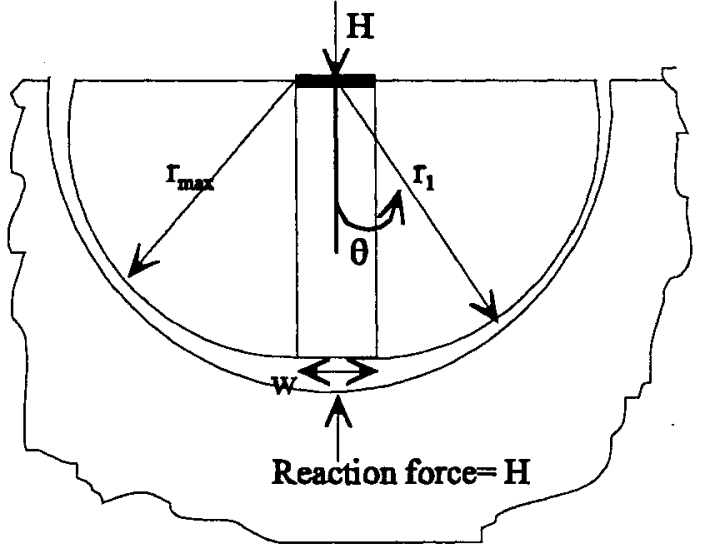

Figure 3.5b: External force and total reaction force

expressed in the following force diagrams: 


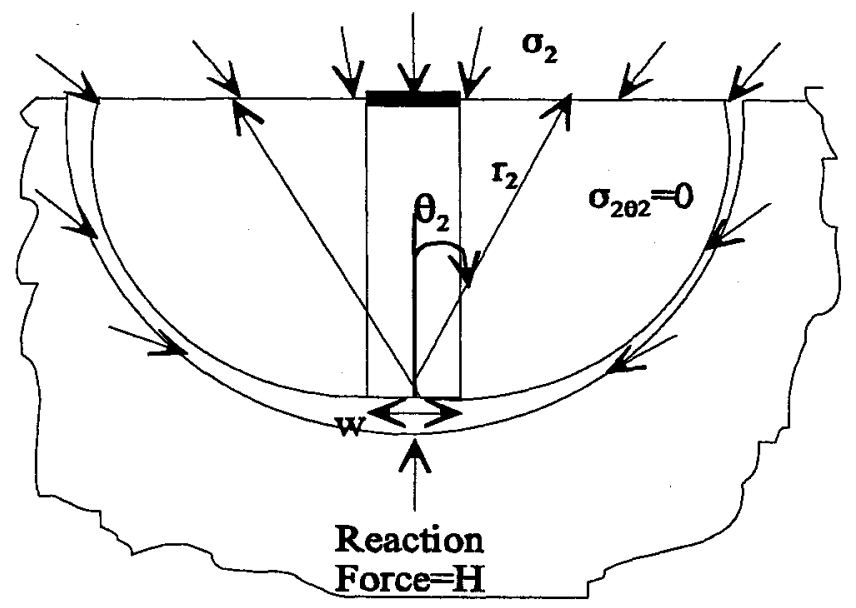

Figure 3.5c: Boundary reaction to $H$

A realistic model of the stress distribution within the disturbed soil mass can be obtained by superposing three statically equivalent systems in order to produce the desired boundary conditions. The three systems shown in Figure 3.5a, 3.5b and 3.5c are statically equivalent. System $3.5 \mathrm{a}$ is the system which represents the two dimensional stress radial distribution from a point force. The stresses in system 3.5a are distributed radially $\left(\sigma_{1}\right)$ and there are no stresses perpendicular to the radius $\left(\sigma_{\theta}=0\right)$. This system does not satisfy the mechanism shown in Figure 3.3. Nevertheless, just for the boundary force analysis, the reaction stress $\left(\sigma_{1}\right)$ can be expressed by another statically equivalent system as a concentrated force $(\mathrm{H})$, which has to be equal in magnitude to the external force $\mathrm{H}$ to keep the system in equilibrium (Figure 3.5b). Then the concentrated force, $\mathrm{H}$ also would produce radial stresses in the opposite direction $\left(\sigma_{2}\right)$ which are represented in the system $3.5 \mathrm{c}$. Superposing the systems $3.5 \mathrm{a}$ and $3.5 \mathrm{c}$ third statically equivalent system is obtained (Figure 3.6). 


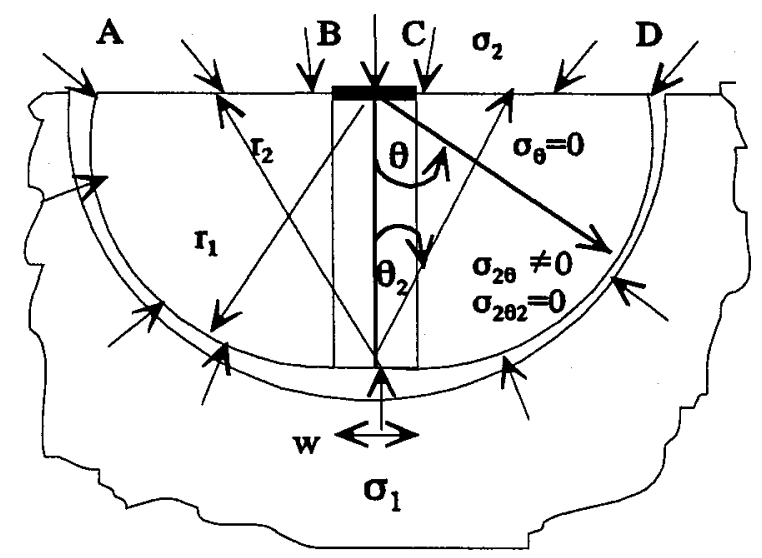

Figure 3.6: Superposition of reaction forces

However, the stresses shown on the free edges $A B$ and $C D\left(\sigma_{2}\right.$ in Figure 3.6) cannot exist in reality, since the edges do not contact any other soil. Then, to free the edges from any stresses, a distributed force equal to the one on those edges but in the opposite direction has to be subtracted. Thus, the final system can be expressed as shown in Figure 3.7.

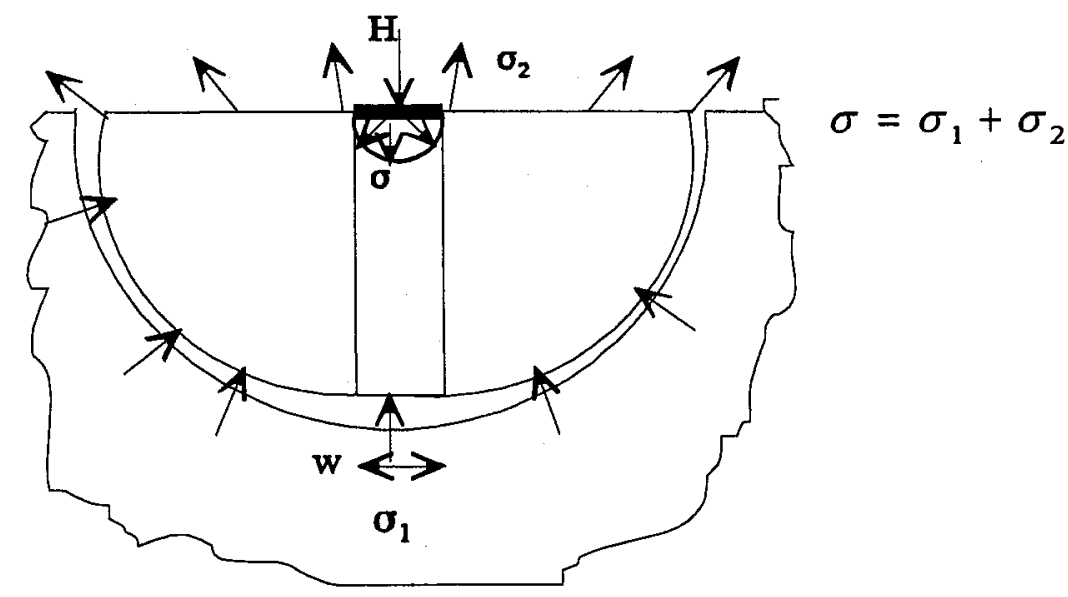

Figure 3.7: Final system for the analysis

Then, the stresses at any point within the cross section are the stresses produced by the force applied by the blade $(\sigma)$, minus the reaction stress $\left(\sigma_{1}\right)$, minus the stresses produced by the forces distributed at the free edge $\left(\sigma_{2}\right)$. 


\subsection{Mathematical Model Development:}

Frocht (1948), Sokolovski (1956) and Harr (1966) presented a general equation that predicts radial stresses produced by a concentrated load acting on a semi-infinite plate. The equation is of the form:

$\sigma_{r}=\frac{A \cos \theta}{r}$

Where $A$ is an integration constant.

Equation (3.1) was developed from the stress function $\Phi=A r \cos (\theta)$; therefore $\sigma_{\theta}=0$ and $\tau_{r \theta}=0$. This thesis presents a model which combines the radial stress distribution $(\sigma)$ produced by a concentrated force $(H)$, with the stresses produced by a distributed and non uniform force $\left(\sigma_{2}\right)$ applied at the free edges of the cross section (Figure 3.8).

The horizontal force $(\mathrm{H})$, increases linearly with depth, and it is a function of the soil parameters and geometry of the blade. The analysis is within the Rankine passive zone on which the weight of the soil is not the major stress Figures $3.2 \mathrm{a}$ and $3.2 \mathrm{~b}$ ).

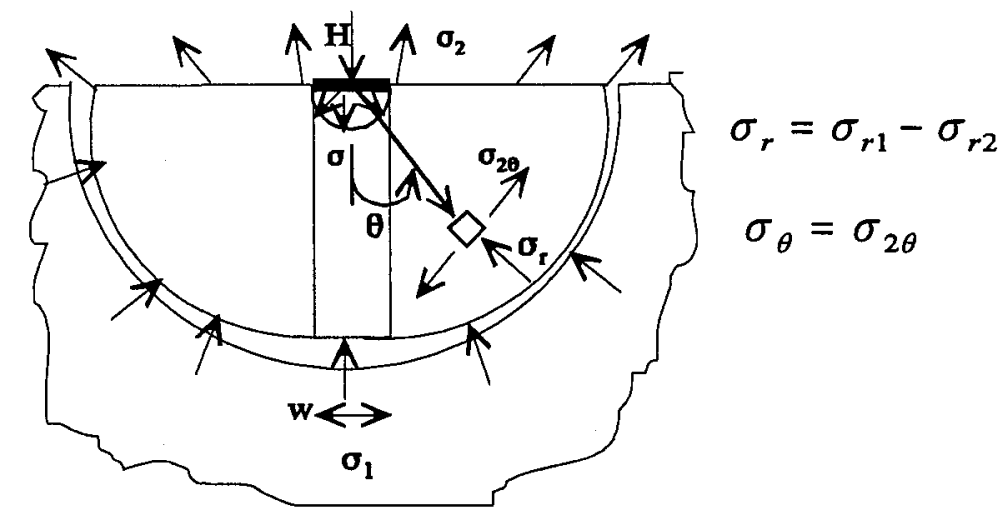

Figure 3.8: Final system for the analysis of internal points

The stresses at any point within the cross section are the stresses produced by the 
external force from the blade $(\sigma)$ decreased by the stresses produced by the reaction forces at the boundary $\left(\sigma_{2}\right.$ in Figure 3.8), and lateral component of the soil weight, $\gamma \mathrm{zK}_{o}$, where $\gamma$ is the unit soil weight, $z$ is the depth from the surface, $K_{o}$ is the "at rest" lateral stress coefficient $(1-\sin \phi)$. Therefore the stresses at any point are given by:

$$
\begin{gathered}
\sigma_{r}=\sigma_{r 1}-\sigma_{r 2}-\gamma z K_{o} \\
\sigma_{\theta}=-\sigma_{\theta 2}-\gamma z K_{o} \\
\tau_{r \theta}=-\tau_{r \theta 2}
\end{gathered}
$$

Equation 3.1 was developed for a concentrated force acting on a disk of thickness $t$. Then this model proposes the use of finite soil slices of thickness $t$, on which is acting a horizontal force $H_{t}$ as shown in Figure 3.9.

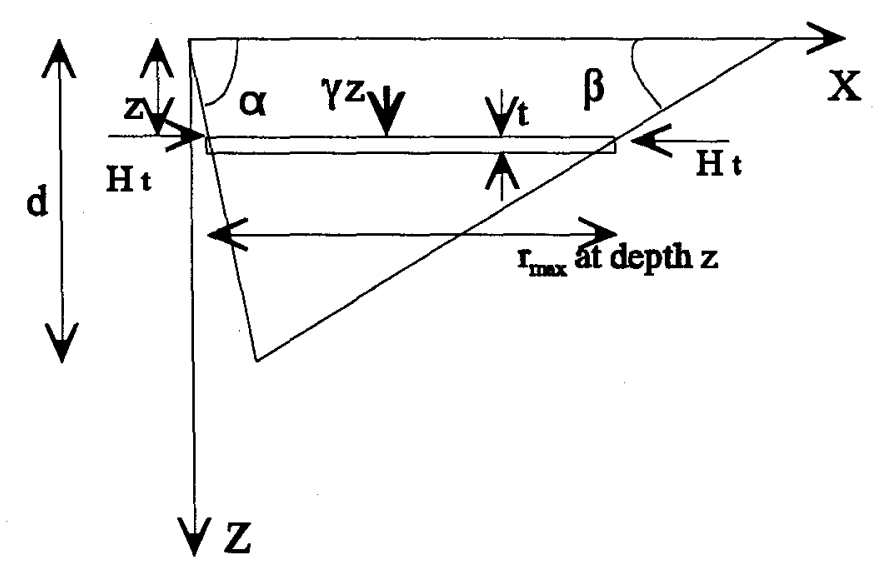

Figure 3.9: Forces acting on a soil slice 


\subsubsection{Calculation of $\sigma_{1}$ at any soil element:}

The general equation (3.1) can be expressed as:

$\sigma_{r 1}=\left(\frac{2 H_{t} \cos \theta}{\pi t r}\right)$

where the integration constant $A=2 H_{t} / \pi t ; H_{t}$ is the concentrated horizontal force acting on each soil slice; $\theta$ is the horizontal angle from the centre of the blade; $t$ is the thickness of the soil slice; and $r$ is the horizontal radial distance from the centre of the blade to any point in the cross section of the soil slice.

\subsubsection{Calculation of $\sigma_{2}$ (distributed force acting on the free edge of the soil slice):}

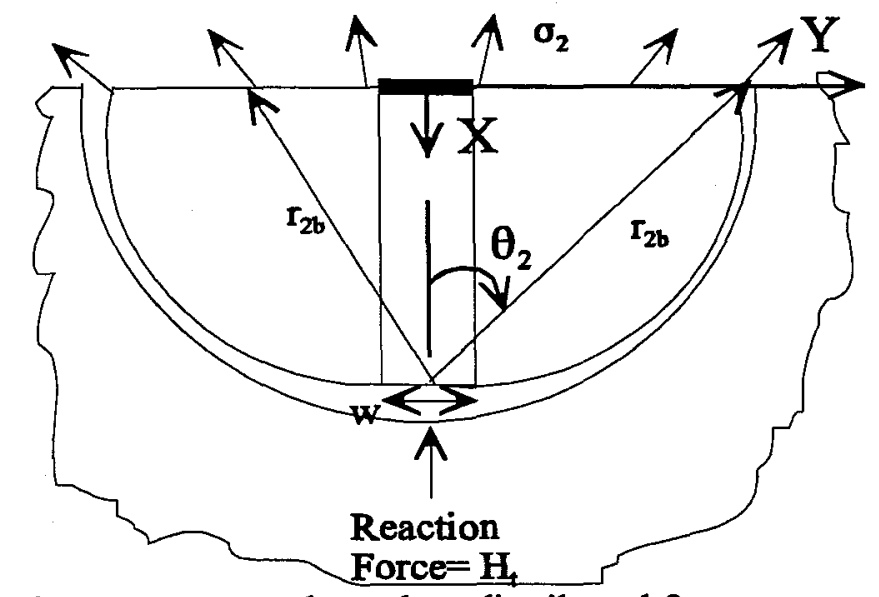

Figure 3.10: Free boundary distributed forces

The stresses at the boundary $\left(\sigma_{2}\right)$, where $r_{2}=r_{2 b}$ (Figure 3.10) are given by a similar expression to equation (3.3), but with opposite sign since it is acting in tension:

$$
\sigma_{2}=\frac{-2 H_{t} \cos \theta_{2}}{\pi t r_{2 b}}
$$


where:

$$
r_{2 b}=\frac{r_{\max }}{\cos \theta_{2}} \quad \text { for } 0 \leq \theta_{2} \leq \tan ^{-1}\left(\frac{r_{\max }+w / 2}{r_{\max }}\right)
$$

Equations (3.4b and 3.4c) are valid for the flat portion of the surface, from the centre of the blade to the edge where the circular portion starts (Figure 3.8). Within this portion is the section which is required for the analysis of $\sigma_{2}$. then:

$$
\sigma_{2}=\frac{-2 H_{t} \cos ^{2} \theta_{2}}{\pi t r_{\max }}
$$

Similarly to the analysis done for the concentrated force $\mathrm{H}_{b}$, acting at the centre of the blade, where $H_{t}$ produces only radial stresses $\left(\sigma_{1}\right)$ with respect to $(\theta)$, the concentrated reaction force $\left(H_{t}\right)$ produces only radial stresses $\left(\sigma_{2}\right)$ with respect to $\left(\theta_{2}\right)$ (Figure 3.10). Thus, as previously, $\sigma_{2 \theta 2}=0$ and $\tau_{12 \theta 2}=0$. Nevertheless, the stresses produced at the free boundary $\sigma_{2}$ will produce stresses perpendicular and parallel to $r_{1}$, (Figure 3.8) $\left(\sigma_{\theta} \neq 0\right.$ and $\tau_{r \theta} \neq 0$ produced by $\left.\sigma_{2}\right)$.

To find the components in the $r$ and $\theta$ directions of $\sigma_{2}$, it is simpler to find the components in $x$ and $y$ axis and later translate them to the polar coordinates $r$ and $\theta$.

\subsubsection{Components of $\sigma_{2}$ in rectangular coordinates, $x$ and $y$ :}

The stress $\sigma_{2 x}$ can be expressed as:

$$
\begin{aligned}
& \sigma_{2 x}=\sigma_{2} \cos \theta_{2} \\
& \sigma_{2_{x}}=-\frac{2 H_{t} \cos ^{3} \theta_{2}}{\pi t r_{\max }}
\end{aligned}
$$

The stress $\sigma_{2 y}$ can be expressed as: 


$$
\begin{aligned}
& \sigma_{2 y}=\sigma_{2} \sin \theta_{2} \\
& \sigma_{2_{y}}=-\frac{2 H_{t} \cos ^{2} \theta_{2} \sin \theta_{2}}{\pi t r_{\max }}
\end{aligned}
$$

The distribution of these stress components $\sigma_{2 x}$ and $\sigma_{2 y}$ are shown in Figure 3.11a and Figure 3.11b.

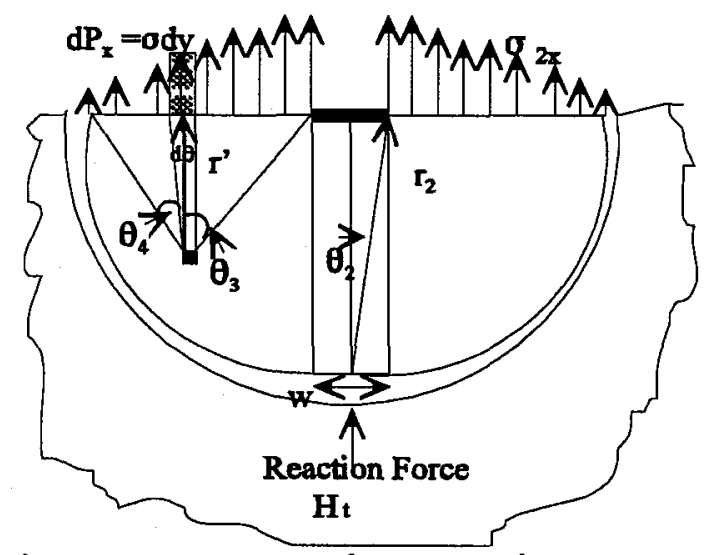

Figure 3.11a: Free Boundary stresses in $x$

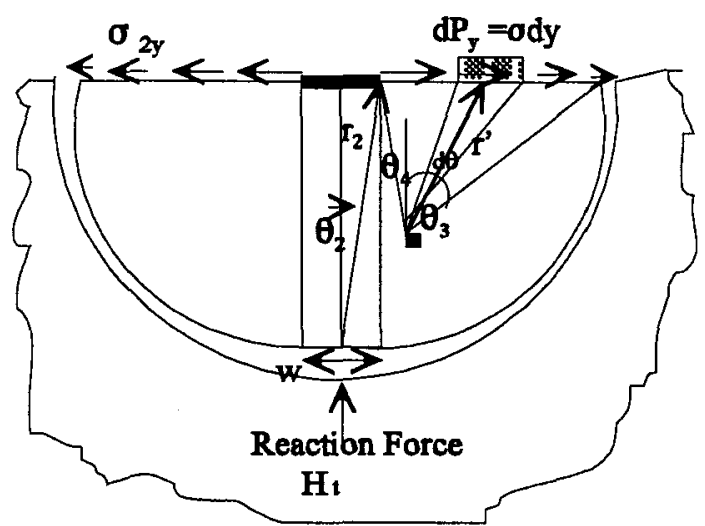

Figure 3.1 lb: Free Boundary stresses in y

\subsubsection{Internal stresses on each element of soil produced by $\sigma_{2 x}$ and $\sigma_{2 y}$ :}

Since $\sigma_{2 x}$ and $\sigma_{2 y}$ are not equally distributed forces, to calculate the internal stresses produced by $\sigma_{2 x}$ and $\sigma_{2 y}$ on each element of soil within the cross section, is easier by evaluating the stresses produced by an element of force $(d P)$ and then integrating to find the total stresses. The element of forces for each component in $x$ and $y$ are given by:

$d P_{x}=\frac{2 H_{t} \cos \theta_{2} d \theta_{2}}{\pi t}$ 


$$
d P_{y}=\frac{2 H_{t} \sin \theta_{2} d \theta_{2}}{\pi t}
$$

A more detailed development of the equations is presented in Appendix A.

3.4.4.1 The stresses produced by the element of force $\left(d P_{x}\right)$ in $x$ and $y$ coordinates at any point within the soil segment are given by:

$\sigma_{\left(d P_{x}\right) x}=\frac{2 d P_{x}\left[\frac{3}{8}\left(\theta_{4}-\theta_{3}\right)+\frac{1}{4}\left(\sin 2 \theta_{4}-\sin 2 \theta_{3}\right)+\frac{1}{32}\left(\sin 4 \theta_{4}-\sin 4 \theta_{3}\right)\right]}{\pi t r \cos \theta}$

$$
\sigma_{\left(d P_{x}\right) y}=\frac{2 d P_{x}\left[-\left(\cos \theta_{4}+\cos \theta_{3}\right)+\frac{1}{3}\left(\cos ^{3} \theta_{3}-\cos ^{3} \theta_{4}\right)\right]}{\pi \operatorname{tr} \cos \theta}
$$

$$
\tau_{\left(d P_{x}\right)_{x y}}=\frac{2 d P_{x}\left[\frac{1}{3}\left(\sin ^{2} \theta_{4}-\sin ^{2} \theta_{3}\right)+\frac{1}{4}\left(\sin ^{4} \theta_{3}-\sin ^{4} \theta_{4}\right)\right]}{\pi \operatorname{tr} \cos \theta}
$$


Each of these rectangular components of stresses will have to be further transformed into components parallel and perpendicular to $r$, (section 3.4.5).

3.4.4.2 The stresses produced by the element of force $\left(d P_{y}\right)$ in rectangular components $x$ and $y$ at any point within the soil slice are given by:

$\sigma_{\left(d P_{y}\right) x}=\frac{d P_{y}\left[\frac{1}{3}\left(\cos ^{3} \theta_{4}-\cos ^{3} \theta_{3}\right)-\frac{1}{2}\left(\cos ^{2} \theta_{4}-\cos ^{2} \theta_{3}\right)\right]}{\pi \operatorname{tr} \cos \theta}$

$$
\sigma_{\left(d P_{y}\right) y}=\frac{d P_{y}\left[\frac{1}{2}\left(\sin ^{2} \theta_{4}-\sin ^{2} \theta_{3}\right)+\frac{1}{4}\left(\sin ^{4} \theta_{3}-\sin ^{4} \theta_{4}\right)\right]}{\pi \operatorname{tr} \cos \theta}
$$

$\tau_{\left(d P_{y}\right) x y}=\frac{d P_{\cdot y}\left[\frac{1}{2}\left(\theta_{4}-\theta_{3}\right)-\frac{1}{4}\left(\theta_{4}-\theta_{3}\right)-\frac{1}{16}\left(\sin \theta_{4}-\sin \theta_{3}\right)\right]}{\pi \operatorname{tr} \cos \theta}$

Similarly to the stresses produced by the force $\left(d P_{x}\right)$, the rectangular components of $\left(d P_{y}\right)$ have to be expressed in radial components (section 3.4.5). 
3.4.4.3 Angles $\theta_{4}$, and $\theta_{3}$, for the evaluation of equations (3.9) to (3.14):

The angle $\theta_{4}$, or $\theta_{3}$, are given by:

$$
\begin{aligned}
& \theta_{3}=\operatorname{tg}^{-1}\left(\frac{r_{\max }-r \sin \theta-w / 2}{r \cos \theta}\right) \\
& \theta_{4}=\operatorname{tg}^{-1}\left(\frac{r \sin \theta-w / 2}{r \cos \theta}\right)
\end{aligned}
$$

\subsubsection{Integration of the element of forces $(d P)$ :}

Equations (3.11) to (3.14) are functions of the differential forces $(d P)$ which are independent of the angles $\theta, \theta_{4}$, or $\theta_{3}$. The elemental forces $(d P)$ depend only on $\theta_{2}$, thus, their integration can be done separately, and the results are:

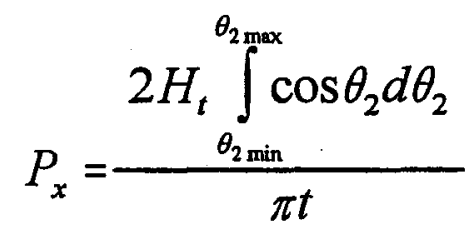

$$
P_{y}=\frac{2 H_{t} \int_{\theta_{2 \min }}^{\theta_{2 \max }} \sin \theta_{2} d \theta_{2}}{\pi t}
$$

where: 


$$
\begin{aligned}
& \theta_{2 \min }=\operatorname{tg}^{-1}\left(\frac{w}{2 r_{\max }}\right) \\
& \theta_{2 \max }=\operatorname{tg}^{-1}\left(\frac{r_{\text {max }}-\frac{w}{2}}{r_{\max }}\right)
\end{aligned}
$$

Then:

$$
P_{x}=\frac{2 H\left[\sin \left(\operatorname{tg}^{-1}\left(\frac{r_{\max }+w / 2}{r_{\max }}\right)\right)-\sin \left(\operatorname{tg}^{-1}\left(\frac{w / 2}{r_{\max }}\right)\right)\right]}{\pi}
$$

and

$$
P_{y}=\frac{-2 H\left[\cos \left(\operatorname{tg}^{-1}\left(\frac{r_{\max }+w / 2}{r_{\max }}\right)\right)-\cos \left(\operatorname{tg}^{-1}\left(\frac{w / 2}{r_{\max }}\right)\right]\right.}{\pi}
$$

3.4.5 Calculation of the components in $r$ and $\theta$ of the stresses produced by the element of forces $\left(d P_{x}\right)$ and $\left(d P_{y}\right)$ :

$$
\begin{aligned}
& \sigma_{r_{2}}=\sigma_{x} \cos ^{2} \theta+\sigma_{y} \sin ^{2} \theta \\
& \sigma_{\theta_{2}}=\sigma_{x} \sin ^{2} \theta+\sigma_{y} \cos ^{2} \theta
\end{aligned}
$$




\subsubsection{Using $\left(d P_{x}\right)$ :}

$$
\begin{aligned}
\sigma_{r\left(d P_{x}\right)} & =\frac{2 d P_{x} \cos \theta}{\pi t r}\left[\frac{3}{8}\left(\theta_{4}-\theta_{3}\right)+\frac{1}{4}\left(\sin 2 \theta_{4}-\sin 2 \theta_{3}\right)+\frac{1}{32}\left(\sin 4 \theta_{4}-\sin 4 \theta_{3}\right)\right] \\
& +\frac{2 d P_{x} \sin ^{2} \theta}{\pi t r \cos \theta}\left[\frac{1}{3}\left(\cos ^{3} \theta_{3}-\cos ^{3} \theta_{4}\right)-\left(\cos \theta_{4}+\cos \theta_{3}\right)\right] \\
\sigma_{\theta\left(d P_{x}\right)} & =\frac{2 d P_{x} \sin ^{2} \theta}{\pi t r \cos \theta}\left[\frac{3}{8}\left(\theta_{4}-\theta_{3}\right)+\frac{1}{4}\left(\sin 2 \theta_{4}-\sin 2 \theta_{3}\right)+\frac{1}{32}\left(\sin 4 \theta_{4}-\sin 4 \theta_{3}\right)\right] \\
& +\frac{2 d P_{x} \cos \theta}{\pi t r}\left[\frac{1}{3}\left(\cos ^{3} \theta_{3}-\cos ^{3} \theta_{4}\right)-\left(\cos \theta_{4}+\cos \theta_{3}\right)\right]
\end{aligned}
$$

\subsubsection{Using $\left(d P_{y}\right)$ :}

$$
\begin{aligned}
\sigma_{r\left(d P_{y}\right)} & =\frac{d P_{y} \cos \theta}{\pi t r}\left[\frac{1}{3}\left(\cos ^{3} \theta_{4}-\cos ^{3} \theta_{3}\right)-\frac{1}{2}\left(\cos ^{2} \theta_{4}-\cos ^{2} \theta_{3}\right)\right] \\
& +\frac{d P_{y} \sin ^{2} \theta}{\pi t r \cos \theta}\left[\frac{1}{2}\left(\sin ^{2} \theta_{4}-\sin ^{2} \theta_{3}\right)-\frac{1}{4}\left(\sin ^{4} \theta_{4}-\sin ^{4} \theta_{3}\right)\right] \\
\sigma_{\theta\left(d P_{y}\right)} & =\frac{d P_{y} \sin ^{2} \theta}{\pi t r \cos \theta}\left[\frac{1}{3}\left(\cos ^{3} \theta_{4}-\cos ^{3} \theta_{3}\right)-\frac{1}{2}\left(\cos ^{2} \theta_{4}-\cos ^{2} \theta_{3}\right)\right] \\
& +\frac{d P_{y} \cos \theta}{\pi t r}\left[\frac{1}{2}\left(\sin ^{2} \theta_{4}-\sin ^{2} \theta_{3}\right)-\frac{1}{4}\left(\sin ^{4} \theta_{4}-\sin ^{4} \theta_{3}\right)\right]
\end{aligned}
$$

3.4.6 Final stress equations: Total stresses in $r$ and $\theta$ produced by $\left(\sigma_{1}\right)$ and ( $\left.\sigma 2\right)$ :

Substituting equations (3.3), (3.21), (3.22), (3.23) and (3.24) into the set of equations (3.2a) and (3.2b), the final expression for the radial and angular stresses can be found: 


$$
\begin{aligned}
& \sigma_{r}=\sigma_{r 1}-\sigma_{r 2}-\gamma z K_{o} \rightarrow \sigma_{r}=\sigma_{r 1}-\sigma_{r d P_{x}}-\sigma_{r d P_{y}}-\gamma z K_{o} \\
& \sigma_{\theta}=-\sigma_{\theta 2}-\gamma z K_{o} \rightarrow \sigma_{\theta}=-\sigma_{\theta d P_{x}}-\sigma_{\theta d P_{y}}-\gamma z K_{o}
\end{aligned}
$$

Similarly the shear stresses which are given by equations (3.11) and (3.14) can also be transformed to radial components and then substituted the results in equation $(3.2 \mathrm{c})$.

$$
\tau_{r \theta_{2}}=\left(\tau_{x y\left(d P_{x}\right)}+\tau_{x y\left(d P_{y}\right)}\right) \cos \theta \sin \theta
$$

And then:

$$
\tau_{r \theta}=-\tau_{r \theta 2} \rightarrow \tau_{r \theta}=-\left(\tau_{x y\left(d P_{x}\right)}+\tau_{x y\left(d P_{y}\right)}\right) \cos \theta \sin \theta
$$

\subsection{Maximum Radial Distance from the Centre of the Blade to any point on the Border of the Cross Section:}

The stress equations (3.25), (3.26) and (3.28) are valid at any point $(r, \theta)$ within the cross section of the soil slice where $r \leq r_{b}$. The maximum value that the radial distance $\left(r_{b}\right)$ can be evaluated from the centre of the cross section is given by:

$$
\begin{aligned}
& r_{b}=r_{\max }+\Delta r \\
& \Delta r={ }_{2}^{w} \sin \theta \\
& r_{b}=r_{\max }+\frac{w}{2} \sin \theta
\end{aligned}
$$

\subsection{Shear Failure Criterion:}

The shear failure criterion used in this research is the Mohr-Coulomb theory for 
frictional materials. The theory defines the principle stresses and the shear stresses, at any point within the soil segment in the following manner:

$$
\begin{aligned}
& \sigma_{1}=\frac{\sigma_{r}+\sigma_{\theta}}{2}+\left(\frac{\sigma_{r}-\sigma_{\theta}}{2}\right)^{2}+\tau_{r \theta}^{2} \\
& \sigma_{3}=\frac{\sigma_{r}+\sigma_{\theta}}{2}-\left(\frac{\sigma_{r}-\sigma_{\theta}}{2}\right)^{2}+\tau_{r \theta}^{2} \\
& \tau_{f}=\left(\frac{\sigma_{1}-\sigma_{3}}{2}\right) \cos \phi \\
& \sigma_{1}-\sigma_{3}=\left(\sigma_{1}+\sigma_{3}\right) \sin \phi+2 c^{*} \cos \phi
\end{aligned}
$$

where $\sigma_{1}$ and $\sigma_{3}$ are the largest and smallest principal stresses, $\phi$ is the angle of internal friction, and $c$ is the soil cohesion.

The Mohr Coulomb failure envelope is described by:

$$
\tau=c+\sigma \tan \phi
$$

Once the principal normal stresses $\left(\sigma_{1}\right)$ and $\left(\sigma_{3}\right)$ and the shear stress $\left(\tau_{f}\right)$ are calculated using equations (3.30a), (3.30b), and (3.30c), the following failure criteria can be applied:

\subsubsection{Shear Failure:}

The values of shear stress at failure calculated with equation (3.30c) can be compared with the values of the Mohr-Coulomb Failure envelope (equation 3.31). If the shear force at failure $\left(\tau_{f}\right)$ is equal to or greater than the value of the failure envelope, the soil segment fails in shear. 


\subsubsection{Tension Fracture:}

The minor principal stress ( $\sigma_{3}$ in equation $3.30 \mathrm{~b}$ ) can be compared to the tensile strength of the soil, (T), If the minor normal stress is equal to or greater than the tensile strength $(\mathrm{T})$, the soil fails in tension fracture on a plane perpendicular to $\sigma_{3}$.

\subsubsection{Simultaneous Shear Failure and Tension Fracturing:}

The soil can theoretically fail simultaneously in both shear and tension. This is only possible when the value of shear stress is equal to the value of the Mohr-Coulomb failure envelope, and the minor principle stress is equal to the tensile strength (T).

The three cases of failure are explained in more detail in Chapter 5.

\subsubsection{Tensile Strength:}

The literature review shows that there is no reliable laboratory test to measure the tensile strength of cohesive soils directly. Therefore it was required to custom design and construct an apparatus to measure the values of the tensile strength (T) of the soil used in this research. The instrument and procedure are explained in detail in Chapter 6. The theory and reasoning for the tensile strength method is presented in Chapter 4.

\subsection{Horizontal Force (draft), H}

The force $\mathrm{H}_{\mathrm{t}}$ applied at each soil slice, calculated by McKyes and Ali's model (1977) and can also be validated by the results from the tillage simulator.

$d H=H_{t}=\left(\gamma z N_{\gamma}+c N_{c}\right) \sin (\alpha+\delta) w$

The total force $\boldsymbol{H}$ is the calculated by summation of the forces $\mathrm{H}_{\mathrm{t}}$, and then the total $\mathrm{H}$ can be compared to the total draft force $(\mathrm{H})$ required in the tillage operation and measured in the laboratory. 
3.8 Maximum radius measured from the edge of the blade $\left(r_{\max }\right)$ for each soil slice:

Using a linear failure surface similar to McKyes and Ali's model (1977), and evaluating the $r_{\max }$, at each increment of depth $t$ (Figure 6):

$$
r_{\max }=(d-z)(\cot \alpha+\cot \beta)
$$




\section{TENSILE STRENGTH TEST OF COHESIVE SOILS}

\subsection{Background:}

Like the other mechanical properties of cohesive soils, specifically cohesion and friction angle, the tensile strength of cohesive soils is highly dependent on its physical and chemical composition, including moisture content, soil density and stress history. Each of these physical and chemical properties is affected by the environmental factors of temperature, rain pattern and land use. Because of the complexity of the compositional factors and their influence on mechanical properties, the understanding of soil behavior and simulation in the laboratory are difficult.

The objective of any laboratory test is to define material properties independently of sample size and geometry. Thus the properties can be cataloged in materials handbooks to be used for material selection. Standardized tensile strength tests for metals, polymers, wood and composites have already been developed, and different societies of testing materials have recommendations of geometries and sizes for specimens to be tested and equipment to perform the tests. In soils, however, there is no standard test to find the tensile strength.

The test should be easy to perform, and easy to replicate for the purpose of statistical analysis. Also, because of the wide range of soil composition and behavior, the test should be performed over typical ranges of property values and conditions. The results of the tests can be represented in graphical or tabulated form for later use in the design and optimization of tillage operations. Based on all of these considerations the following test was designed.

\subsection{Tensile Strength Apparatus:}

The tensile strength apparatus is described in detailed in Chapter 6. In this chapter only the technical considerations and preliminary evaluation of the performance of the test are presented.

The design of the apparatus for testing soil tensile strength follows a similar 
principle of the apparatus used for testing metal or wood specimens. It consists of a sample holder that applies a force perpendicular to the sample cross section in tension (Figure 4.1). Then the tension force is gently increased until the sample breaks (Photo 4.1).

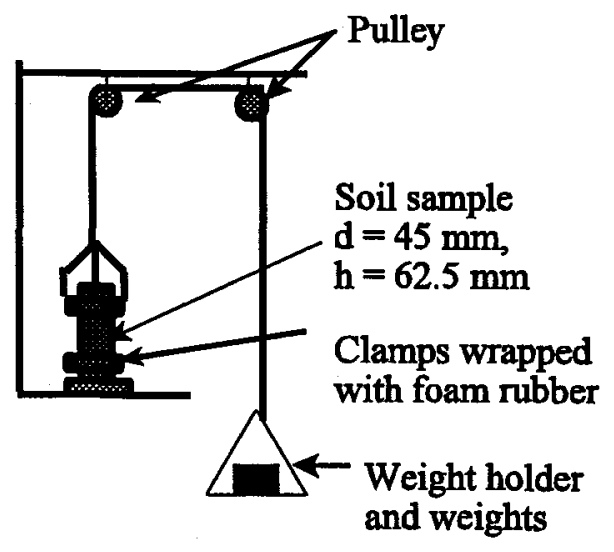

Figure 4.1: Diagram of Tensile Strength Apparatus for Soil Samples

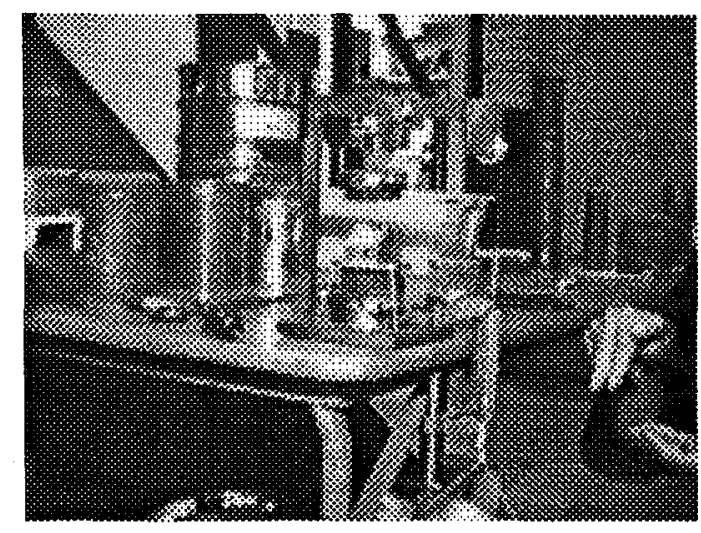

Photo 4.1: Tensile Strength Apparatus for Soil Samples

\subsection{Preliminary Performance Observations of the Tensile Strength Test:}

From the initial tests using the tension apparatus, the results were consistent and logical, as shown in Chapter 6. Some observations of its performance were: 
1) Because of the fragility of the soil sample, the ends have to be clamped in a gentle manner, and the pressure applied to the sample has to be uniform around the diameter of the specimen. The system used in the preliminary tests was to apply pressure around the sample with a layer of foam rubber inside the clamp. Once the desirable pressure is applied, the system works very well.

2) It is recommended to use a cylindrical shape for the specimen, and the soil specimen cannot be too small. After different trials, sample dimensions which gave more consistent and repeatable values were $45 \mathrm{~mm}$ diameter and $62.5 \mathrm{~mm}$ length.

3) It is easier to work with moist soil, where the cohesive strength is higher.

4) The sample was compacted using a constant pressure to achieve uniformity in the sample. A mass of $10 \mathrm{~kg}$ was applied to the soil sample as it was built up in its 45 $\mathrm{mm}$ diameter cylinder in three layers. The weight was held constant during 40 seconds for each layer.

5) The soil specimen has to be long enough for the soil to clearly break in the middle section were the soil is not clamped, otherwise, the test is not reliable.

6) The type of fracture obtained is a brittle fracture (Photo 4.1). The soil sample breaks on a plane perpendicular to the direction of the tension force, and the breaking plane is not at any of the points where the sample is held.

7) The apparatus has to be balanced before the test is performed by measuring the force to balance the specimen holder mass. In the test performed for this research, the balancing mass was $58 \mathrm{~g}(0.568 \mathrm{~N}$ force $)$.

8) The friction losses due to the pulley were measured by putting different known weights on the apparatus and measuring the force required to start movement. The friction losses at the pulley were small, between 2 and $5 \mathrm{~g}(0.02-0.05 \mathrm{~N})$.

9) The force required for calibration of the apparatus and the force required for overcoming the friction at the pulley have to be subtracted from the total force calculated for the soil break up, to calculate the tensile strength of the soil sample. 


\section{TENSION FAILURE CRITERIA}

\subsection{Introduction:}

All aspects of material stability depend in some way on material strength. Most relationships used in practice for the characterization of stress-deformation and strength properties are based on description of the material behavior. For soils, the Mohr-Coulomb equation is by far the most widely used for shear strength.

The Mohr-Coulomb equation is an empirical model which describes the stresses on the shear failure plane. For cohesionless materials, where there is no physical or chemical cementation, like sand or dry grains, the Mohr-Coulomb theory is valid for any value of normal stress since the minimum value that the minor normal stress $\left(\sigma_{3}\right)$ can have is zero. Therefore, cohesionless materials have no tensile strength. The last statement is not true for cohesive materials, like agricultural soils for which the MohrCoulomb envelope extends beyond the zero normal stress to the negative side of the normal stress or tensile stresses (Figure 5.1).

The minimum value that the normal stress can have is the tensile strength. The tensile strengths of most construction materials are already available in tabulated form. These values of tensile strength are independent of the geometry of the material, and depend only on physical, mechanical and chemical properties.

The literature review presents some studies of the measurement of tensile strength of soil aggregates. The results of those studies show a unique value of tensile strength of an aggregate which depends only on the geometry of the sample. These values are useful in the analysis of an agricultural seed bed, but they are not applicable to soil fracturing and breaking up, where the soil can be assumed to be a continuous mass. Therefore, there has been no known value of general soil tensile strength, or a method to measure it.

Knowing the tensile strength of soils is critical in the study of soil tillage, since tension fracturing is what produces soil break-up and crumbling. It can also be useful in the design and optimization of the tillage implements for soil loosening purposes. 


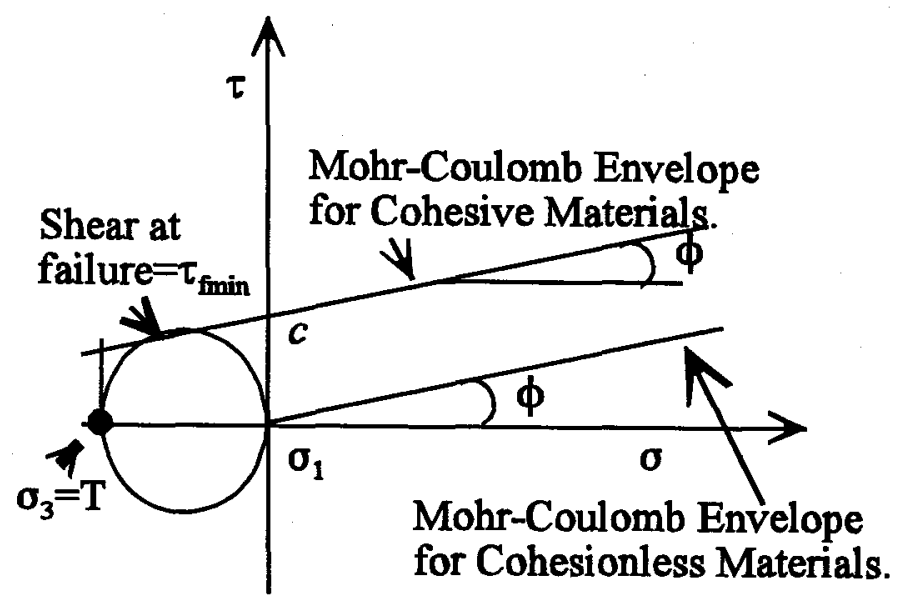

Figure 5.1: Tension Failure Criteria, $\sigma=$ normal stress, and $\tau=$ shear stress on the same plane.

\subsection{Criteria for Failure in Tension:}

There are three possibilities for a soil to fail in tension. The three cases are represented in Figure 5.3.

1) Shear failure.

2) Tensile fracturing.

3) Both of the cases mentioned above (1 and 2) occurring at the same time, in which case the soil will fail simultaneously in shear failure and tensile fracturing.

The three cases of failure are explained in more detail in Section 5.4.

To be able to evaluate the previous failure criteria, it is required to have the mathematical expression for the minimum values that the shear stress and the principle normal stresses at failure can have for failure. These values should also be equal to, or less than, the value predicted by the Mohr-Coulomb shear failure theory. The minimum values correspond to the values that describe the minimum Mohr circle which can exist tangent to the Mohr-Coulomb failure envelope (Figure 5.3). 


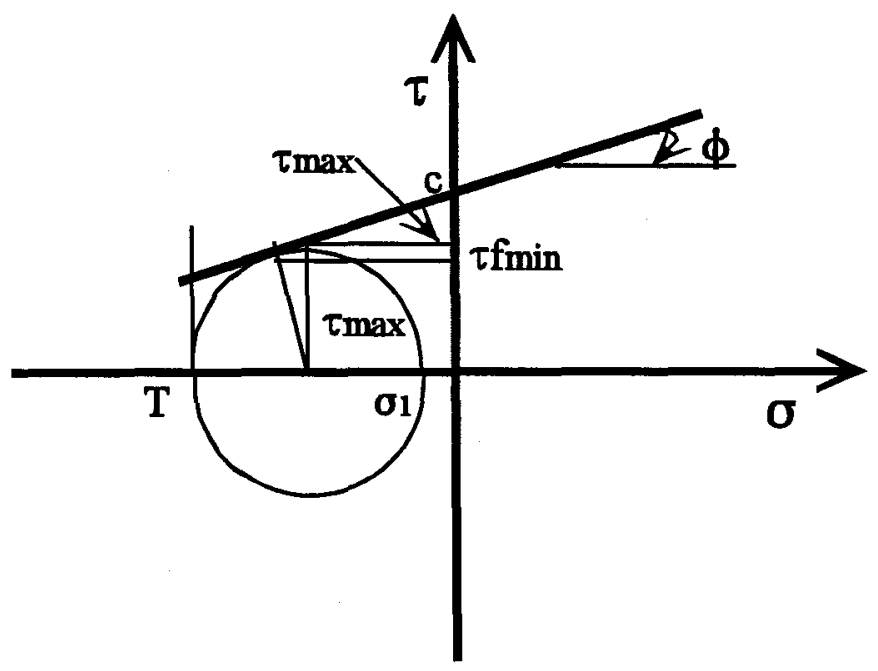

Figure 5.2: Minimum values of stresses for tension failure.

The following equations were developed using the geometry of Figure 5.2.

$\sigma_{3_{\max }}=-T$

$\sigma_{1_{\min }}=\frac{2(c+\operatorname{Ttg} \phi)}{\cos \phi-(1-\sin \phi) \operatorname{tg} \phi}+T$

$\tau_{\max }=\frac{(c+T \operatorname{tg} \phi)}{\cos \phi-(1-\sin \phi) \operatorname{tg} \phi}$ 


$$
\tau_{f_{\min }}=\tau_{\max } \cos \phi
$$

\subsection{Failure Interpretation:}

The equations (5.1) to (5.4) describe only the values for the smallest circle tangent to the Mohr-Coulomb envelope. This circle corresponds to a soil element under a minor normal stress $\sigma_{3}=\mathrm{T}$ and it is not applicable for any other situation.

\subsubsection{Case 3: Shear Failure only}

If the minor normal stress $\left(\sigma_{3}\right)$ calculated with equation (3.30b) is absolutely smaller than the tensile strength $(\mathrm{T})$, then, the general Mohr-Coulomb theory is applied, where the shear stress calculated with equation (3.30c) can be compared with the value predicted by the Mohr-Coulomb Failure criteria expressed in the general equation (3.31) which is duplicated here.

$$
\tau=c+\sigma \tan \phi
$$

If the shear stress at failure $\left(\tau_{f}\right)$ from equation $(3.30 \mathrm{c})$ is equal to or greater than the value of the failure envelope equation (3.31), the soil segment fails only in shear.

\subsubsection{Case 2: Tension fracturing only}

If the minor normal stress $\left(\sigma_{3}\right)$ calculated with equation $(3.30 \mathrm{~b})$ is absolutely equal to, or greater than, the tensile strength $(\mathrm{T})$ of the soil, and the shear stress calculated with equation $(3.30 \mathrm{c})$ is smaller than the minimum value for shear stress $\left(\tau_{\text {fmin }}\right)$ calculated with equation (5.4), the soil fails in tension fracture only.

\subsubsection{Case 3: Simultaneous shear failure and tension fracturing}

The soil can fail simultaneously in both shear failure and tension fracturing. This 
is only possible when the values of shear stress $\left(\tau_{f}\right)$ calculated with equation $(3.30 \mathrm{c})$ is equal to the minimum value $\left(\tau_{\text {fmin }}\right)$ calculated with equation (5.4), and the minor principle stress $\left(\sigma_{3}\right)$ is equal to the tensile strength $(T)$, as described in Section 5.3. The three possible tension failures are represented in (Figure 5.3).

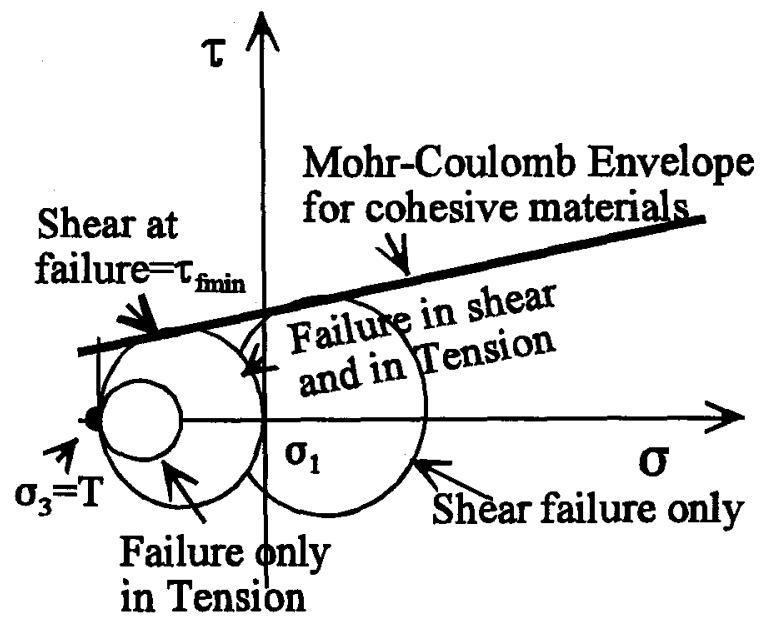

Figure 5.3: Three Cases of Failure 


\section{EXPERIMENTAL PROCEDURE}

\subsection{Introduction:}

The performance of the rational mathematical model for stress distributions was tested in the laboratory using a material representation of the real tillage system. There is no previously reported model similar to the mathematical model presented in this thesis, therefore, many of the instruments used for the evaluation of the model performance are not yet standardized. Thus, a set of custom designed instruments was built. The basic instrumentation used in the research consisted of:

1) A tillage simulator, including a set of blades, a profile meter, a moving tillage tool carrier, and a soil box of $0.375 \mathrm{~m}^{3}$.

2) A set of steel core samplers and a special core driver.

3) An empirical method and a laboratory scale apparatus for testing tensile strength of cohesive soils.

4) Traditional laboratory instruments for measuring the soil mechanical properties of cohesion and friction angle, and a standard set of sieves for gravimetric aggregate size analysis.

\subsubsection{General methodology}

Each test was done following the same methodology. Each of the steps is described in detail in the following sections of this chapter, but in general the steps were:

1) Soil preparation, which included mixing with water in the soil until it was uniformly distributed, sieved and placed in the soil bin.

2) Compaction of the soil and trimming it to the exact desired volume.

3) Carefully placing the soil bin in the tillage simulator to avoid any shaking to keep the soil at its original compacted state.

4) Sampling the soil for initial bulk density and moisture content.

5) Running the tillage blade simultaneously with taking video recordings of the surface for further soil failure pattern analysis. 
6) After the soil was tilled, measuring the profile of the resulting soil furrow, taking soil samples for bulk density within the soil aggregates and taking soil samples for mean weight diameter of aggregates. These measurements are useful in the analysis of the quality of the seed bed.

7) Emptying the soil and taking a profile of the empty furrow for further calculations used in the analysis of quantity of loosened soil.

8) Separately, the soil physical properties of cohesion, friction angle and tensile strength were measured. The cohesion and friction angle were calculated using the standard shear box method. The tensile strength was performed using a nonstandard method which is explained in Chapter 4 and the instrumentation and procedure explained in section 6.9 of this chapter.

\subsection{Soil Preparation:}

Loamy sand from the Macdonald Research Station was the soil used in the experiment. To obtain consistent moisture content and compaction a set of three wooden boxes were built having the following inside dimensions: $1.5 \mathrm{~m} \times 0.5 \mathrm{~m} \times 0.15 \mathrm{~m}$. The wooden boxes were filled with soil using the following procedure:

1) The soil was mixed with the desired quantity of water and sieved, covered with a plastic sheet to prevent evaporation and left for 24 hours to equilibrate to a uniform moisture content.

2) The three boxes were placed beside each other (Photo 6.1a), and filled with the mixed and sieved soil.

3) A frame of thin sheet metal was placed around the edges of the boxes leaving about a $100 \mathrm{~mm}$ high fence around the top of the boxes. The reason for this border was to be able to have extra soil which could be compacted (Photo 6.1b).

4) To achieve realistic compaction, the soil was compacted in one layer. A lawn compactor (roller) with a mass of approximately $75 \mathrm{~kg}$ (200 pounds) was used for the compaction (Photo 6.1c). The roller was placed on top of the soil using a ramp, to prevent bending of the metal fence. The roller was passed 50 times on 
each direction (along and across the boxes), then, the steel fence was removed and again the roller was passed 50 times across and 50 times along the boxes.

5) After the compaction was done, the boxes were covered with a plastic sheet leaving any excess soil on top of the bin to prevent evaporation. At the time of the test, the surface of the soil in each box was trimmed using a band saw, to have a volume of soil equivalent to the exact volume of the wooden box.

6) Then, each box was lifted using a fork lift, hung by two flexible bands and placed on the steel frame to run the tillage tests. During each test, the other boxes were kept without trimming and covered with plastic.

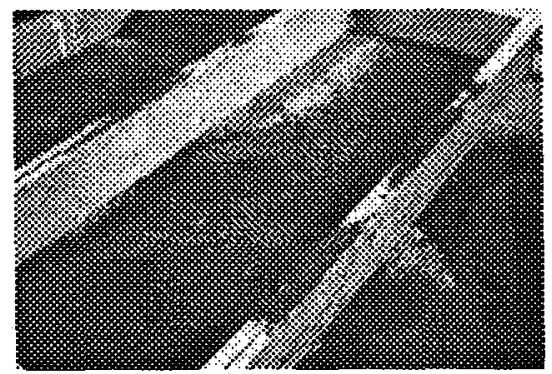

(6.1a)

Photo 6.1a: Set of wooden boxes placed together for soil filling.

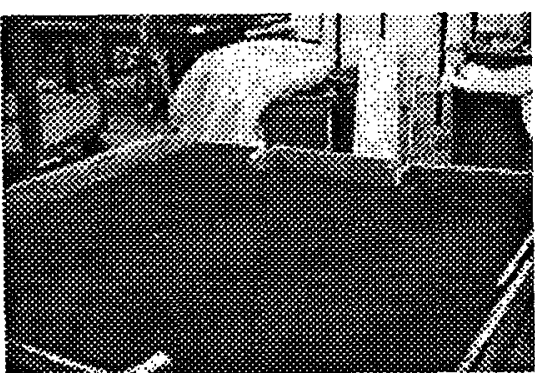

(6.1b)

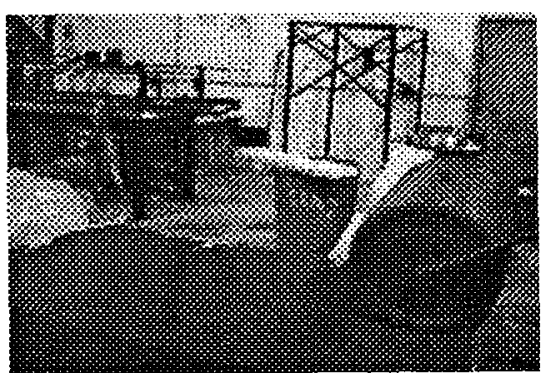

(6.1c)

Photo 6.1b: Filling of soil, the photo shows the steel fence which will be filled up with soil. Photo 6.1c: Compaction of the soil using the lawn roller.

\subsection{Tillage Simulator:}

The tillage simulator consisted of a steel frame in which a bin of prepared soil was 
placed. Exchangeable blades were attached to the tillage simulator, and they were moved horizontally, tilling the soil (Photo 6.2a). The blades were flat steel pieces of different geometries (Photo 6.2b). Six tool geometries were used, all of them acting at $100 \mathrm{~mm}$ depth and having widths of: $50 \mathrm{~mm}$ and $100 \mathrm{~mm}$, and a rake angles to the horizontal of $30^{\circ}, 60^{\circ}$ and $90^{\circ}$.

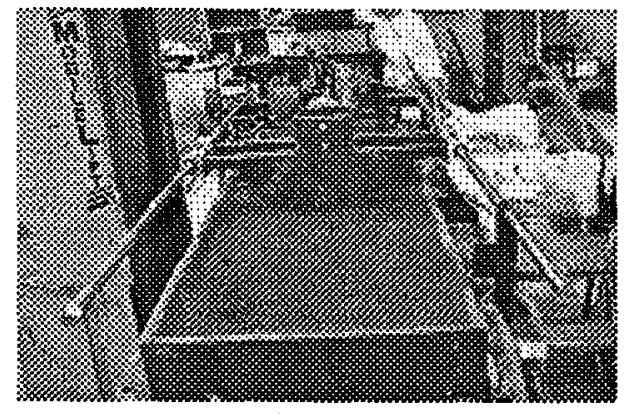

(6.2a)

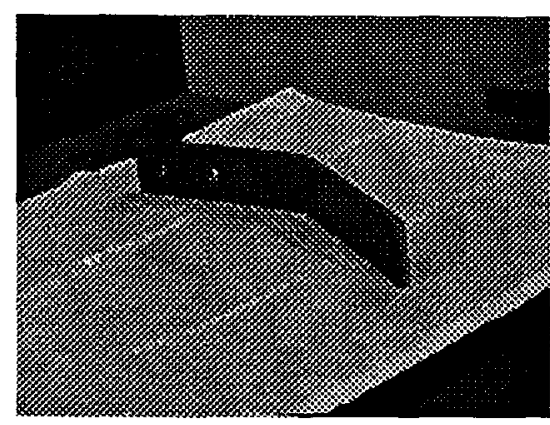

(6.2h)

Photo 6.2a: Tillage simulator. The blade is half way of the length of the soil bin. Photo 6.2b: An example of the tillage blade. The blade laying on its side in the picture, is 50 mm width with a $60^{\circ}$ rake angle.

Each blade was connected to an electronic force transducer from which a graphical representation of the horizontal force (draft) with travel distance was obtained. The blade was moved by an electric motor and rack and pinion device at a constant speed of $50 \mathrm{~mm} / \mathrm{sec}$.

\subsection{Sampling for Initial Bulk Density and Moisture Content:}

Previously to the tilling of the soil, sampling for initial conditions of bulk density and moisture content was done using a custom made apparatus consisting of a set of steel cores and a special core driver (Figure 6.3 a). The steel cores used for this initial sampling were of $30 \mathrm{~mm}$ length and $15 \mathrm{~mm}$ diameter, having thin walls of $1 \mathrm{~mm}$ and sharpened edges to avoid soil disturbance. The core driver was designed to fit inside the steel core and had the same outside diameter. Then the handle could be used to take samples from 
the same soil column at three different soil depths $0-30 \mathrm{~mm}, 30-60 \mathrm{~mm}$ and $60-90 \mathrm{~mm}$.

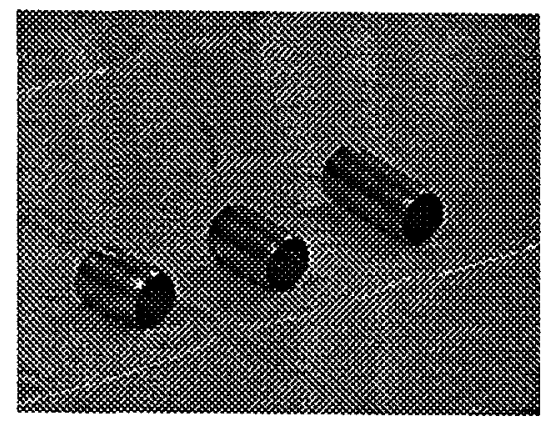

(6.3a)

Photo 6.3a: Set of steel cores, $15 \mathrm{~mm}$ diameter and $30 \mathrm{~mm}, 20 \mathrm{~mm}$ and $15 \mathrm{~mm}$ length.

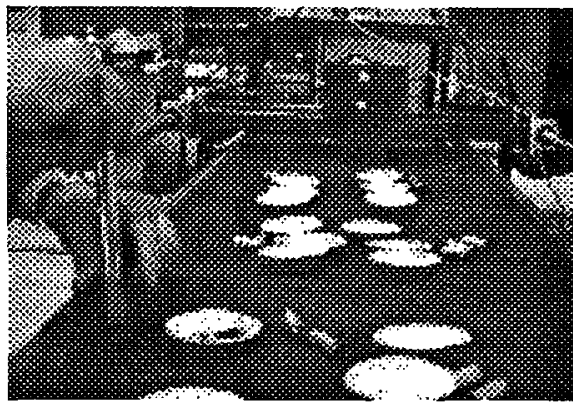

(6.3b)

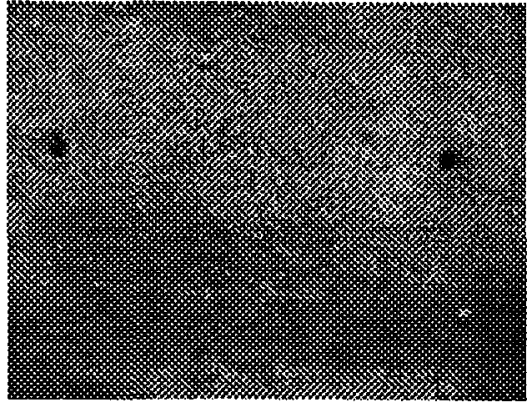

(6.3c)

Photo 6.3b: Taking the soil samples using a especial core driver which can be used at different depths without disturbing the surrounding area. Photo 6.3c: Sample of the holes after the soil has been sampled. Note that there is no visible disturbance around the holes.

\subsection{Measurement of Draft (H):}

The electronic transducer gave a graphical representation of the draft versus travel distance. This force represented the total horizontal force $(\mathrm{H})$ that the tool applied to the soil for failing, inverting and pulverizing it. Previously to the tests, the transducer was calibrated using a set of known weights. Then, using the calibration curve, the draft force was calculated. 


\subsection{Measurement of Tension Lines:}

The stresses within the soil segment are difficult to measure. The tillage operation is fast and the soil is constantly moving. Therefore, for the validation of the tension fracturing lines and their direction, a video record was taken for each test. The tensile lines developed radially from the point of application of the external force, and they were observed by taking pictures of the cracking of the soil. The pictures of the soil fractures were then compared to the results from the mathematical model. Some examples of the pictures are presented in Photo 6.4.
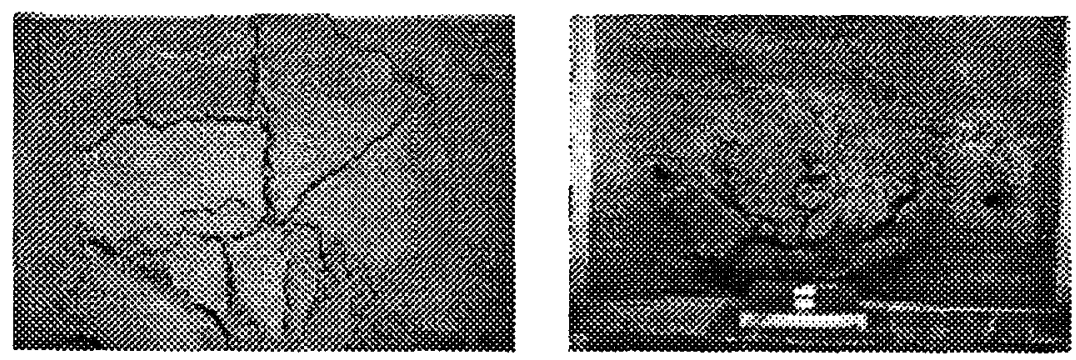

Photo 6.4: A set of pictures from different tillage treatments.

\subsection{Quantity of Loosening:}

Once the blade had been run through the compacted soil, the profile of the disturbed soil was measured. For this purpose, a custom profile meter was designed and built, consisting of a set of rods inserted in a frame. The rod frame was kept in a fixed position and the rods were moved to the surface of the soil. The rods were spaced $20 \mathrm{~mm}$ from each other (Photo 6.5a and Photo6.5b).

The profile meter was used to take readings of the heights of soil disturbed after the tillage operation, and after the soil was removed from the furrow. The quantity of soil loosening was calculated using the profile of the empty furrow. The summation of the measured depths multiplied by the $20 \mathrm{~mm}$ spacing gave the cross section area of the furrow, and thus the volume of soil cut per unit of length could be calculated. 


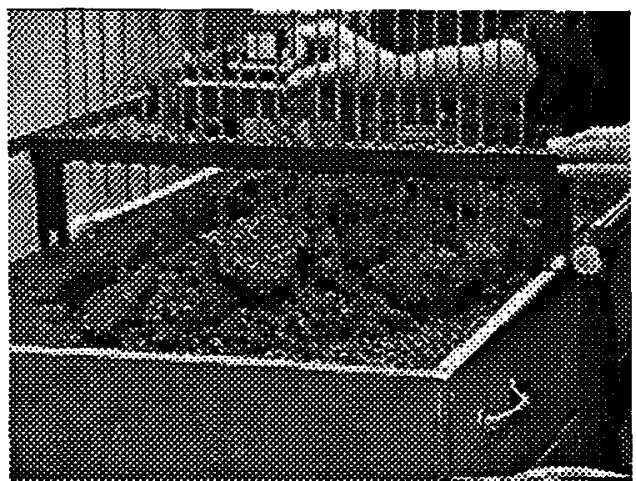

(6.5a)

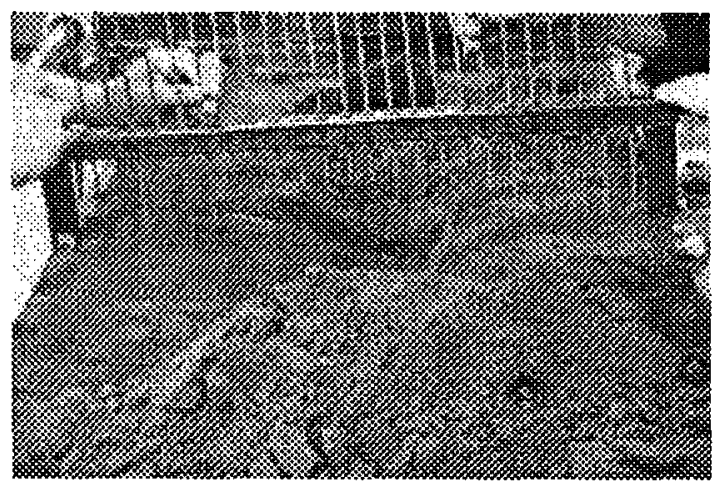

(6.5b)

Photo 6.5a: Measurement of the soil profile after the tillage operation. Photo 6.5b: Profile of empty furrow.

\subsection{Quality of Loosening:}

The size and strength of the aggregates formed by tillage were analyzed using the following procedure:

1) Sieve analysis of aggregates and calculation of mean weight diameter (MWD). The aggregates sampling for MWD was done separately from the surface zone and from the bottom of the furrow. The sieve analysis was gently done after the soil samples were oven dried for 24 hours. The mean weight diameter is defined as (Klute 1986):

$$
M W D=\sum_{i=1}^{n} \bar{x}_{i} w_{i}
$$

where: $x_{i}$ is the mean diameter of each size; and $w_{i}$ is the proportion of the total fraction weight. The entire sample was passed through an $8 \mathrm{~mm}$ sieve prior to analysis.

2) The bulk density of aggregates was measured by using the soil core samplers of 15 or $20 \mathrm{~mm}$ length. Sampling of aggregates was done by pushing the steel cores by hand into the aggregates. The cores were very sharp on the edges to reduce disturbance in the aggregate (Photo 6.3a). 
Useful coefficients in the evaluation of the quality of loosening are:

3) Relative change in soil density: Is given by the density of loose soil (after tillage) divided by the density of the compacted soil (before tillage). This is a dimensionless coefficient $(\mathrm{K})$ equivalent to the load factor used in earth moving operations (Caterpillar Tractor Co. 1975).

4) Swelling factor: is given by (Caterpillar Tractor Co. 1975):

$\%$ swell $=((1 / \mathrm{K})-1) * 100 \%$.

5) The bulk density of aggregates was measured by carefully taking samples from the aggregates using smaller steel cores of 15 or $20 \mathrm{~mm}$ length and $15 \mathrm{~mm}$ diameter and weighing their contents and moisture contents. The steel cores were driven by hand into the aggregates.

\subsection{Measurement of tensile strength:}

The tensile strength of the soil was measured using a custom made apparatus at different moisture contents (Photo 6.6). The apparatus consisted of a set of two metal rings to hold a soil sample of $45 \mathrm{~mm}$ diameter and $62.5 \mathrm{~mm}$ length. To hold the soil sample, the metal braces were wrapped inside with a foam rubber to achieve uniform pressure and avoid cutting from the metal edge of the braces (Photo 6.6).

The top ring was hooked to a pulley system with very small friction losses (between a range from $2 \mathrm{~g}$ to $5 \mathrm{~g}$ or 0.02 to $0.05 \mathrm{~N}$ ). The pulley system was connected to a weight holder where small weights were carefully added until each sample broke. Then, using the total known weight and the diameter of the sample, the tensile strength for each sample was calculated. 


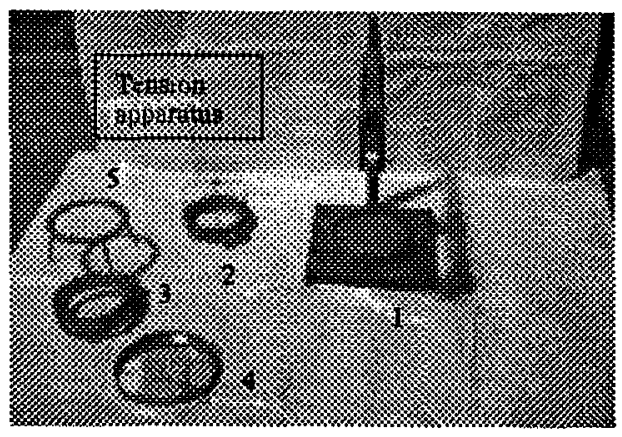

Photo 6.6: Tension apparatus. 1) main frame; 2) Top sample holder; 3) bottom sample holder; 4) weight tray; 5) Tripod for keeping the holders in position.

\subsubsection{Calibration of the apparatus}

The tensile test apparatus was calibrated by using weights without any soil sample, to find the force required for the system to be in equilibrium. It was found that for the system to be in balance it was required a weight of $58 \mathrm{~g}(0.568 \mathrm{~N}$ force) (Photo 6.7).

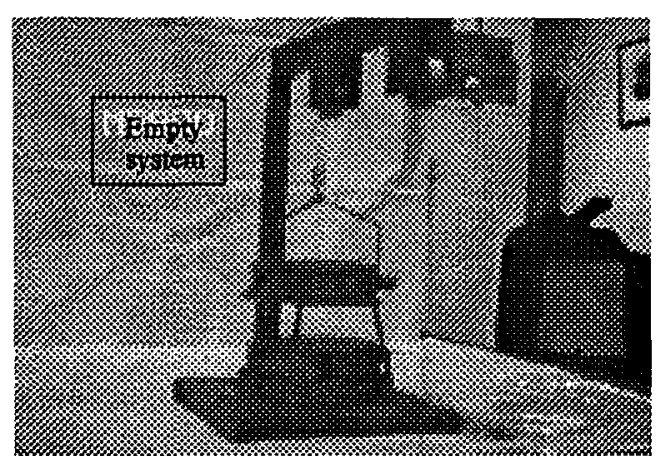

Photo 6.7: Calibration of the tension apparatus.

The friction loss in the pulley system was measured by hanging known weights at the place were the soil sample was going to be pulled, and measuring the weight required to just start movement. The results of friction measurements were between 2 and $5 \mathrm{~g}$ ( 0.02 to $0.05 \mathrm{~N}$ force). For this study they were considered insignificant, since the weights 
required for the soil to break was in the order of few hundreds grams.

\subsubsection{Soil specimen preparation}

The soil samples were prepared using a steel core of $50 \mathrm{~mm}$ diameter and 62.5 $\mathrm{mm}$ height. The soil was placed in the steel core and compacted with a steel weight of 10 $\mathrm{kg}$, placed on top of the soil and left for 40 seconds. Then more soil was placed on top to refill the core, and the weight was placed again for 40 seconds, and a third layer of soil was placed and the process repeated. With the three layers of soil the steel core was full. Then the soil core was trimmed to have the exact volume of the inside steel core.

The trimmed steel core full of soil was carefully placed on a stand to be able to take the soil out of the steel core with minimum disturbance. A lighter weight of $0.5 \mathrm{~kg}$ was placed on top of the soil and the soil was taken out of the core. A spatula was placed under the soil core to receive the soil without letting it drop. With the same spatula, the soil core was placed on the tensile strength apparatus (Photo 6.8).

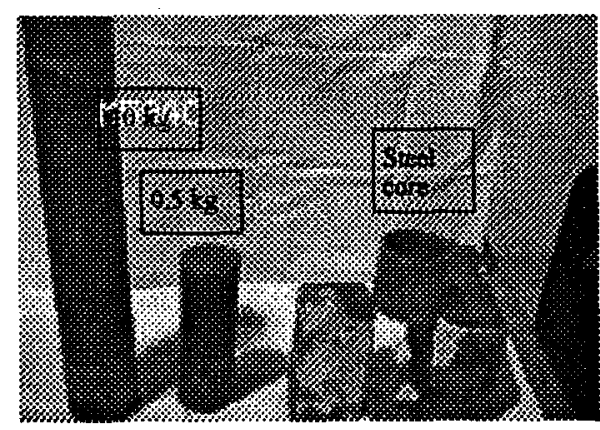

Photo 6.8: Steel core for soil specimen preparation and steel weights for compaction.

A second sample of soil using the same procedure and the same moisture content was prepared for each sample that was placed in the tensile strength apparatus. The second sample was used to measure moisture content and bulk density.

Five samples were broken for each moisture content, and four moisture contents were tested. In total 20 tensile strength tests were performed on the test soil. 


\subsubsection{Soil breaking}

Once the soil was placed in the proper position in the tensile strength apparatus, it was grabbed by the two ends using metal braces wrapped with foam rubber (Photo 6.6). Special care was taken at the time of closing the braces. Stands were used to hold the braces during the placement to prevent them from twisting and applying any torsion to the sample.

After the soil was properly held, weights were added carefully to the weight holders until the soil broke. The broken sample was inspected to make sure that the fracture plane was not at the edge of the metal brace (Photo 6.9).

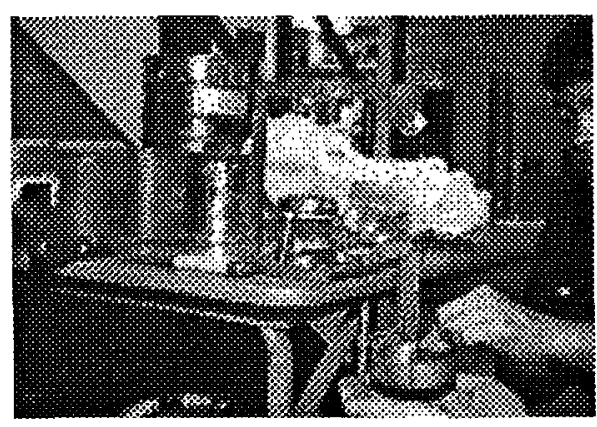

Photo 6.9: Tensile strength test. 


\section{RESULTS FROM THE EXPERIMENTAL STUDY}

\subsection{Laboratory Results:}

The results from the laboratory experiments can be divided into soil physical and mechanical properties, and parameters measured using tillage simulation:

1) Soil physical and mechanical properties include moisture content, soil density, cohesion, and friction angle for five different soil samples. In addition to those parameters the tensile strength of soil in four conditions was measured. The best linear fit of the calculated values of cohesion, friction angle and tensile strength are shown in Figure 7.1.

2) Measurements done using the tillage simulator were photographic records, furrow profile and draft force for each tool geometry and different soil conditions of moisture content and bulk density, which totalled 18 tests. The results are shown in Table 7.1. Examples of the photographic records are presented in the photo data section 7.1.4, and a complete set of pictures of the soil fracturing for each test performed is presented in Appendix B. The measurements of the total draft force (H) are presented in Table 7.5. The same Table 7.5 shows the results of profile measurements of the disturbed cross section and information collected about the aggregate size distribution and some physical properties.

\subsubsection{Soil Physical parameters.}

The soil physical properties of moisture content and bulk density presented in this section correspond to the conditions at which each test was performed. Additional physical properties were measured after the tillage operation was performed. Those values are presented in Section 7.1.1.2. 


\subsubsection{Initial moisture content, bulk density and tensile strength.}

The values of soil physical properties presented in Table 7.1 were measured after the soil was compacted and placed in the soil box for the tillage test to be performed. Thus the values represent the initial conditions of each test performed.

Table 7.1: Mean values of soil density and moisture content.

\begin{tabular}{|r|r|r|r|}
\hline $\begin{array}{r}\text { Rake angle, } \\
\alpha,\left(^{\circ}\right)\end{array}$ & $\begin{array}{c}\text { Tool width, } \\
\text { w, } \\
(\mathrm{mm})\end{array}$ & $\begin{array}{c}\text { Moisture content, } \\
\text { MC* }(\mathrm{SD}) \\
(\%)\end{array}$ & $\begin{array}{c}\text { Soil bulk density, } \\
\mathrm{BD},(\mathrm{SD}) \\
\left(\mathrm{Mg} / \mathrm{m}^{3}\right)\end{array}$ \\
\hline 30 & 50 & $13.34(1.09)$ & $0.94(0.07)$ \\
\hline 30 & 50 & $14.6(0.42)$ & $0.86(0.05)$ \\
\hline 30 & 50 & $16.06(0.83)$ & $0.84(0.08)$ \\
\hline 30 & 100 & $13.17(0.79)$ & $0.89(0.07)$ \\
\hline 30 & 100 & $15.27(0.87)$ & $0.84(0.05)$ \\
\hline 30 & 100 & $16.45(0.37)$ & $0.85(0.08)$ \\
\hline 60 & 50 & $13.52(0.79)$ & $1.04(0.07)$ \\
\hline 60 & 50 & $15.07(1.26)$ & $0.87(0.06)$ \\
\hline 60 & 50 & $16.00(1.04)$ & $0.85(0.10)$ \\
\hline 60 & 100 & $13.29(0.53)$ & $0.94(0.04)$ \\
\hline 60 & 100 & $14.37(1.04)$ & $0.91(0.12)$ \\
\hline 60 & 100 & $15.67(0.29)$ & $0.86(0.09)$ \\
\hline 90 & 50 & $12.89(0.79)$ & $0.94(0.07)$ \\
\hline 90 & 50 & $15.05(0.43)$ & $0.80(0.05)$ \\
\hline 90 & 50 & $15.76(0.41)$ & $0.87(0.08)$ \\
\hline 90 & 100 & $13.51(0.73)$ & $0.92(0.05)$ \\
\hline 90 & 100 & $14.47(0.86)$ & $0.92(0.08)$ \\
\hline 90 & 100 & $15.88(0.70)$ & $0.84(0.07)$ \\
\hline
\end{tabular}

$*=\mathrm{MC}$ values are $\%$ by mass on a dry basis.

$\mathrm{SD}=$ Standard Deviation (18 measurements each). 


\subsubsection{Soil mechanical properties}

The cohesion and friction angle were measured using a standard laboratory shear box, and the results are presented in Table 7.2. The tensile strength was measured using non-standard laboratory equipment (Chapter 6, Section 6.9), and the results are shown in Table 7.3.

Table 7.2: Cohesion, and Friction angle at different soil moisture.

\begin{tabular}{|r|r|r|r|}
\hline $\begin{array}{c}\text { Sample } \\
\text { No. }\end{array}$ & $\begin{array}{c}\text { MC*, (SD) } \\
(\%)\end{array}$ & $\begin{array}{c}\text { Cohesion, c, (SD) } \\
(\mathrm{kPa})\end{array}$ & $\begin{array}{c}\text { Friction angle, } \phi, \\
\left({ }^{\circ}\right)\end{array}$ \\
\hline 1 & $4.16(0.01)$ & $10.69(0.11)$ & 19.03 \\
\hline 2 & $8.66(0.10)$ & $8.32(0.11)$ & 13.50 \\
\hline 3 & $17.72(0.35)$ & $2.97(0.01)$ & 11.30 \\
\hline 4 & $18.04(0.48)$ & $2.38(0.01)$ & 11.30 \\
\hline 5 & $20.10(0.35)$ & $1.78(0.006)$ & 9.65 \\
\hline
\end{tabular}

The values of cohesion, and friction angle presented in Table 7.2 were plotted and the best linear fits are shown in Figure 7.1. The fitting of the values was done to facilitate the evaluation of the mathematical model. The same was done with the results obtained from the tensile strength tests, which are presented in Table 7.3. The values of tensile strength depends on both moisture content and soil density. Then, a multiple regression was performed and the best linear fit is also shown in Figure 7.1. 
Table 7.3: Measured values \pm 0.001 , of Soil Tensile Strength, $\mathrm{T}$, in $\mathrm{kPa}$ at different soil moisture contents and soil densities.

\begin{tabular}{|c|c|c|c|}
\hline $\begin{array}{c}\text { Sample } \\
\text { No }\end{array}$ & $\begin{array}{l}\mathrm{MC}^{*} \\
(\%)\end{array}$ & $\begin{array}{c}\mathrm{BD} \\
\left(\mathrm{Mg} / \mathrm{m}^{3}\right)\end{array}$ & $\begin{array}{c}\text { Tensile Strength }(\mathrm{T}) \\
\text { in }(\mathrm{kPa})\end{array}$ \\
\hline 1 & 20.463 & 1.716 & 3.539 \\
\hline 2 & 20.467 & 1.729 & 3.440 \\
\hline 3 & 20.376 & 1.727 & 3.441 \\
\hline 4 & 20.077 & 1.679 & 3.552 \\
\hline 5 & 20.087 & 1.704 & 3.543 \\
\hline 6 & 19.054 & 1.670 & 3.742 \\
\hline 7 & 18.794 & 1.633 & 4.061 \\
\hline 8 & 18.962 & 1.655 & 2.629 \\
\hline 9 & 18.843 & 1.656 & 2.775 \\
\hline 10 & 18.803 & 1.649 & 2.825 \\
\hline 11 & 18.728 & 1.640 & 2.320 \\
\hline 12 & 18.576 & 1.653 & 2.531 \\
\hline 13 & 18.300 & 1.605 & 2.478 \\
\hline 14 & 18.782 & 1.643 & 2.593 \\
\hline 15 & 16.103 & 1.513 & 1.476 \\
\hline 16 & 16.604 & 1.505 & 1.809 \\
\hline 17 & 16.531 & 1.475 & 1.958 \\
\hline 18 & 16.131 & 1.563 & 2.250 \\
\hline 19 & 16.244 & 1.513 & 1.674 \\
\hline 20 & 16.322 & 1.514 & 1.923 \\
\hline
\end{tabular}

$*=\mathrm{MC}$ values are $\%$ by mass on a dry basis. 


\section{Linear fitting of average values \\ soil mechanical properties}

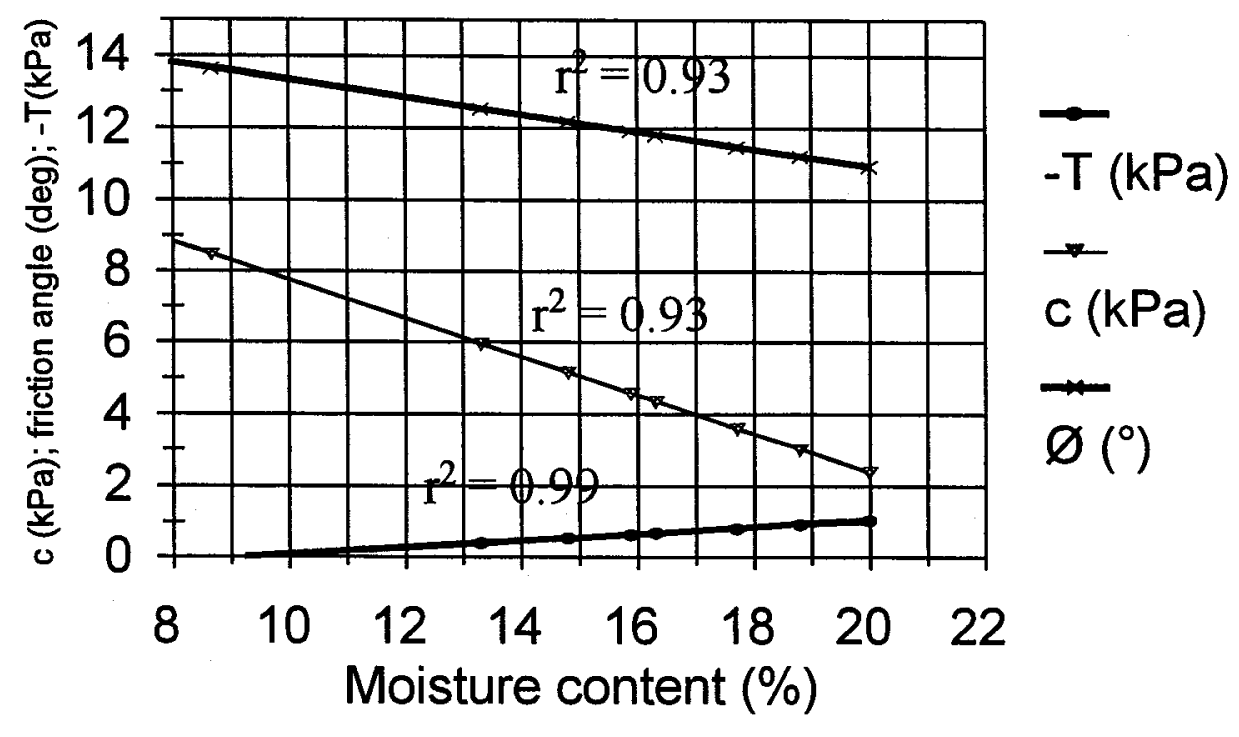

Figure 7.1: Best fit values of cohesion, friction angle and tensile strength for different values of moisture content near the range of the tillage simulations.

Form the Figure 7.1 the values of cohesion, friction angle and tensile strength were taken at the average moisture content corresponding to that of each experimental soil tillage simulation. The values are presented in Table 7.4.

Table 7.4: Best fit values used for the mathematical model validation.

\begin{tabular}{|l|l|l|l|l|}
\hline \multicolumn{1}{|c|}{ MC (\%) } & \multicolumn{1}{|c|}{$\gamma\left(\mathrm{Mg} / \mathrm{m}^{3}\right)$} & \multicolumn{1}{|c|}{$c(\mathrm{kPa})$} & \multicolumn{1}{|c|}{$\phi\left(^{\circ}\right)$} & \multicolumn{1}{c|}{$\mathrm{T}(\mathrm{kPa})$} \\
\hline 13.32 & 0.947 & 5.87 & 12.53 & -0.38 \\
\hline 14.82 & 0.883 & 4.90 & 12.15 & -0.45 \\
\hline 15.90 & 0.858 & 4.35 & 11.92 & -0.48 \\
\hline
\end{tabular}


The values presented in Table 7.4 are the values that were used for the evaluation of the mathematical model. Thus those values of soil physical parameters are the ones used in the identification of each soil tillage test.

\subsubsection{Tillage test identification}

To simplify the presentation of the results, the nomenclature presented in Table 7.5 will be followed. The identification of each test will be expressed as the following example: $301-100$, where the first two digits represent the rake angle $\left(30^{\circ}\right)$, the following digit represents the moisture content $(1=13.32 \%, 2=14.82 \%, 3=15.90 \%)$ and the number after the dash represent the tool width $(100 \mathrm{~mm})$. 
Table 7.5: Identification of the performed tests. This nomenclature will be used to identify the measurements done using the tillage simulator and the predictions from the mathematical model.

\begin{tabular}{|c|c|c|c|}
\hline$\alpha\left({ }^{\circ}\right)$ & MC (\%) & $\mathrm{w}(\mathrm{mm})$ & Test ID \\
\hline 30 & $13.32(1)$ & 50 & $301-50$ \\
\hline 30 & $14.82(2)$ & 50 & $302-50$ \\
\hline 30 & $15.90(3)$ & 50 & $303-50$ \\
\hline 30 & $13.32(1)$ & 100 & $301-100$ \\
\hline 30 & $14.82(2)$ & 100 & $302-100$ \\
\hline 30 & $15.90(3)$ & 100 & $303-100$ \\
\hline 60 & $13.32(1)$ & 50 & $601-50$ \\
\hline 60 & $14.82(2)$ & 50 & $602-50$ \\
\hline 60 & $15.90(3)$ & 50 & $603-50$ \\
\hline 60 & $13.32(1)$ & 100 & $601-100$ \\
\hline 60 & $14.82(2)$ & 100 & $602-100$ \\
\hline 60 & $15.90(3)$ & 100 & $603-100$ \\
\hline 90 & $13.32(1)$ & 50 & $901-50$ \\
\hline 90 & $14.82(2)$ & 50 & $902-50$ \\
\hline 90 & $15.90(3)$ & 50 & $903-50$ \\
\hline 90 & $13.32(1)$ & 100 & $901-100$ \\
\hline 90 & $14.82(2)$ & 100 & $902-100$ \\
\hline 90 & $15.90(3)$ & 100 & $903-100$ \\
\hline
\end{tabular}




\subsubsection{Tillage simulator:}

The total draft force measured for each tillage simulation is presented in Table

7.6. The surface widths of the cross sections and depths of the empty furrows of soil disturbed for different tool geometries are also presented in Table 7.6. From the photographs, the maximum horizontal angle of soil breaking up, measured from the centre of the blade, $\left(\theta_{\max }\right)$, and calculations of aggregate bulk density and some coefficients are also presented in Table 7.6. A sample of the surface fractures is presented in Photos 7.1a and 7.1b.

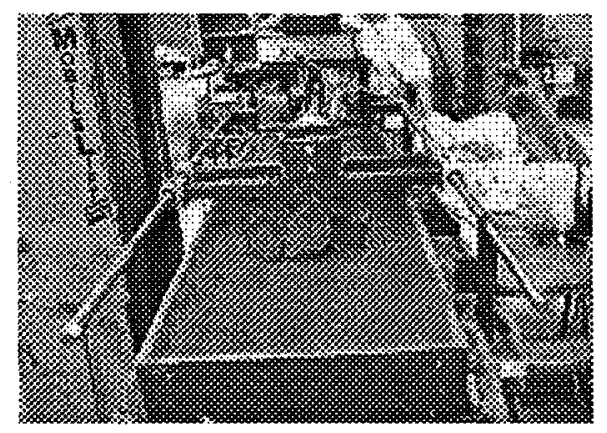

(7.1a)

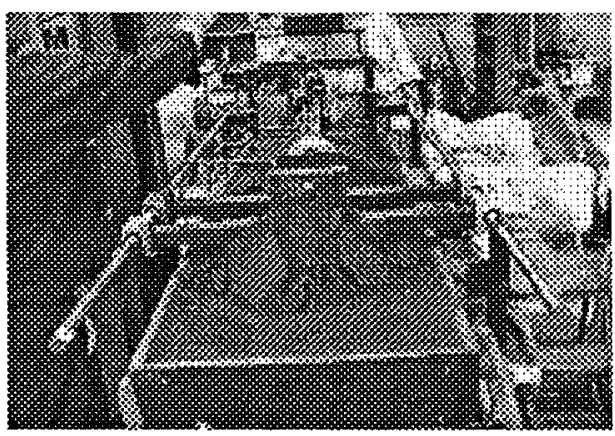

(7.1b)

Photos 7.1a and 7.1b show that the aggregation produced at the surface of the soil volume keeps its pattern along the way of the tillage tool. 
Table 7.6: Measured Draft Force in N, maximum angle of soil fractures $\left(\theta_{\max }{ }^{\circ}\right)$, width $(\mathrm{mm})$ and depth $(\mathrm{mm})$ of the empty furrow, seed bed properties: aggregate density $\left(\mathrm{Mg} / \mathrm{m}^{3}\right)$ and mean weight diameter of aggregates (MWD).

\begin{tabular}{|c|c|c|c|c|c|c|c|}
\hline \multirow[t]{2}{*}{ Test ID } & \multirow{2}{*}{$\begin{array}{l}\text { Draft } \\
\text { Force } \\
(\mathrm{N})\end{array}$} & \multirow{2}{*}{$\begin{array}{l}\text { Theta } \\
\text { Max. } \\
\left(\theta_{\max }^{\circ}\right)\end{array}$} & \multicolumn{2}{|c|}{ Empty furrow } & \multirow{2}{*}{$\begin{array}{c}\text { Aggregate } \\
\text { density } \\
\left(\mathrm{Mg} / \mathrm{m}^{3}\right)\end{array}$} & \multicolumn{2}{|c|}{ MWD } \\
\hline & & & $\begin{array}{l}\text { Width } \\
(\mathrm{mm})\end{array}$ & $\begin{array}{l}\text { Depth } \\
(\mathrm{mm})\end{array}$ & & $\begin{array}{l}\text { Top } \\
(\mathrm{mm})\end{array}$ & $\begin{array}{l}\text { Bottom } \\
(\mathrm{mm})\end{array}$ \\
\hline $301-50$ & 47.04 & 80 & 300 & 190 & 1.05 & 2.22 & 1.72 \\
\hline $302-50$ & 45.12 & 45 & 320 & 185 & 0.89 & 1.78 & 1.52 \\
\hline $303-50$ & 47.24 & 32 & 220 & 200 & 1.21 & 7.46 & 2.44 \\
\hline $301-100$ & 86.24 & 55 & 300 & 170 & 1.00 & 1.72 & 1.42 \\
\hline $302-100$ & 84.35 & 40 & 260 & 190 & 1.09 & 6.46 & 3.25 \\
\hline $303-100$ & 78.40 & 32 & 300 & 165 & 1.05 & 4.83 & 1.44 \\
\hline $601-50$ & 117.60 & 50 & 290 & 170 & 1.00 & 2.54 & 1.86 \\
\hline $602-50$ & 125.00 & 45 & 240 & 181 & 0.93 & 2.32 & 1.34 \\
\hline $603-50$ & 133.28 & 45 & 260 & 182 & 1.00 & 7.99 & 2.96 \\
\hline 601-100 & 143.16 & 60 & 260 & 169 & 1.00 & 1.65 & 1.62 \\
\hline $602-100$ & 122.10 & 48 & 290 & 183 & 1.18 & 7.22 & 6.97 \\
\hline $603-100$ & 113.84 & 40 & 320 & 172 & 0.90 & 7.25 & 1.99 \\
\hline $901-50$ & 148.96 & 52 & 220 & 169 & 1.00 & 2.55 & 1.86 \\
\hline $902-50$ & 200.00 & 48 & 240 & 175 & 0.90 & 1.39 & 1.52 \\
\hline $903-50$ & 227.00 & 40 & 240 & 189 & 0.85 & 7.88 & 1.82 \\
\hline $901-100$ & 217.52 & 45 & 280 & 181 & 0.99 & 1.62 & 1.43 \\
\hline $902-100$ & 209.48 & 50 & 280 & 181 & 1.16 & 7.97 & 4.8 \\
\hline $903-100$ & 262.40 & 43 & 260 & 181 & 0.92 & 4.58 & 2.06 \\
\hline
\end{tabular}




\subsubsection{Photographic data of soil fracturing}

For each tillage test a set of photographs was taken. An example of the test 301100 is presented in Photos 7.2a and 7.2b. The rest of the pictures are presented in Appendix B. Photos 7.2a and 7.2b show different stages of the soil fracturing.

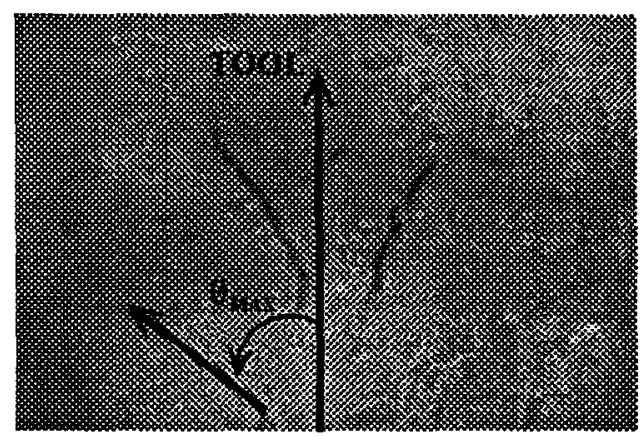

Photo 7.2a: Initial fracturing of the soil.

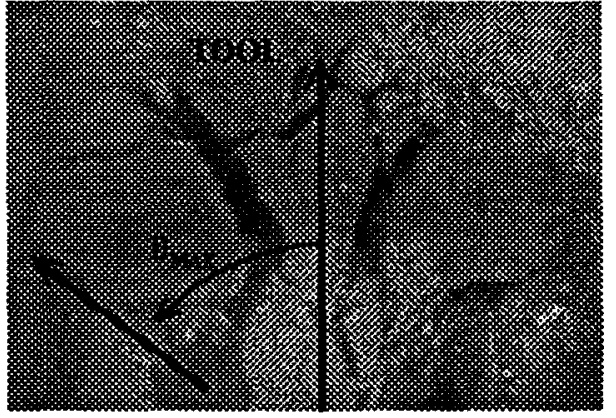

Photo 7.2b: A more advance stage of the fracturing. Notice that the pattern of tensile fracturing is the same.

The maximum angle from the centre of the cross section, $\theta_{\max }$, delimits the area where tensile fracturing occurs. This angle increases with tool depth, but it is constant along the length of the furrow as can be seen in Photo 7.3.

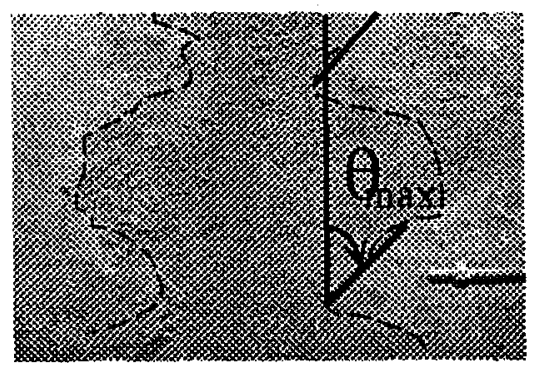

Photo 7.3 shows the empty furrow. It can be noticed that the angle of tension fracturing is constant at the surface after the initial cut. The profile seems more rounded with depth. 


\subsection{Theoretical Predictions:}

The theoretical results are the different parameters that can be calculated using the mathematical model presented in Chapter 3 . The model gives equations to calculate stresses within the soil segment. It gives equations for the normal and shear stresses, which can be used to calculate the principle stresses to evaluate the Mohr-Coulomb failure criteria and tensile fracture, the results are presented in section 7.2.1.

Section 7.2.2 presents the results of draft force and maximum radial distance from the edge of the blade predicted by McKyes and Ali's model (1977).

\subsubsection{Tension fracturing and shear failure:}

Graphical representation of one set of results from equation (3.30b) are shown in Figure 7.2a. The pattern of stress distribution within the cross section in Figure 7.2a is similar for each soil test, (see Appendix C). Figure 7.2b shows the shear stress distribution which represents the values calculated with equation (3.30c).
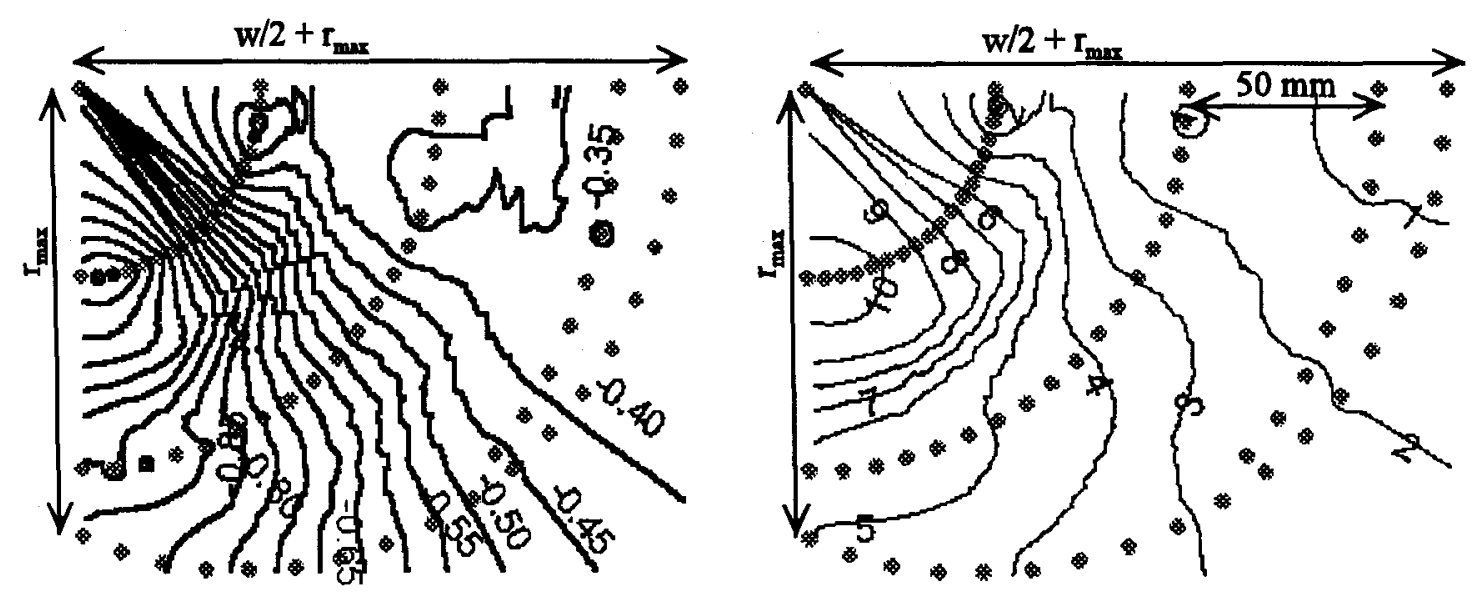

Figure 7.2a: contour lines of $\left(\sigma_{3}\right)$ in $\mathrm{kPa}$.

Figure 7.2b: Example of shear stress distribution in $\mathrm{kPa}$.

Figures 7.2a and 7.2b show the tensile and shear stress distributions calculated with equations (3.30b) and (3.30c). The examples relate to the test 902-100. 
The example in Figure 7.2a shows that the minor principle stress $\left(\sigma_{3}\right)$, reaches the value of the tensile strength $(\mathrm{T}=-0.45 \mathrm{kPa})$ at approximately $\theta=47^{\circ}$ from the centre line. This is the maximum angle from the centre of the blade at which the soil volume can experience a tensile fracture along a radial line. This is called the tension fracturing zone and it is represented in Figure 7.3.

Comparing the values of shear stress represented in Figure 7.2b with the calculations of equation (5.4), $\left(\tau_{\mathrm{f}-\min }\right)$ or equation (3.31), $(\tau=c+\sigma \tan \phi)$, the points of shear failure can be determined. But it is not easy to visualize where the shear failure occurs because shear strength is not a constant value like the tensile strength. However within the tension fracturing zone, the minimum value that the shear stress at failure can reach is the value given by equation (5.4) and which results are the followings:

$$
\begin{aligned}
& \text { for } \quad T=-0.38 \mathrm{kPa} \quad \tau_{f-\min }=7.06 \mathrm{kPa} \\
& \mathrm{T}=-0.45 \mathrm{kPa} \quad \tau_{\mathrm{f}-\min }=5.80 \mathrm{kPa} \\
& \mathrm{T}=-0.48 \mathrm{kPa} \quad \tau_{\mathrm{f}-\mathrm{min}}=5.13 \mathrm{kPa}
\end{aligned}
$$

Then, within the tension failure zone an approximation of the zone of shear failure can be found, and it is shown as a circular portion in Figure 7.3.

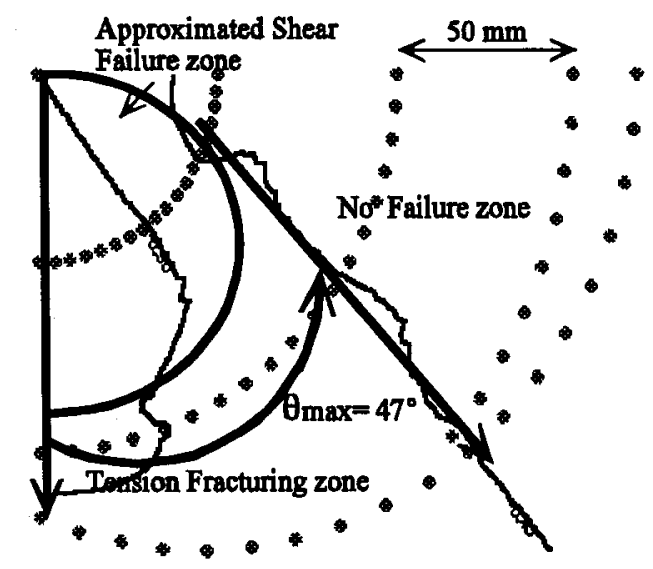

Figure 7.3: Failure zones 
Figure 7.3 shows three distinct sections within the cross section: one small circular portion around the point of application of the force in which the soil fails in shear, a central conical section where the soil fails in tension due to negative $\sigma_{\theta}$ and a third portion outside the conical section in which there is no failure.

The circular portion around the point where the force is applied, which is the section of shear failure, was found by comparing the results from equation (3.30c) with the equations (5.4). The results of shear stresses were found using the computer simulation. Their comparison to shear strength was done for each point evaluated in each test. The results are presented in the Table 7.7 where NSF stands for no shear failure, and SF-r- $(0-\theta)$ stands for shear failure at a radial distance of $r=x x \mathrm{~cm}$ and from an angle 0 to an angle $\theta$ from the centre line. Table 7.7 also shows the maximum angle at which tensile failure can theoretically occur, $\left(\theta_{\max }\right)$. The values of $\left(\theta_{\max }\right)$ were taken from the contour lines like the ones shown in Figure 7.2a and the ones presented in Appendix C. 
Table 7.7: Maximum angle $\theta_{\max }$ which defines the tensile fracturing zone, theoretical width of the disturbed cross section $(\mathrm{mm})$, and the circular portions of shear failure.

\begin{tabular}{|c|c|c|c|c|c|c|}
\hline Test ID & $\begin{array}{l}\theta_{\max }\left({ }^{\circ}\right) \\
\text { surface }\end{array}$ & $\begin{array}{l}\text { Surface } \\
\text { width } \\
(\mathrm{mm})\end{array}$ & $\begin{array}{c}\theta_{\max } \\
\left(^{\circ}\right) \\
\text { at } \mathrm{d} / 2\end{array}$ & $\begin{array}{l}\text { Width } \\
(\mathrm{mm}) \\
\text { at } \mathrm{d} / 2\end{array}$ & $\begin{array}{c}\text { Shear Failure } \\
\text { surface }\end{array}$ & $\begin{array}{c}\text { Shear Failure } \\
\text { at } d / 2\end{array}$ \\
\hline $301-50$ & 72 & 583 & 90 & 170 & NSF & $\mathrm{SF}-5 \mathrm{~cm}-\left(0-75^{\circ}\right)$ \\
\hline $302-50$ & 50 & 462 & 90 & 170 & NSF & $\mathrm{SF}-5 \mathrm{~cm}-\left(0-75^{\circ}\right)$ \\
\hline $303-50$ & 40 & 383 & 90 & 170 & NSF & SF-10cm- $\left(0-80^{\circ}\right)$ \\
\hline $301-100$ & 65 & 595 & 85 & 200 & NSF & SF-5cm- $\left(0-90^{\circ}\right)$ \\
\hline $302-100$ & 35 & 357 & 85 & 200 & NSF & SF- $10 \mathrm{~cm}-\left(0-80^{\circ}\right)$ \\
\hline $303-100$ & 25 & 256 & 85 & 200 & NSF & $\mathrm{SF}-10 \mathrm{~cm}-\left(0-80^{\circ}\right)$ \\
\hline $601-50$ & 63 & 348 & 80 & 110 & NSF & SF-5cm- $\left(0-85^{\circ}\right)$ \\
\hline $602-50$ & 57 & 325 & 80 & 110 & NSF & SF- $5 \mathrm{~cm}-\left(0-85^{\circ}\right)$ \\
\hline $603-50$ & 57 & 324 & 80 & 110 & NSF & SF-5cm- $\left(0-85^{\circ}\right)$ \\
\hline $601-100$ & 55 & 351 & 85 & 140 & $\mathrm{SF}-5 \mathrm{~cm}-\left(0-20^{\circ}\right)$ & SF-5cm- $\left(0-85^{\circ}\right)$ \\
\hline $602-100$ & 45 & 294 & 85 & 140 & SF- $5 \mathrm{~cm}-\left(0-20^{\circ}\right)$ & SF- $5 \mathrm{~cm}-\left(0-90^{\circ}\right)$ \\
\hline $603-100$ & 45 & 323 & 85 & 140 & SF-5cm- $\left(0-20^{\circ}\right)$ & SF-5cm- $\left(0-85^{\circ}\right)$ \\
\hline $901-50$ & 67 & 260 & 75 & 80 & SF-5cm- $\left(0-55^{\circ}\right)$ & SF-5cm- $\left(0-90^{\circ}\right)$ \\
\hline $902-50$ & 58 & 235 & 75 & 80 & SF- $5 \mathrm{~cm}-\left(0-55^{\circ}\right)$ & SF-5cm- $\left(0-90^{\circ}\right)$ \\
\hline $903-50$ & 55 & 225 & 75 & 80 & SF-5cm- $\left(0-55^{\circ}\right)$ & SF- $5 \mathrm{~cm}-\left(0-90^{\circ}\right)$ \\
\hline $901-100$ & 58 & 273 & 85 & 110 & SF-5cm- $\left(0-60^{\circ}\right)$ & SF $-5 \mathrm{~cm}-\left(0-90^{\circ}\right)$ \\
\hline $902-100$ & 47 & 226 & 85 & 110 & SF-5cm- $\left(0-60^{\circ}\right)$ & SF-5cm- $\left(0-90^{\circ}\right)$ \\
\hline $903-100$ & 40 & 192 & 85 & 110 & SF- $5 \mathrm{~cm}-\left(0-60^{\circ}\right)$ & SF-5cm- $\left(0-90^{\circ}\right)$ \\
\hline
\end{tabular}




\subsubsection{Calculation of horizontal forces $\left(\mathrm{H}_{t}\right)$ and maximum radius at the surface soil slice $\left(\mathbf{r}_{\max }\right)$ :}

For purposes of validation of the model, the soil properties used were the best fit values of the laboratory tests, Table 7.4. The values of horizontal force, $(\mathrm{H})$ and maximum radius, $\left(r_{\max }\right)$, used for the model validation are presented in Table 7.8. The force $\mathrm{H}$, and radius $\left(\mathrm{r}_{\max }\right)$, were calculated using McKyes and Ali's model (1977). The forces shown in Table 7.8 are those applied to the surface slice $(z=5 \mathrm{~mm})$, middle soil slice $(z=50 \mathrm{~mm})$ and bottom of the blade $(z=100 \mathrm{~mm})$. The maximum radius presented in Table 7.8 correspond to the surface slice $(z=5 \mathrm{~mm})$ and the middle soil slice $(z=50$ $\mathrm{mm})$. 
Table 7.8: Predicted radius of the circular portion of the soil segment at the depth of 5 $\mathrm{mm}$ (surface soil slice) and at depth of $50 \mathrm{~mm}$ correspondent to the middle soil slice. Horizontal force applied by the tool at the surface soil slice $(\mathrm{z}=5 \mathrm{~mm})$, middle soil slice $(z=50 \mathrm{~mm})$ and bottom of the soil segment $(z=d=100 \mathrm{~mm})$ which correspond to the bottom of the blade.

\begin{tabular}{|c|c|c|c|c|c|}
\hline \multirow[t]{2}{*}{ Test ID } & \multirow{2}{*}{$\begin{array}{l}\mathrm{r}_{\max }(\mathrm{mm}) \\
\text { surface } \\
\mathrm{z}=5 \mathrm{~mm}\end{array}$} & \multirow{2}{*}{$\begin{array}{c}\mathrm{r}_{\max }(\mathrm{mm}) \\
\mathrm{d} / 2 \\
\mathrm{z}=50 \mathrm{~mm}\end{array}$} & \multicolumn{3}{|c|}{$\begin{array}{c}\text { Force }(\mathrm{N}) \\
\mathrm{H}_{\mathrm{z}}\end{array}$} \\
\hline & & & $\mathrm{z}=0-5 \mathrm{~mm}$ & $\begin{array}{c}\mathrm{z}=0-50 \\
\mathrm{~mm}\end{array}$ & $\begin{array}{c}\mathrm{z}=0-100 \\
\mathrm{~mm} \\
\mathrm{H} \text { (total) }\end{array}$ \\
\hline $301-50$ & 283 & 148.90 & 1.51 & 15.07 & 31.94 \\
\hline $302-50$ & 282 & 148.50 & 1.72 & 17.17 & 36.20 \\
\hline $303-50$ & 281 & 148.30 & 2.07 & 20.74 & 43.51 \\
\hline $301-100$ & 283 & 148.90 & 2.53 & 25.27 & 53.68 \\
\hline $302-100$ & 282 & 148.50 & 2.87 & 28.69 & 60.62 \\
\hline $303-100$ & 281 & 148.30 & 3.47 & 34.68 & 72.91 \\
\hline $601-50$ & 173 & 91.21 & 5.68 & 56.80 & 116.40 \\
\hline $602-50$ & 172.5 & 90.80 & 6.42 & 64.25 & 131.47 \\
\hline $603-50$ & 172 & 90.52 & 7.80 & 78.01 & 159.26 \\
\hline $601-100$ & 173 & 91.21 & 7.29 & 72.91 & 150.16 \\
\hline $602-100$ & 172.5 & 90.80 & 8.26 & 82.63 & 169.78 \\
\hline $603-100$ & 172 & 90.52 & 10.00 & 99.92 & 204.72 \\
\hline $901-50$ & 118.5 & 62.30 & 10.67 & 106.67 & 217.14 \\
\hline $902-50$ & 117.6 & 61.90 & 12.13 & 121.29 & 246.58 \\
\hline $903-50$ & 117.1 & 61.60 & 14.76 & 147.62 & 299.60 \\
\hline $901-100$ & 118.5 & 62.30 & 14.11 & 141.13 & 287.77 \\
\hline $902-100$ & 117.6 & 61.90 & 16.13 & 161.29 & 328.34 \\
\hline $903-100$ & 117.1 & 61.60 & 19.51 & 195.06 & 396.39 \\
\hline
\end{tabular}




\section{ANALYSIS AND CONCLUSIONS}

\subsection{Introduction:}

The research presents a combination of known theories and a new model developed for predicting stress distribution within a tilled soil volume. The mathematical model is new for this specific purpose. Therefore the results cannot be compared to previous studies. In the process of developing the mathematical model, a set of instruments was custom designed and built. Some of the instrumentation was similar to instruments used for other research, but they were modified to satisfy the requirements of the present study. Then, the analysis of the predictions from the mathematical model was evaluated with the actual measurements done in the laboratory. The analysis of the results from the mathematical model is presented in section 8.2.1, and the evaluation of it with respect to the measurements done using the tillage simulator is presented in section 8.2..2.

The analysis of the seed bed soil quality and tilled quantity is put together with some deductions made from the analysis of the stress contour lines and failure zones in section 8.2.2.2 and 8.2.2.3. An analysis of the predicted and measured draft force is in section 8.2.2.4. Finally section 8.3 presents an analysis of the performance of the tensile strength apparatus and the preliminary results obtained for the present study.

The stress predictions from the mathematical model can be calculated at any depth within the soil segment, but the only soil slice in which shear and tensile failure patterns can be validated with pictures is the surface slice.

\subsection{Analysis:}

\subsubsection{Prediction from the mathematical model}

1) Three well defined zones can be selected from the family of equal stress lines. One is the zone of tensile fracturing where the absolute value of the negative principle minor stress $\left(\sigma_{3}\right)$ is greater than or equal to the tensile strength $(T)$. Second is the zone of shear fracturing, where the shear stress at failure is comparable to the shear strength values defined by the MohrCoulomb failure criteria. And third is the zone which does not fail. The 
three zones can be defined for each soil slice, but only on the soil surface can they actually be seen. Thus the zones at the soil surface are the ones that were selected for the validation of predicted stress patterns, and compared with the pictures.

2) The angle which divides the tensile fracturing zone from the zone where there is no failure increases with depth theoretically, and at half depth $(\mathrm{d} / 2)$ the angle is very close to $90^{\circ}$ (Table 7.8). Similarly, the shear failure zone increases with depth, and at $d / 2$ the included angle of shear failure is close to $90^{\circ}$. The radial distance of the shear failure zone is theoretically greater for the smaller rake angle $\left(30^{\circ}\right)$ and higher moisture contents (tests 303 $50,302-100$ and 303-100).

3) It is assumed that the shear combined with tension fracturing, produces a matrix of material failure lines as shown in Figures 8.1a and 8.1b.

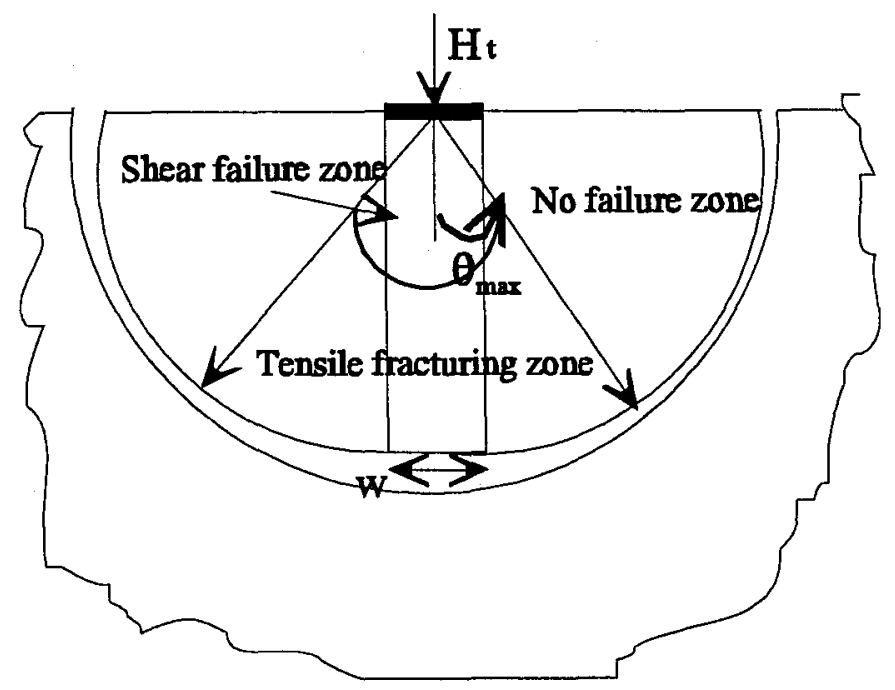

Figure 8.1a: Failure zones at surface 


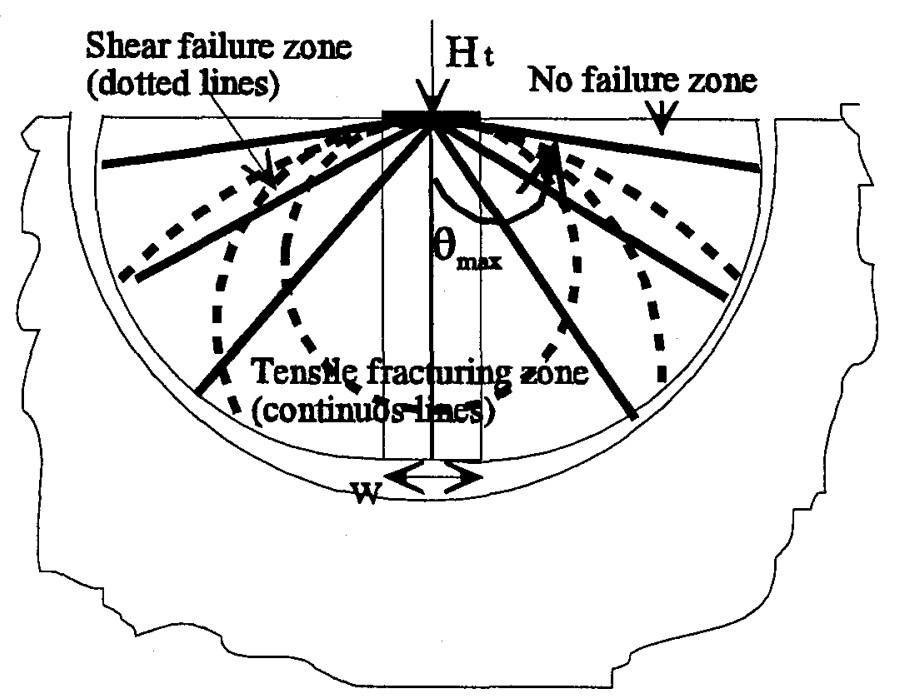

Figure 8.1b: Failure zones at deeper soil slice

The combination of the two soil failure zones shown in Figure $8.1 \mathrm{~b}$ will produce soil crumbling. The tool which produces a larger volume of crumbled soil will be the more efficient for tillage loosening. From Table 7.8 , the tool that is more efficient in crumbling soil is the one with rake angle of $30^{\circ}$. The combination of shear failure and tension fracturing increases towards the bottom part of the soil furrow, producing smaller aggregates. It has being proven that the smaller the aggregates, the stronger is the soil's resistance to erosion, and the more stable is the soil arrangement.

4) Table 7.8 shows that the tools which disturb more soil at the lowest soil moisture content are those with a rake angle of $30^{\circ}$. In general, the disturbed cross section area is greater for the lowest moisture content for all the tool rake angles and widths. The results also show that changing the tool width does not greatly affect the width of disturbed cross section. 


\subsubsection{Comparison of the predicted results with the laboratory measurements}

The values of stress patterns that can be compared between the predicted and the actual measurements are: 1$)$ The maximum angle of fracture $\left(\theta_{\max }\right)$ predicted by the model with the measured angle from the photographic records, 2) the cross section area predicted by the width of the tension fracturing zone from the mathematical model with the cross section measured with the profile metre, 3) the pattern of tension cracks predicted by the stress distribution model compared with photographs of the experimental soil surface, and 4) the total tool draft force predicted by the soil cutting model with the total draft measured with the draft force transducer. Although the effects of the results are inter-correlated, some analysis was done separately.

\subsubsection{Maximum angle of tension fracturing and pattern of tension cracks}

1) The tension fractures are clearly radial in direction. The maximum tensile stress is on the centre line, and decreases towards the borders of the soil segment. The tension stresses reach the value of tensile strength $(T)$ within an angle $\left(\theta_{\max }\right)$ (Figure 8.2a). The photographic records show that the lines at the edges of this zone, which correspond to the tensile strength value, are the most clearly defined, and they appear to be the first to be completely developed, probably because the forward movement of the tillage tool. Evidence for the last statement can be seen in Photos 8.1a and 8.1b, which are the front and side view of the same test (Test 601-100), and also in the other pictures presented in Appendix B. 


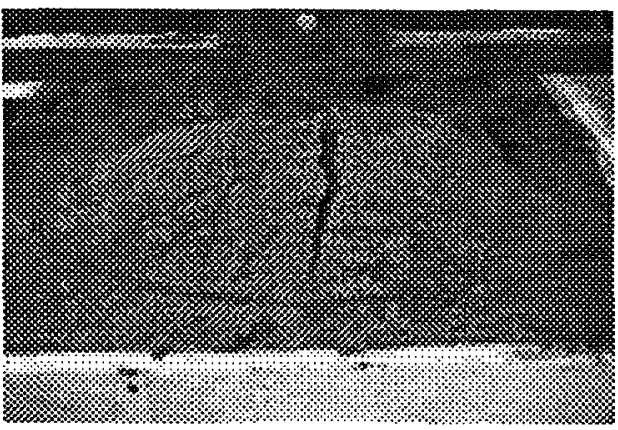

Photo 8.1a: Front view of test $601-100$

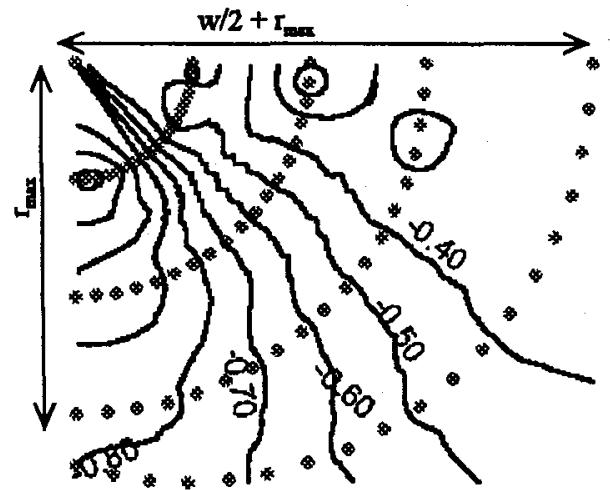

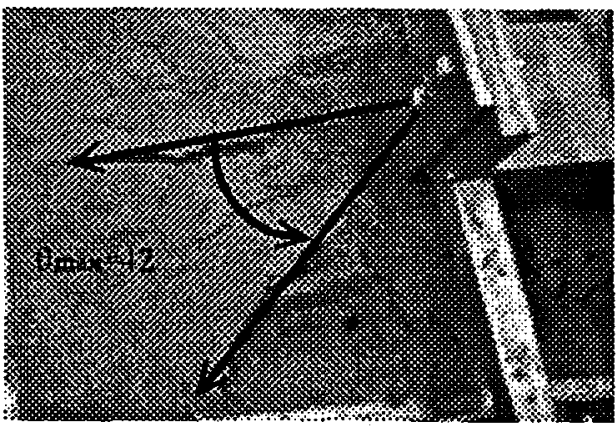

Photo 8.1b: Measured Maximum

Theta for the test 601-100.

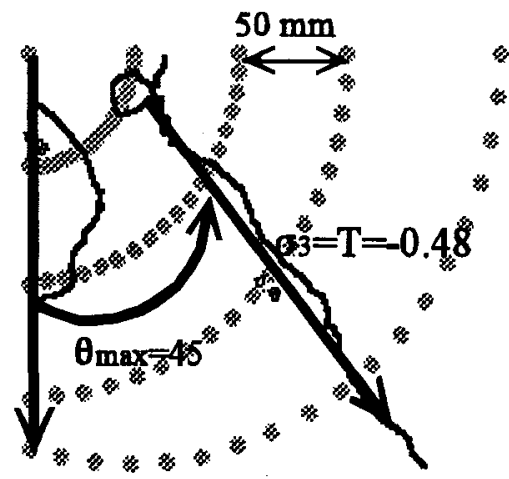

Figure 8.2a: Contours of Minor normal Stress

Figure 8.2b: Tensile Fracturing Zone.

Figures $8.2 \mathrm{a}$ and $8.2 \mathrm{~b}$ correspond to the predicted maximum angle of fracturing for the test 601-100.

2) Photo 8.1a shows a very clear and developed centre fracture. Nevertheless this was not always the case. The lines within the fracture zone were not always well defined, and the direction of these lines depends on the existence of fissures within the soil where the cracks can develop more easily. 
3) In general, the predicted angles were slightly higher than the actual observed angles (see Tables 7.6 and 7.7). For 11 tests out of 18 , the predicted angle of the tensile fracturing zone is somewhat higher than the measured angle, the range of difference being 3 to $15^{\circ}$. The largest difference of $15^{\circ}$ was for the test $901-100$, which corresponds to the $90^{\circ}$ rake angle, $100 \mathrm{~mm}$ tool width and the lowest moisture content. In the soil surface cross sections, where the maximum radial distance is $118.5 \mathrm{~mm}$, this angle difference is not of great significance with respect to the volume of soil failed in tension fracture.

4) In general the largest difference in maximum tensile fracture angle is given at the lowest soil moisture content. The difference tends to be smaller with increasing moisture content. This is reasonable, because at lower moisture content there are more pre-existing fissures in the soil mass, and then the direction of the fractures could be changed by them.

5) The greater angles occurred at the driest moisture content. This tendency, predicted by the mathematical model, is confirmed by the photographic results (see Tables 7.6 and 7.7).

6) The maximum angle of fracturing $\left(\theta_{\max }\right)$, is constant along the length of the furrow. The validity of this statement can be observed in Photo 7.4.

\subsubsection{Cross sectional area of the furrow and quantity of disturbed soil.}

1) The largest predicted horizontal cross section of the tilled furrow is given by the tool with rake angle of $30^{\circ}$ (Table 7.8). With respect to the rest of the tests, the rake angle $30^{\circ}$ gives the largest values at all moisture contents and the two tool widths used in the study. These results are consistent with the measured values of cross section presented in Table 7.6. The depth of the furrow cannot be compared to the theoretical predictions, but from the measured values the tool with $30^{\circ}$ gives the deepest soil furrow. Therefore the tool with rake angle of $30^{\circ}$ will produce 
the largest volume of disturbed soil.

2) The predicted values of cross section width decreases with moisture content for each set of tests using the same tool geometry. This prediction is not always consistent with the measured values (see Table 7.6). The differences could be because the soil after tillage is more fragile in the areas surrounding the disturbed furrow, and some pieces of soil could fall during the emptying of the soil from the furrow.

\subsubsection{Seed bed observations and analysis quality of the seed bed:}

For the analysis of the quality of the tilled seed bed, some coefficients were calculated using the measured values of initial bulk density and aggregate bulk density, and the mean weight of aggregates. These coefficients are the load factor $(\mathrm{K})$, swelling factor and uniformity coefficient presented in Table 8.1.

1) The swelling factor is an indicator of the average arrangement of the aggregates immediately after the tillage operation (see Section 6.8). A large value of swelling factor means that the resulting seed bed is a less mechanically stable arrangement, being more susceptible to compaction by machinery traffic. From the results, the rake angle of $30^{\circ}$ gave the smallest values and the least variance in swelling factor with respect to moisture content and tool width (see Table 8.1).

2) A large uniformity coefficient indicates a small difference in the sizes of aggregates between the top aggregates and the ones at the bottom of the furrow (see Section 6.8). The most uniform initial arrangement will produce a seed bed with even distribution of aggregate size. The largest values of uniform coefficient are given at the lower moisture content for all sets of tests (see Table 8.1).

3) A small swelling factor combined with a large uniformity coefficient will indicate a seed bed that is more resistant to erosion from rain or wind. 
4) The difference between the aggregate size on the top and bottom of the furrow seems to be more a function of the moisture content than the tool rake angle or width. The most uniform distribution of aggregates with respect to the top to bottom part of the furrow seems to be at moisture content of $13.32 \%$ for most of the tool geometries.

5) The aggregate densities (Table 7.6) were taken from the medium and large aggregates, where the small steel cores could be inserted without much disturbance. The results seems to be very uniform for all the tests performed and slightly higher than the initial values of bulk density. This could be an indication of slightly increased density and strength in the resultant aggregates. 
Table 8.1: Useful coefficients for the analysis of the seed bed quality.

\begin{tabular}{|c|c|c|c|}
\hline Test ID & $\begin{array}{c}\mathrm{K}= \\
\gamma_{\mathrm{f}} / \gamma_{\mathrm{o}}\end{array}$ & $\begin{array}{c}\text { Swell factor } \\
(\%)\end{array}$ & $\begin{array}{c}\text { Uniformity } \\
\text { coefficient } \\
(\%)\end{array}$ \\
\hline $301-50$ & 0.654 & 52.29 & 77.5 \\
\hline $302-50$ & 0.673 & 48.59 & 85.4 \\
\hline $303-50$ & 0.630 & 58.73 & 32.7 \\
\hline $301-100$ & 0.730 & 36.99 & 82.5 \\
\hline $302-100$ & 0.830 & 20.48 & 50.3 \\
\hline $303-100$ & 0.716 & 39.66 & 29.8 \\
\hline $601-50$ & 0.665 & 50.38 & 73.2 \\
\hline $602-50$ & 0.548 & 82.48 & 57.8 \\
\hline $603-50$ & 0.967 & 3.41 & 37.0 \\
\hline $601-100$ & 0.449 & 122.72 & 98.2 \\
\hline $602-100$ & 0.690 & 44.93 & 96.5 \\
\hline $603-100$ & 0.496 & 101.61 & 27.4 \\
\hline $901-50$ & 0.665 & 50.38 & 72.9 \\
\hline $902-50$ & 0.815 & 22.70 & 109.3 \\
\hline $903-50$ & 0.500 & 100.00 & 23.0 \\
\hline $901-100$ & 0.536 & 86.57 & 88.2 \\
\hline $902-100$ & 0.601 & 66.39 & 60.2 \\
\hline $903-100$ & 0.598 & 67.22 & 44.9 \\
\hline
\end{tabular}




\subsubsection{Draft force analysis.}

1) In general for all the tool rake angles and soil moisture conditions, the wider blades required higher draft than the narrower blades. The biggest difference is given by the rake angle of $30^{\circ}$ for which the $100 \mathrm{~mm}$ blade width has about twice the draft requirement of the $50 \mathrm{~mm}$ width in the predicted values. The previous pattern is consistent with the measured values of draft (see Tables 7.6 and 7.8).

2) The draft requirements also increase with moisture content. This behaviour is also consistent between the predicted and the measured forces.

3) Among the tested tool rake angles, the $30^{\circ}$ required the lower draft force and the requirement increases with increments in angle, this tendency was consistent between the measured and predicted total draft (see tables 7.6 and 7.8).

\subsection{Performance of the tensile strength apparatus and preliminary data of the tensile strength.}

1) The results of the tensile strength were very consistent among each set of samples taken for each of the four moisture contents.

2) The results of tensile strength were used for the predictions of the stress distribution model, and the predictions from the model are reasonably good compared with the actual measurements. Therefore, the performance of the tensile strength apparatus can be said to be satisfactory. 


\subsection{Conclusions:}

\subsubsection{The mathematical model}

1) The mathematical model predicts stress distributions and shear and tension failure planes which were validated with the tillage simulator. The results from the model were not $100 \%$ exact, but they are reasonably good considering that the instrumentation used for some important measurements in the validation were not standard or previously tested.

2) The model clearly predicts three zones, tension fracturing, shear failure and a no fracturing zone. The shear plane spreads simultaneously with tension fracturing. The tension fracturing produces opening of the soil segment in radial manner within the cross section, while the shear failure produces relative sliding along radial lines. As a result the model gives an indication of the crumbling of soil.

3) The model predicts the cross section of the soil segment, which is the shape of the tension fracturing zone. The model can be used for predictions of furrow cross section at any depth. However, it does not predict the depth of the furrow.

4) The equations used to calculate stresses are long and tedious to work with by hand, but they can easily be programmed in a computer language and directly exported to a GIS program for graphical visualization. Once the model is computerized the only values that are required to be fed into the program are geometrical parameters of the tool, the maximum radius of the soil slice, and the soil mechanical properties of cohesion, friction angle, density, and tensile strength.

5) The program is developed for a simple tool geometry, but it should be feasible to adjust for a more complex geometry. The model can be useful for design and optimization of tillage operations by testing the effects of different tool geometries theoretically. 


\subsubsection{Tool geometry, resulting seed bed, and draft force.}

1) The final shape of the soil segment, which was cut and crumbled during the tillage process, is of conical cross section from the top view. The cone is delimited by the limits of the tension fracturing zone.

2) The $30^{\circ}$ tool rake angle gives the most stable aggregate arrangement.

3) The most uniform aggregate distribution was achieved at the lowest moisture content which was $13.32 \%$.

4) The $30^{\circ}$ rake angle requires less force for a specific depth and width with respect to the other rake angles, and it also produces the largest volume of soil disturbed. Thus the tillage input energy is more efficiently used with this tool angle.

5) The lowest value of draft force requirements are with the $50 \mathrm{~mm}$ tool width and at the lowest moisture content of $13.32 \%$.

6) The predictions of draft force by the McKyes and Ali (1977) model matched those measured in the laboratory tillage simulations fairly well. Both presented the same pattern giving the lowest values for the smallest rake angle and increasing the draft requirements for the higher angles. The predictions were lower compared to the measurements for the $30^{\circ}$ and higher for the $60^{\circ}$ and $90^{\circ}$.

The previous set of conclusions can be summarized as follows: The smaller width and smaller rake angle among the ones used in this research are the more efficient geometry in producing the largest, most uniform and stable seed bed. At the same time it is the more efficient in energy utilization. The tools performed better at the lowest moisture content of the ones used in the different tests, which was $13.32 \%$.

\subsubsection{Tensile strength apparatus}

The design of the tensile strength apparatus gave good results. It has being tested only with the soil type that was used in this research. It should be evaluated with more 
soil types. It also needs some improvements in the holders of the sample to provide a more constant pressure for all the soil specimens. 


\section{CONTRIBUTIONS TO KNOWLEDGE}

1. The main novel contribution from the research is a new mathematical model which describes the stress distribution within the tilled soil segment. It gives equations for the normal and shear stresses, which could be used to calculate the failure planes using the Mohr-Coulomb shear and brittle tension failure criteria.

2. The mathematical model considers the concept of tensile strength of cohesive soils. The model is based on the criterion that tensile fracture is due to the minor principle stress reaching the tensile strength value. It reasonably explains the soil tensile fracturing which occurs in tillage operations.

3. A method of measuring the tensile strength in soil cylinders has been developed in this research. It includes the design of the tensile strength apparatus, the method of preparing the soil specimen and guidelines for the performance of the tests.

4. The major aim of the project is to provide a better understanding of the soil pulverization produced by tillage operations, and therefore a better understanding of the seed bed produced by a specific tool shape. The present research provides a preliminary logical understanding of the conditions of the seed bed, with respect to the soil conditions and tillage tool actions.

5. The mathematical model is easy to solve for the results on a spread sheet or a computer program. The computed values of stresses can be directly exported to a GIS software for mapping, graphical representation and manipulation of the data.

6. This study also introduced a method of analyzing the seed bed arrangement and quality of aggregation. The method is based on the interpretation of the aggregate size uniformity coefficient, which is defined as the ratio of aggregate size at the bottom to the aggregate size at the top part of the furrow. The analysis also considers the swelling factor which has been used for earthmoving soil volume analysis. The swelling factor is interpreted in this study as an indication of changes in aggregate size and arrangement.

7. The study uses the mini-core method for analyzing aggregate density. This is a 
rare approach and has not been reported. The advantage of the core method is that it can be performed in situ. 


\section{RECOMMENDATIONS FOR FURTHER RESEARCH}

1. The mathematical model could be modified for other tool shapes (triangular or curved for example), to find a relation between the energy requirements and the resulting seed bed soil structure. It could be very useful in the design and optimization of tools for different tillage operations, as a function of the crop requirements.

2. It is recommended that a more extensive study of the tensile strength of soils be conducted, in which soil physical and chemical properties are evaluated for different soil types. A family of curves for typical ranges of soil types and moisture contents could be very useful in the analysis of root penetration and tillage pulverization.

3. A better understanding of the soil strength in tension could be very useful in other type of engineering structures as well. An example could be soil fractures produced around retaining walls, bridge piers and dams.

4. The method of analysing the resultant seed bed, using the swelling factor, the uniformity coefficient and aggregate density could be very useful for a better evaluation of its performance in different soils.

5. Also the method of measuring aggregate density using the core method has not been reported previously. It would be very interesting to compare the results using this method with the results using a more standard methods.

6. More detailed measurements of aggregate arrangement and soil density within the aggregates would be interesting. This would give a better correlation between tillage operations and the stability of the seed bed. 


\section{REFERENCES}

Abebe A.T. and A.J. Koolen. 1995. Fracture behavior of a cohesive soil under crushing stress loading. Journal of Terramechanics. 32:167-179.

Aitchison, G.D. 1961. Relationships of moisture stress and effective stress functions in unsaturated soils. P.47-52 in Pore pressure and suction in soils. Butterworths (London).

Aluko O.B. and D.A. Seig. 2000. An experimental investigation of the characteristics of and conditions for brittle fracture in two-dimensional soil cutting. Soil and Tillage Research 57:143-157.

Bodman G.B. 1949. Methods of measuring soil consistency. Soil Science 68:37-56.

Braunack M.V., J.S. Hewitt and A.R. Dexter. 1979. Brittle fracture of soil aggregates and the compaction of aggregate beds. Journal of Soil Science 30:653-667.

Browning G.M. 1950. Principles of soil physics in relation to tillage. Agricultural Engineering. July:341-344.

Chi L. and R.L. Kushwaha. 1989. Finite element analysis of forces on a plane soil blade. CSAE Paper No. 88-205. 31(2):135-140.

Chi L. and R.L. Kushwaha. 1990. Finite element analysis of soil forces on two tillage tools. CSAE Paper No. 89-1103. 32(1):39-45.

Chi L. and R.L. Kushwaha. 1993. A nonlinear 3-D finite element analysis of soil forces on curved tillage tools. ASAE Paper No. 90-1546. 35:11-15.

Chuang P.H.1992. Stability analysis in geomechanics by linear programing. Journal of Geothechnical Engineering. 118(11):1696-1726.

Caterpillar Tractor Co.1975. Fundamentals of earthmoving. Trademarks of Caterpillar Tractor. Co. USA.

Coulomb M. 1776. Sur une application des règles de maximis \& minimis à quelques problèmes de statique, relatifs à l'architecture. Academie Royale des Sciences. Paris, Vol. 7: 343-382.

Desai C.S.; M.M. Zaman; J.G. Lightner and H.J. Siriwardane. 1984. Thin-Layer element for interfaces and joints. International Journal for Numerical Methods in Geomechanics. 8:19-43. 
Desir F.L. 1981. A field evaluation of the wedge approach to the analysis of soil cutting by narrow blades. M.Sc. Thesis, McGill Univ., Montreal, Quebec:245 pp.

Dexter A.R. 1975. Uniaxial compression of ideal brittle tilths. Journal of Terramechanics. 12(1):3-14.

Dexter A.R. 1976. Internal structure of tilled soil. Journal of Soil Sci. 27:267-278.

Dexter A.R. and B. Kroesbergen. 1985. Methodology for determination of tensile strength of soil aggregates. J. Agric. Engng. Res. 31:139-147.

Dexter A.R. and N.R.A. Bird. (2001). Methods for predicting the optimum and the range of soil water contents for tillage based on the water retention curve. Soil and Tillage Research 57:203-212.Dexter A.R.

Duncan, J.M. and C.Y. Chang. 1970. Nonlinear analysis of stress and strain in soil. J. Soil Mech. And Foundations Div., Proc. Of Am. Soc. Civ. Engrs. 96(SM\%):1629-1653.

Fisher R.A. 1926. On the capillary forces in the ideal soil; correction of formulae given by W.B. Haines. J. Agri. Sci., 16:492-505.

Frocht M.M.; 1941-1948. Photo elasticity. John Wiley \& Sons, Inc. New York: Volume I and II.

Frocht M.M. and F. Guernsey. 1952. A special investigation to develop a general method for three-dimensional photoelastic stress analysis. Contract No. Naw-5959: Natnl. Adv. Comm. for Aeronautics Technical Note 2822.

Frydman S. 1964. The applicability of the Brazilian (Indirect Tension) test to soils. Aust. J. Sci. 15:335-343.

Gill W.R. and W.F. McCreery. 1960. Relation of size of cut to tillage tool efficiency. ASAE. June:372-375.

Gill W.R. and G.E. Vanden Berg. 1967. Soil dynamics in tillage and traction. Agricultural Research Service. United States Department of Agriculture. 511 pp.

Godwin R.J. and G. Spoor. 1977. Soil failure with narrow tines. J. Agric. Engng. Res. 22:213-228.

Griffith A.A. 1921. The phenomena of rupture and flow in solids. Phil. Trans. Royal Soc. London, A. 221:163-198.

Gupta S.C. and W.E. Larson. 1982. Modeling soil mechanical behaviour during tillage. Chapter 10 Predicting tillage effects on soil physical properties and processes. Madison, Wi. 151-179. 
Hadas A. 1987. Long-Term tillage practice effects on soil aggregation modes and strength. Soil Sci. Soc. Am. J. 51:191-197.

Hadas A. and G. Lennard. 1988. Dependence of tensile strength of soil aggregates on soil constituentes, density and load history. J. Soil Sci. 39(4):577-586.

Haines W.B. 1927. Studies in the physical properties of soils. IV. A further contribution to the theory of capillary phenomena in soil. J. Agr. Sci. 17:264-290.

Harr, M.E.; 1966. Foundations of theoretical soil mechanics. McGraw-Hill, New York.

Hettiaratchi, D.R.P.; B.D. Witney and A.R. Reece. 1966. The calculation of passive pressure in two-dimensional soil failure. J. Agric. Engng. Res. 11(2): 89-107.

Hettiaratchi , D.R.P. and A.R. Reece. 1967. Symmetrical three-dimensional soil failure. Journal of Terramechanics. 4(3):45-67.

Hettiaratchi , D.R.P. and A.R. Reece. 1974. The calculation of passive soil resistance. Géotechnique. 24(3): 289-310.

Johnson C.E., R.D. Grisso, T.A. Nichols and A.C. Bailey. 1987. Shear measurement for agricultural soils. A review. Transactions of the ASAE. 30:935-938.

Kay B.D. and A.R. Dexter. 1992. The influence of dispersable clay and wetting/drying cycles on the tensile strength of a red-brown earth. Aus. J. Soil. Res. 30:297-310.

Kirkham D., M.F. de Boodt and L de Leenheer. 1959. Modulus of rupture determination on undisturbed soil core samples. Soil Sci. 87:141-144.

Klingebiel A.A. and A.M. O'Neal. 1952. Structure and its influence on tilth of soils. Soil Sci. Soc. Proc. 16:77-80.

Klute A. 1986. Methods of soil analysis. Part 1- Physical and Mineralogical Methods. Agronomy No.9. Part 1. $2^{\text {nd }}$ Edition. ASA.SSSA. Publisher. Madison, Wisconsin USA.

Kondner R.L. 1963. Hyperbolic stress-strain response: cohesive soils. Journal of soil mechanics and foundations division, Proceedings of the ASCE 89(1):115-141.

Kushwaha R.L. and J. Shen. 1995. Finite element analysis of the dynamic interaction between soil and tillage tool. Transactions of the ASAE. 35:1315-1319.

Larson, W.E., and S.C. Gupta. 1980. Estimating critical stresses in unsaturated soils from changes in pore water pressure during confined compression. Soil Sci. Soc. Am. J. 44:1127-1132. 
Martinson D.C. and L.B. Olmstead. 1949. Crushing strength of aggregated soil materials. Soil Sci. Soc. Proc. 14:34-38.

McKyes E. and O.S. Ali. 1977. The Cutting of soil by narrow blades. Journal of Terramechanics 14(2):43-58.

McKyes E. 1985. Soil cutting and tillage. Developments in Agricultural Engineering No. 7. Elsevier Science Publishers B.V. Amsterdam, The netherlands.

McKyes E., P. Nyamugafata and K.W. Nyamapfene. 1993. Characterization of cohesion, friction and sensitivity of two hard-setting soils from Zimbabwe. Soil \& Tillage Research 29:357-366.

Mitchell J.K. 1993. Fundamentals of soil behavior. Second Edition. John Wiley \& Sons, Inc. New York, NY.

Ojeniyi S.O. and A.R. Dexter. 1979. Soil factors affecting the macro-structures produced by tillage. Transactions of the ASAE 22:339-343.

Payne, P.C.J. 1956. The relationship between the mechanical properties of soils and the performance of simple cultivation implements. J. Agr. Eng. Res. 1(1):23-50.

Perumpral J.V., R.D. Grisso and C.S. Desai. 1983. A Soil-Tool model based on limit equilibrium analysis. Transactions of the ASAE 26:991-995.

Richards L.A. 1953. Modulus of rupture as an index of crusting of soil. Soil Sci. Soc. Am. Proc. 17:321-323.

Reece. A.R. 1965. The fundamental equation of earthmoving mechanics. Symposium on Earthmoving Machinery, Institute of Mechanical Engineers, 179, Part 3F, London.

Rogowski A.S., W.C. Moldenhauer and Don Kirkham. 1968. Rupture parameters of soil aggregates. Soil Sci. Soc. Am. Proc. 32:720-724.

Russell M.B. 1949. Methods of measuring soil structure and aereation. soil science 68:2535 .

Sharifat K. and R.L. Kushwaha. 2000. Modeling soil movement by tillage tools. CSAE 42:165-172.

Snyder V.A. and R.D. Miller. 1985. A Pneumatic method for measuring the tensile strength of unsaturated soils. Soil Sci. Soc. Am. J. 49:1369-1374.

Snyder V.A. and R.D. Miller. 1985. Tensile strength of unsaturated soils. Soil Sci. Am. J. 49:58-65. 
Soehne W. 1953. Friction and cohesion in arable soils. Grundlagen der Landtechnik 5:6480.

Soehne W. 1956. Some principles of soil mechanics as applied to agricultural engineering. Grundlagen der Landtechnik 7:11-27. (Nat. Inst. Agr. Engin. Eng. Ttanslation 53).

Sokolovski, V.V. 1956. Statics of soil media. Butterworth, London.

Sternberg E. and E. Rosenthal. 1952. The elastic sphere under concentrated loads. J. Appl. Mech. 19(4):413-421.

Swick W.C. and J.V. Perumpral. 1988. A model for predicting soil-tool interaction. Journal of Terramechanics. 25(1):43-56.

Tennessee Valley Authority. 1952. Design of TVA projects. Tech. Rep. No. 24, Civil and Structural Design. U.S. Gov't. Print. Off., Washington, D.C.

Terzaghi, K. 1941. General wedge theory of earth pressures. Trans. Am. Soc. Civil. Eng. 106:68-80

Ura T. and Y. Tamamoto.1978. Stability of dragged anchors. Institute of Industrial Science: The University of Tokyo. Published Minato-Ku, Tokyo, Japan. 27(4) serial 174:1-19.

Utomo W.H. and A.R. Dexter. 1981. Soil friability. J. of Soil Sci. 32:203-213.

Yong R.N. and A.W. Hanna. 1977. Finite element analysis of plane soil cutting. Journal of Terramechanics. 14(3):103-125. 


\section{APPENDICES}


Appendix A: Development of equations for internal stresses on each element of soil produced by $\sigma_{2 x}$ and $\sigma_{2 y}$ (Section 3.4.4).

A.1: Stress at the free edges of the soil segment, (from Sections 3.4.2 and 3.4.3):

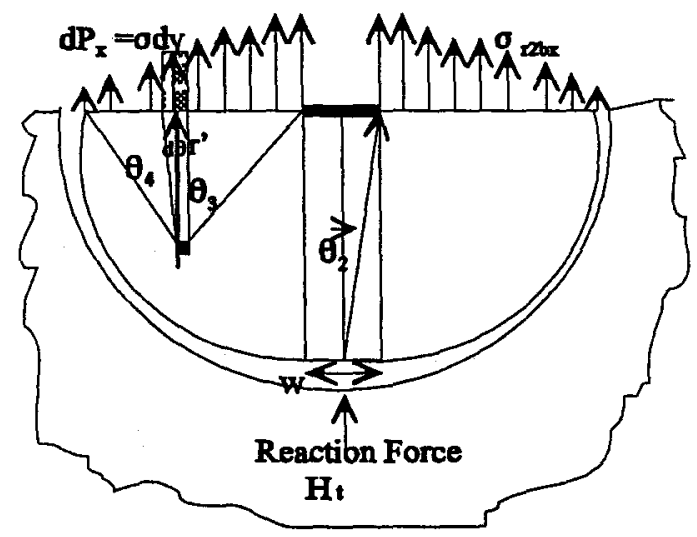

Figure 8: Free Boundary reaction in $\mathrm{x}$

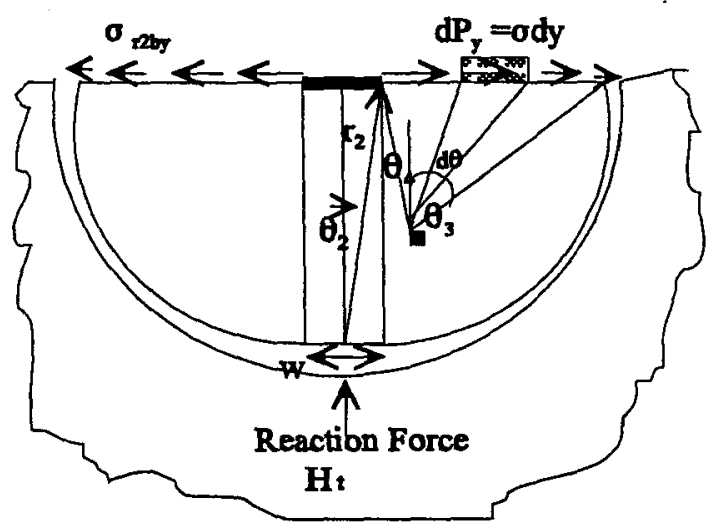

Figure 8: Free Boundary reaction in $y$

$$
\begin{aligned}
& \sigma_{2}=\frac{-2 H_{t} \cos ^{2} \theta_{2}}{\pi t r_{\max }} \\
& \sigma_{2_{x}}=-\frac{2 H_{t} \cos ^{3} \theta_{2}}{\pi t r_{\max }} \\
& \sigma_{2_{y}}=-\frac{2 H_{t} \cos ^{2} \theta_{2} \sin \theta_{2}}{\pi t r_{\max }}
\end{aligned}
$$




\section{A.2: Calculation of the differential force $d P$ :}

Calculation of the differential force in $x\left(d P_{x}\right)$ :

$$
\begin{aligned}
& d P_{x}=\sigma_{2_{x}} d y \\
& d y=\frac{r_{2} d \theta_{2}}{\cos \theta_{2}}=\frac{r_{\max } d \theta_{2}}{\cos ^{2} \theta_{2}} \\
& d P_{x}=\frac{2 H \cos \theta_{2} d \theta_{2}}{\pi t}
\end{aligned}
$$

Calculation of the differential force in $y\left(d P_{y}\right)$ :

$$
\begin{aligned}
& d P_{y}=\sigma_{2_{y}} d y \\
& d y=\frac{r_{2} d \theta_{2}}{\cos \theta_{2}}=\frac{r_{\max } d \theta_{2}}{\cos ^{2} \theta_{2}} \\
& d P_{y}=\frac{2 H \sin \theta_{2} d \theta_{2}}{\pi t}
\end{aligned}
$$

\section{A.3: Calculation of the stresses produced by the differential force on any soil} element in rectangular coordinates $x$ and $y$ :

\section{A.3.1) Using $d P_{x^{*}}$}

Calculation of $\sigma_{(\mathbb{A P x}) x}, \sigma_{(\mathbb{d P x}) y}$ and $\tau_{(\mathrm{dPX}) \mathrm{xy}}$ : 


$$
\begin{aligned}
& 2 d P_{x} \int_{\theta_{3}}^{\theta_{4}} \cos ^{3} \theta^{\prime} d \theta^{\prime} \\
& \sigma_{\left(d P_{x}\right)_{x}}=\sigma_{r^{\prime}(d P x)} \cos ^{2} \theta^{\prime} \rightarrow \sigma_{\left(d P_{x}\right)_{x}}=\frac{\theta_{3}}{\pi t r^{\prime}} \\
& r^{\prime}=\frac{r \cos \theta}{\cos \theta^{\prime}} \rightarrow \sigma_{\left(d P_{x}\right)_{x}}=\frac{2 d P_{x} \int_{\theta_{3}}^{\theta_{4}} \cos ^{4} \theta^{\prime} d \theta^{\prime}}{\pi t r \cos \theta} \\
& \sigma_{\left(d P_{x}\right)_{x}}=\frac{2 d P_{x}\left[\frac{3}{8}\left(\theta_{4}-\theta_{3}\right)+\frac{1}{4}\left(\sin 2 \theta_{4}-\sin 2 \theta_{3}\right)+\frac{1}{32}\left(\sin 4 \theta_{4}-\sin 4 \theta_{3}\right)\right]}{\pi \operatorname{tr} \cos \theta} \\
& \begin{array}{l}
\sigma_{\left(d P_{x}\right)_{y}}=\sigma_{r^{\prime}\left(d P_{x}\right)} \sin ^{2} \theta^{\prime} \rightarrow \sigma_{\left(d P_{x}\right)_{y}}=\frac{2 d P_{x} \int_{\theta_{3}}^{\theta_{4}} \cos \theta^{\prime} \sin ^{2} \theta^{\prime} d \theta^{\prime}}{\pi t r^{\prime}} \\
r^{\prime}=\frac{r \cos \theta}{\cos \theta^{\prime}} \rightarrow \sigma_{\left(d P_{x}\right)_{y}}=\frac{2 d P_{x} \int_{\theta_{3}}^{\theta_{3}} \cos ^{2} \theta^{\prime} \sin ^{2} \theta^{\prime} d \theta^{\prime}}{\pi t r \cos \theta}
\end{array} \\
& \sigma_{\left(d P_{x}\right)_{y}}=\frac{2 d P_{x}\left[-\left(\cos \theta_{4}+\cos \theta_{3}\right)+\frac{1}{3}\left(\cos ^{3} \theta_{3}-\cos ^{3} \theta_{4}\right)\right]}{\pi \operatorname{tr} \cos \theta}
\end{aligned}
$$




$$
\begin{aligned}
& \tau_{\left(d P_{x}\right)_{x y}}=\sigma_{r^{\prime}\left(d P_{x}\right)} \sin \theta^{\prime} \cos \theta^{\prime} \rightarrow \tau_{\left(d P_{x}\right)_{x y}}=\frac{2 d P_{x} \int_{\theta_{3}}^{\theta_{4}} \cos ^{2} \theta^{\prime} \sin \theta^{\prime} d \theta^{\prime}}{\pi t r^{\prime}} \\
& r^{\prime}=\frac{r \cos \theta}{\cos \theta^{\prime}} \rightarrow \tau_{\left(d P_{x}\right)_{x y}}=\frac{2 d P_{x} \int_{\theta_{3}}^{\theta_{4}} \cos ^{3} \theta^{\prime} \sin \theta^{\prime} d \theta^{\prime}}{\pi t r \cos \theta} \\
& \tau_{\left(d P_{x}\right)_{x y}}=\frac{2 d P_{x}\left[\frac{1}{3}\left(\sin ^{2} \theta_{4}-\sin ^{2} \theta_{3}\right)+\frac{1}{4}\left(\sin ^{4} \theta_{3}-\sin ^{4} \theta_{4}\right)\right]}{\pi \cos \theta}
\end{aligned}
$$

\section{A.3.2 Using $d P_{y}$ :}

Calculation of $\sigma_{(\mathrm{dPY}) \mathrm{x}}, \sigma_{(\mathrm{dPy} y \mathrm{y}}$ and $\tau_{(\mathrm{dP} y) x y}$ :

$$
\begin{aligned}
& \sigma_{\left(d P_{y}\right)_{x}}=\sigma_{r^{\prime}\left(d P_{y}\right)} \sin ^{2} \theta^{\prime} \rightarrow \sigma_{\left(d P_{y}\right)_{x}}=\frac{d P_{y} \int_{\theta_{3}}^{\theta_{4}} \cos \theta^{\prime} \sin ^{2} \theta^{\prime} d \theta^{\prime}}{\pi t r^{\prime}} \\
& r^{\prime}=\frac{r \cos \theta}{\sin \theta^{\prime}} \rightarrow \sigma_{\left(d P_{y}\right)_{x}}^{\theta_{4}}=\frac{d P_{y} \int_{\theta_{3}} \cos \theta^{\prime} \sin ^{3} \theta^{\prime} d \theta^{\prime}}{\pi t r \cos \theta} \\
& \sigma_{\left(d P_{y}\right)_{x}}=\frac{d P_{y}\left[\frac{1}{3}\left(\cos ^{3} \theta_{4}-\cos ^{3} \theta_{3}\right)-\frac{1}{2}\left(\cos ^{2} \theta_{4}-\cos ^{2} \theta_{3}\right)\right]}{\pi \cos \theta}
\end{aligned}
$$




$$
\begin{gathered}
\sigma_{\left(d P_{y}\right)_{y}}=\sigma_{r^{\prime}\left(d P_{y}\right)} \cos ^{2} \theta^{\prime} \rightarrow \sigma_{\left(d P_{y}\right)_{y}}=\frac{d P_{y} \int_{\theta_{3}}^{\theta_{4}} \cos ^{3} \theta^{\prime} d \theta^{\prime}}{\pi t r^{\prime}} \\
r^{\prime}=\begin{array}{l}
r \cos \theta \\
\sin \theta^{\prime}
\end{array} \rightarrow \sigma_{\left(d P_{y}\right)_{y}}=\frac{d P_{y} \int_{\theta_{3}}^{\theta_{4}} \cos ^{3} \theta^{\prime} \sin \theta^{\prime} d \theta^{\prime}}{\pi t r \cos \theta} \\
\sigma_{\left(d P_{y}\right)_{y}}=\frac{d P_{y}\left[\frac{1}{2}\left(\sin ^{2} \theta_{4}-\sin ^{2} \theta_{3}\right)-\frac{1}{4}\left(\sin ^{4} \theta_{4}-\sin ^{4} \theta_{3}\right)\right]}{\pi t r \cos \theta}
\end{gathered}
$$

$$
\begin{aligned}
& \tau_{\left(d P_{y}\right)_{x y}}=\sigma_{r^{\prime}\left(d P_{y}\right)} \sin \theta^{\prime} \cos \theta^{\prime} \rightarrow \tau_{\left(d P_{y}\right)_{x y}}=\frac{d P_{y} \int_{\theta_{3}}^{\theta_{4}} \cos ^{2} \theta^{\prime} \sin \theta^{\prime} d \theta^{\prime}}{\pi t r^{\prime}} \\
& r^{\prime}=\begin{array}{c}
r \cos \theta \\
\sin \theta^{\prime}
\end{array} \rightarrow \tau_{\left(d P_{y}\right)_{x y}}=\frac{d P_{y} \int_{\theta_{3}}^{\theta_{4}} \cos ^{2} \theta^{\prime} \sin ^{2} \theta^{\prime} d \theta^{\prime}}{\pi t r \cos \theta}
\end{aligned}
$$

$$
\tau_{\left(d P_{y}\right)_{x y}}=\frac{d P_{y}\left[\frac{1}{2}\left(\theta_{4}-\theta_{3}\right)-\frac{1}{4}\left(\theta_{4}-\theta_{3}\right)-\frac{1}{16}\left(\sin \theta_{4}-\sin \theta_{3}\right)\right]}{\pi \operatorname{tr} \cos \theta}
$$

Where: 


$$
\begin{gathered}
\theta_{3}=\operatorname{tg}^{-1}\left(\frac{r_{\text {max }}-r \sin \theta-w / 2}{r \cos \theta}\right) \\
\theta_{4}=\operatorname{tg}^{-1}\left(\frac{r \sin \theta-w / 2}{r \cos \theta}\right)
\end{gathered}
$$

\section{A.4: Calculation of components on $r$ and $\theta$ :}

A.4.1 The components on $r$ and $\theta$ using $d P_{x}$ or $d P_{y}$ are expressed by:

$$
\begin{aligned}
& \sigma_{r}=\sigma_{x} \cos ^{2} \theta+\sigma_{y} \sin ^{2} \theta \\
& \sigma_{\theta}=\sigma_{x} \sin ^{2} \theta+\sigma_{y} \cos ^{2} \theta \\
& \tau_{r \theta 2}=\left(\tau_{\left(d P_{x}\right) x y}+\tau_{\left(d P_{y}\right) x y}\right) \sin \theta \cos \theta
\end{aligned}
$$

Note: the fully extended equation for $\tau_{\mathrm{r} \theta}$ is done in the computer, because it is too long.

\section{A.4.2 Using $d P_{x^{*}}$}

$$
\begin{aligned}
\sigma_{r d P_{x}}= & \frac{2 d P_{x} \cos \theta}{\pi t r}\left[\frac{3}{8}\left(\theta_{4}-\theta_{3}\right)+\frac{1}{4}\left(\sin 2 \theta_{4}-\sin 2 \theta_{3}\right)+\frac{1}{32}\left(\sin 4 \theta_{4}-\sin 4 \theta_{3}\right)\right] \\
& +\frac{2 d P_{x} \sin ^{2} \theta}{\pi t r \cos \theta}\left[\frac{1}{3}\left(\cos ^{3} \theta_{3}-\cos ^{3} \theta_{4}\right)-\left(\cos \theta_{4}+\cos \theta_{3}\right)\right] \\
\sigma_{\theta d P_{x}}= & \frac{2 d P_{x} \sin ^{2} \theta}{\pi t r \cos \theta}\left[\frac{3}{8}\left(\theta_{4}-\theta_{3}\right)+\frac{1}{4}\left(\sin 2 \theta_{4}-\sin 2 \theta_{3}\right)+\frac{1}{32}\left(\sin 4 \theta_{4}-\sin 4 \theta_{3}\right)\right] \\
& +\frac{2 d P_{x} \cos \theta}{\pi t r}\left[\frac{1}{3}\left(\cos ^{3} \theta_{3}-\cos ^{3} \theta_{4}\right)-\left(\cos \theta_{4}+\cos \theta_{3}\right)\right]
\end{aligned}
$$




\section{A.4.3 Using $d P_{y}$ :}

$$
\begin{aligned}
\sigma_{r d P_{y}}= & \frac{d P_{y} \cos \theta}{\pi t r}\left[\frac{1}{3}\left(\cos ^{3} \theta_{4}-\cos ^{3} \theta_{3}\right)-\frac{1}{2}\left(\cos ^{2} \theta_{4}-\cos ^{2} \theta_{3}\right)\right] \\
& +\frac{d P_{y} \sin ^{2} \theta}{\pi t r \cos \theta}\left[\frac{1}{2}\left(\sin ^{2} \theta_{4}-\sin ^{2} \theta_{3}\right)-\frac{1}{4}\left(\sin ^{4} \theta_{4}-\sin ^{4} \theta_{3}\right)\right] \\
\sigma_{\theta d P_{y}}= & \frac{d P_{y} \sin ^{2} \theta}{\pi t r \cos \theta}\left[\frac{1}{3}\left(\cos ^{3} \theta_{4}-\cos ^{3} \theta_{3}\right)-\frac{1}{2}\left(\cos ^{2} \theta_{4}-\cos ^{2} \theta_{3}\right)\right] \\
& +\frac{d P_{y} \cos \theta}{\pi t r}\left[\frac{1}{2}\left(\sin ^{2} \theta_{4}-\sin ^{2} \theta_{3}\right)-\frac{1}{4}\left(\sin ^{4} \theta_{4}-\sin ^{4} \theta_{3}\right)\right]
\end{aligned}
$$

\section{A.5: Calculation of the total stresses on $r$ and $\theta$.}

$$
\begin{aligned}
& \sigma_{r}=\sigma_{r 1}-\sigma_{r 2}-\gamma z K_{o} \rightarrow \sigma_{r}=\sigma_{r 1}-\sigma_{r d P_{x}}-\sigma_{r d P_{y}}-\gamma z K_{o} \\
& \sigma_{\theta}=-\sigma_{\theta 2}-\gamma z K_{o} \rightarrow \sigma_{\theta}=-\sigma_{\theta d P_{x}}-\sigma_{\theta d P_{y}}-\gamma z K_{o} \\
& \tau_{r \theta}=-\tau_{r \theta 2} \rightarrow \tau_{r \theta}=-\tau_{r \theta d P_{x}}-\tau_{r \theta d P_{y}}
\end{aligned}
$$




\section{APPENDIX B: \\ PHOTOGRAPHS OF SOIL FRACTURING.}


The maximum angle was measured directly from the photographs.

$301-50 ; \theta_{\max }=80^{\circ}$
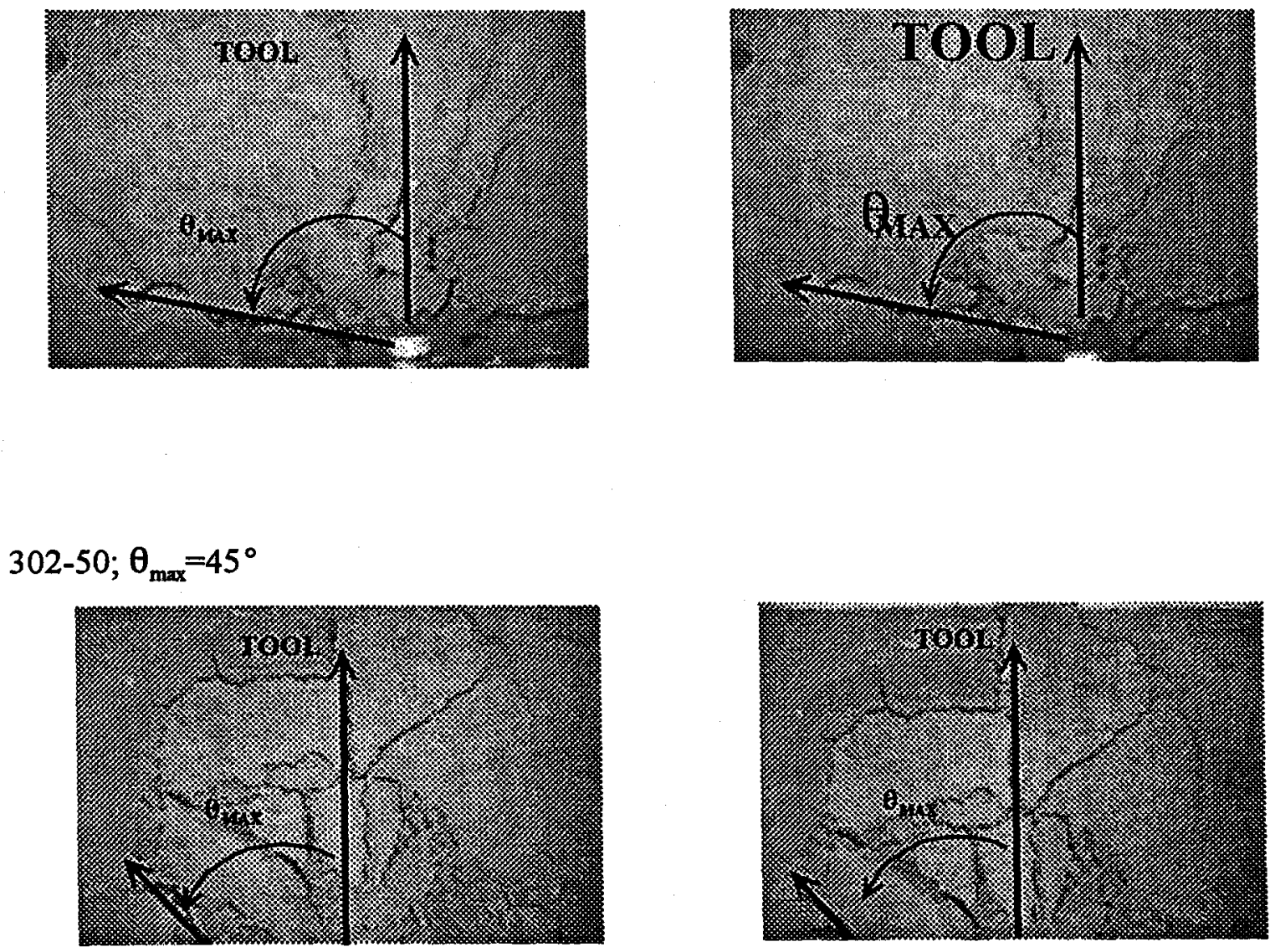

$303-50 ; \theta_{\max }=32^{\circ}$
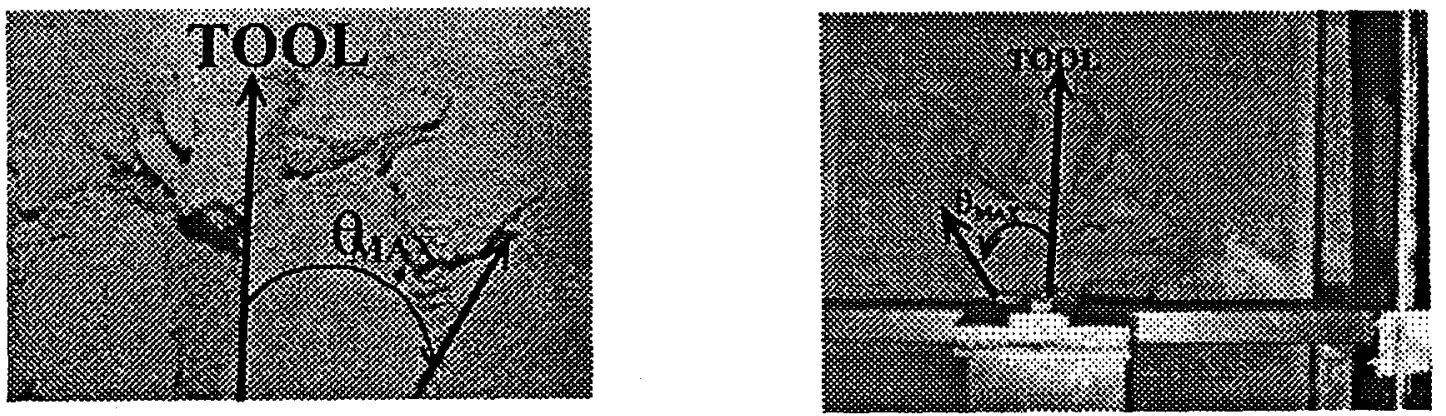
The maximum angle was measured directly from the photographs.
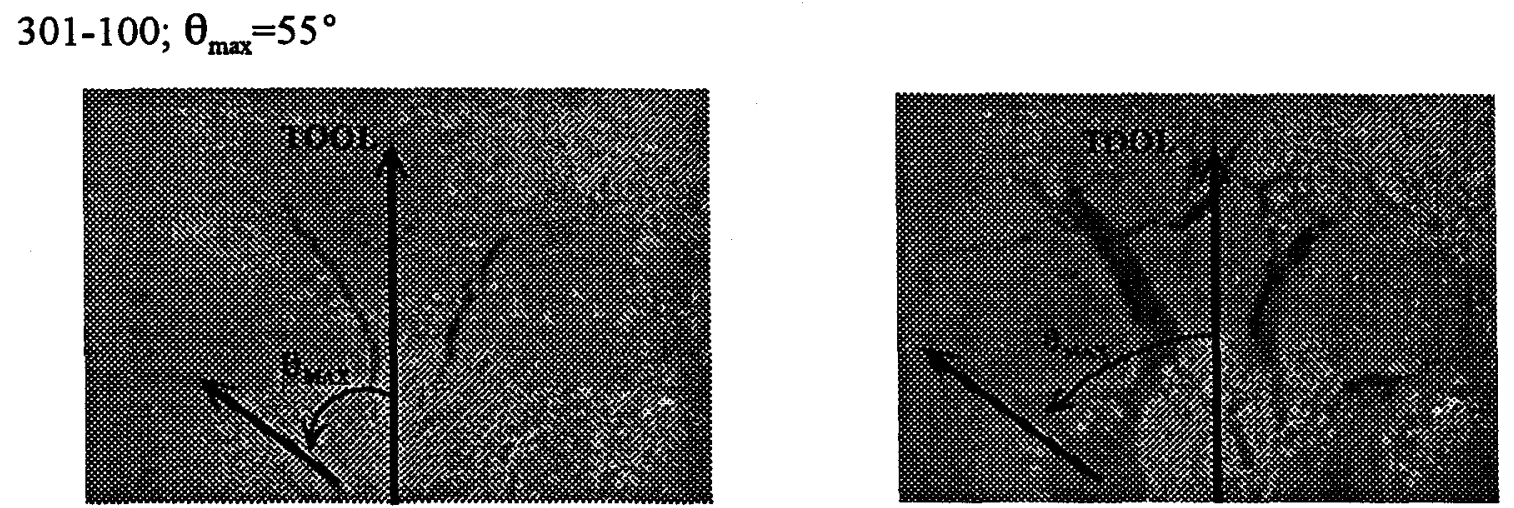

$302-100 ; \theta_{\max }=40^{\circ}$

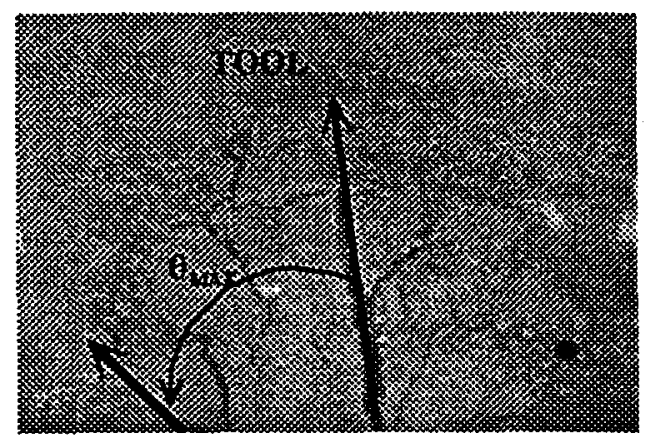

$303-100 ; \theta_{\max }=32^{\circ}$
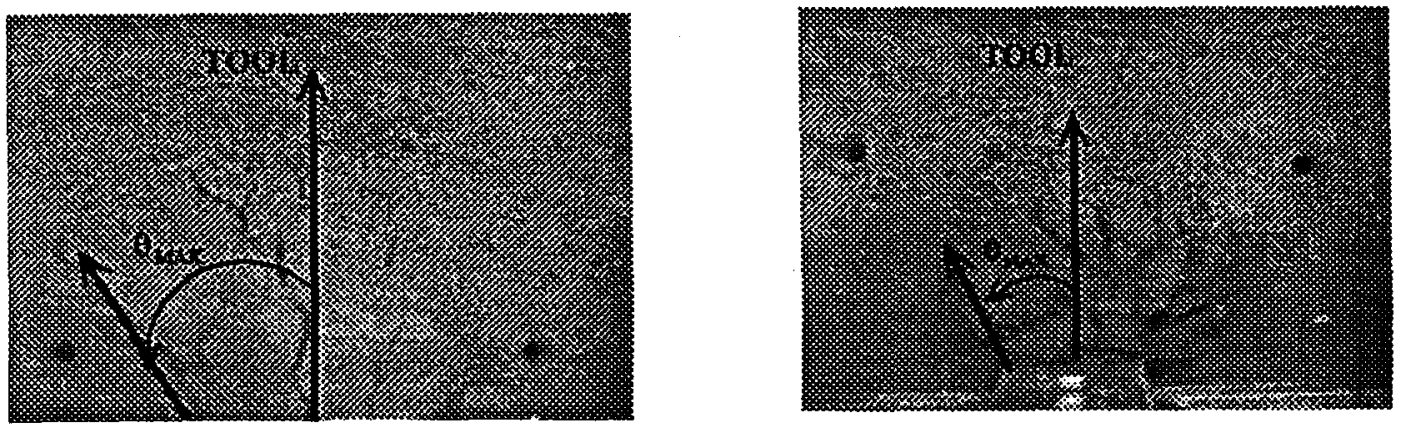
The maximum angle was measured directly from the photographs.

$601-50 ; \theta_{\max }=50^{\circ}$
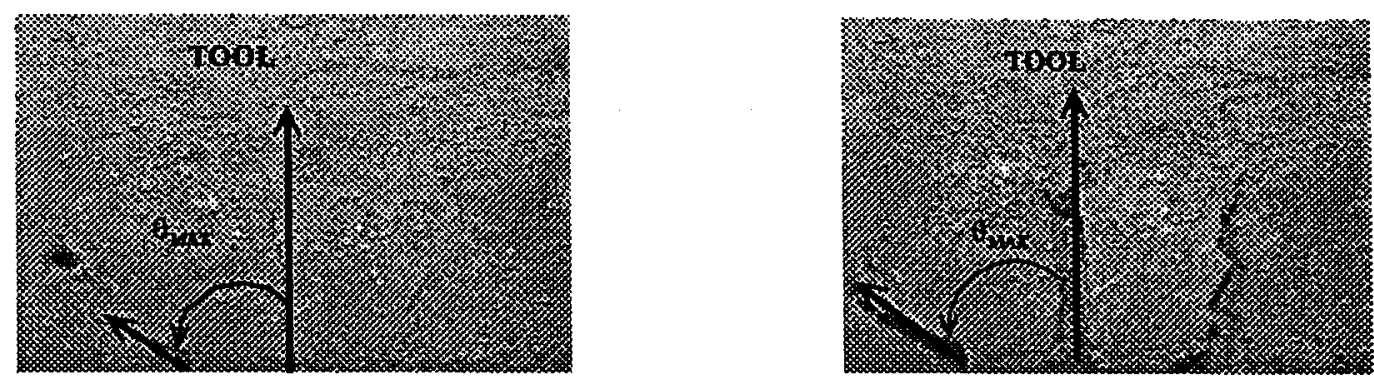

$602-50 ; \theta_{\max }=45^{\circ}$
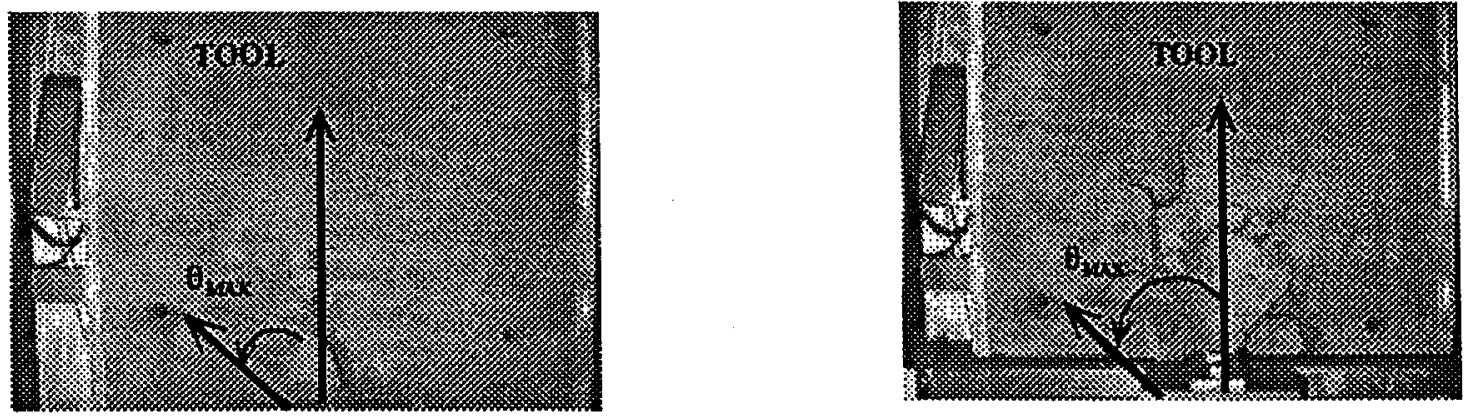

$603-50 ; \theta_{\max }=45^{\circ}$
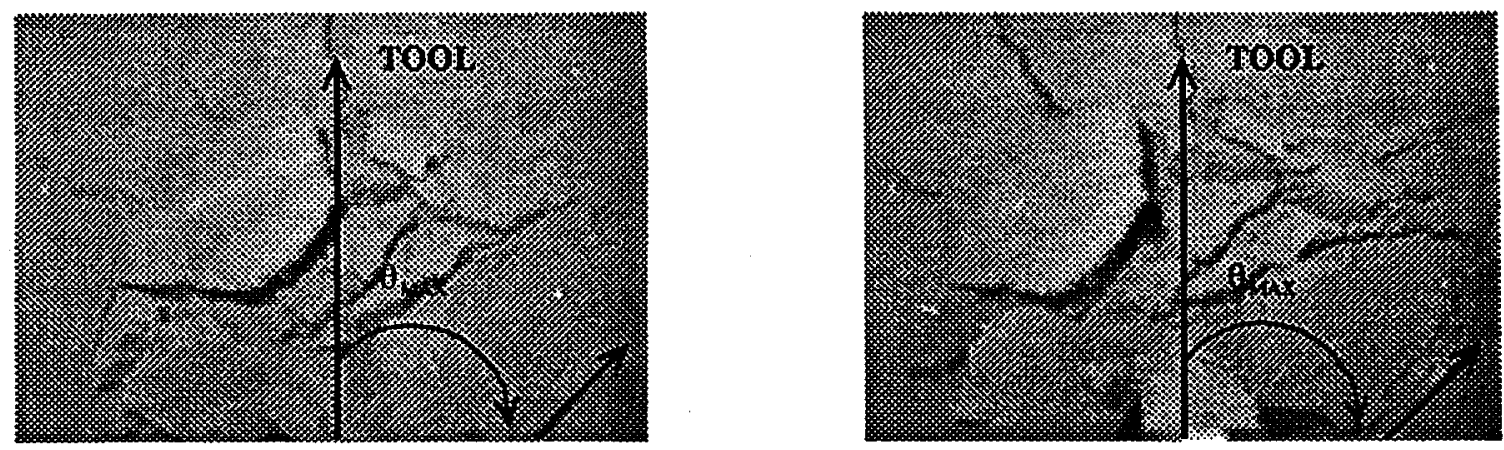
The maximum angle was measured directly from the photographs.

$601-100 ; \theta_{\max }=60^{\circ}$
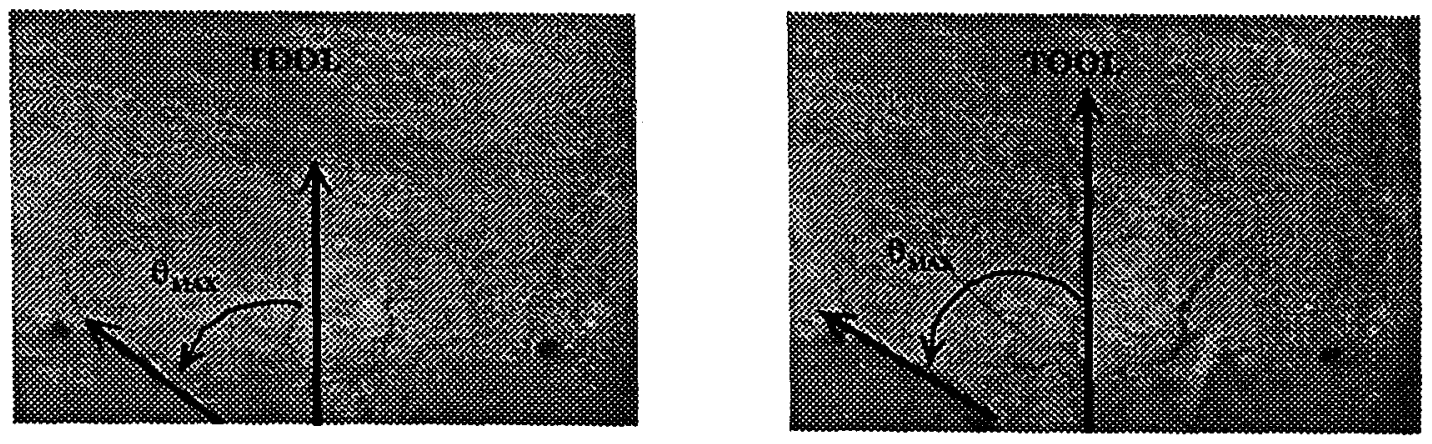

$602-100 ; \theta_{\max }=48^{\circ}$
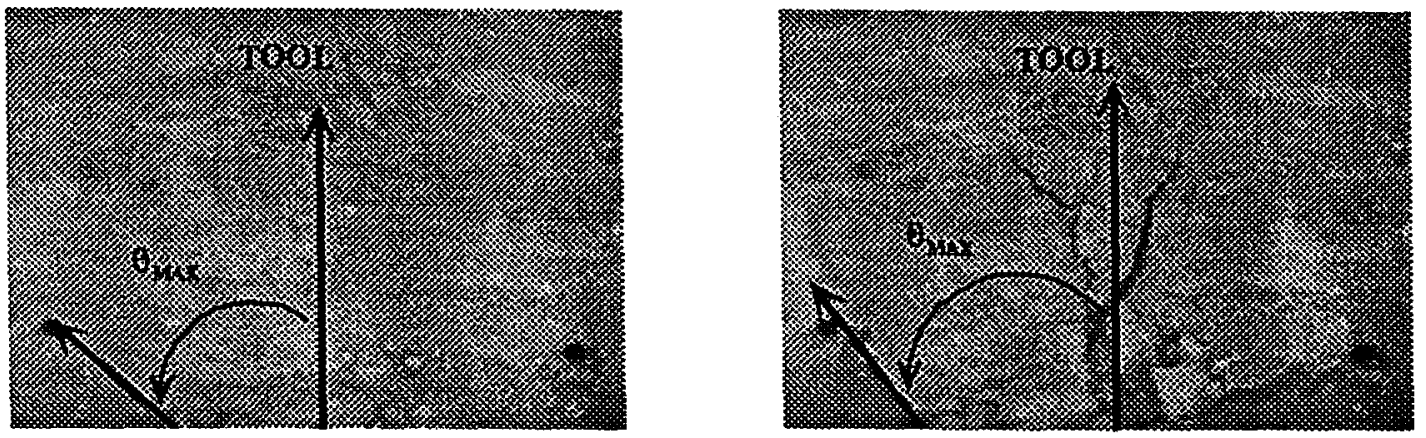

$603-100 ; \theta_{\max }=40^{\circ}$
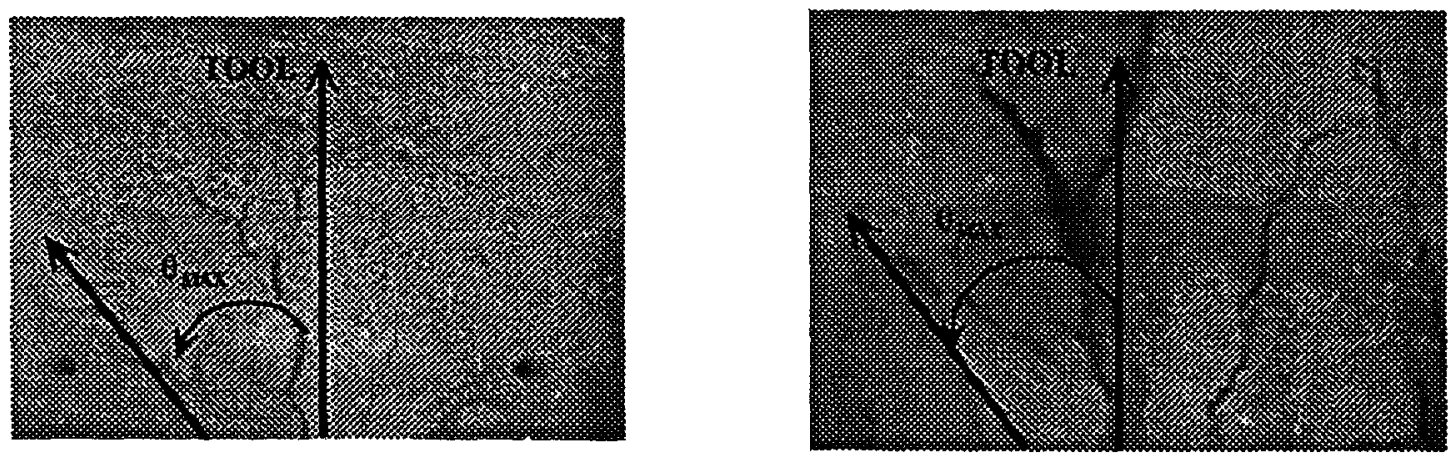
The maximum angle was measured directly from the photographs.
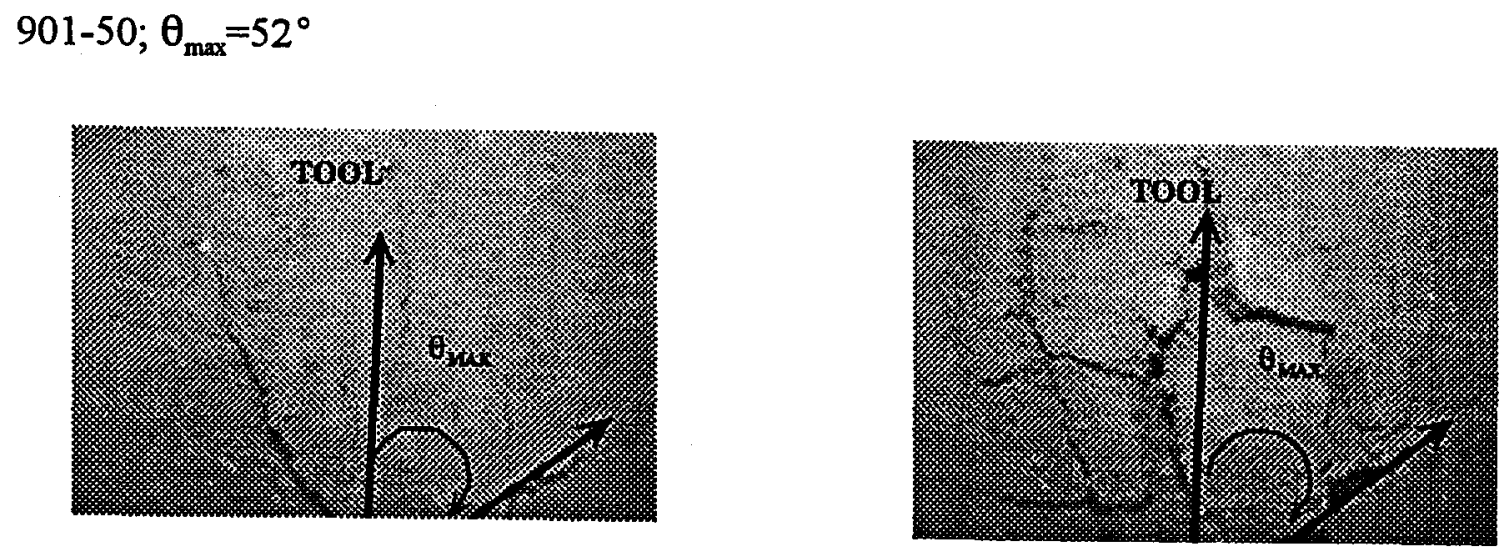

$902-50 ; \theta_{\max }=48^{\circ}$
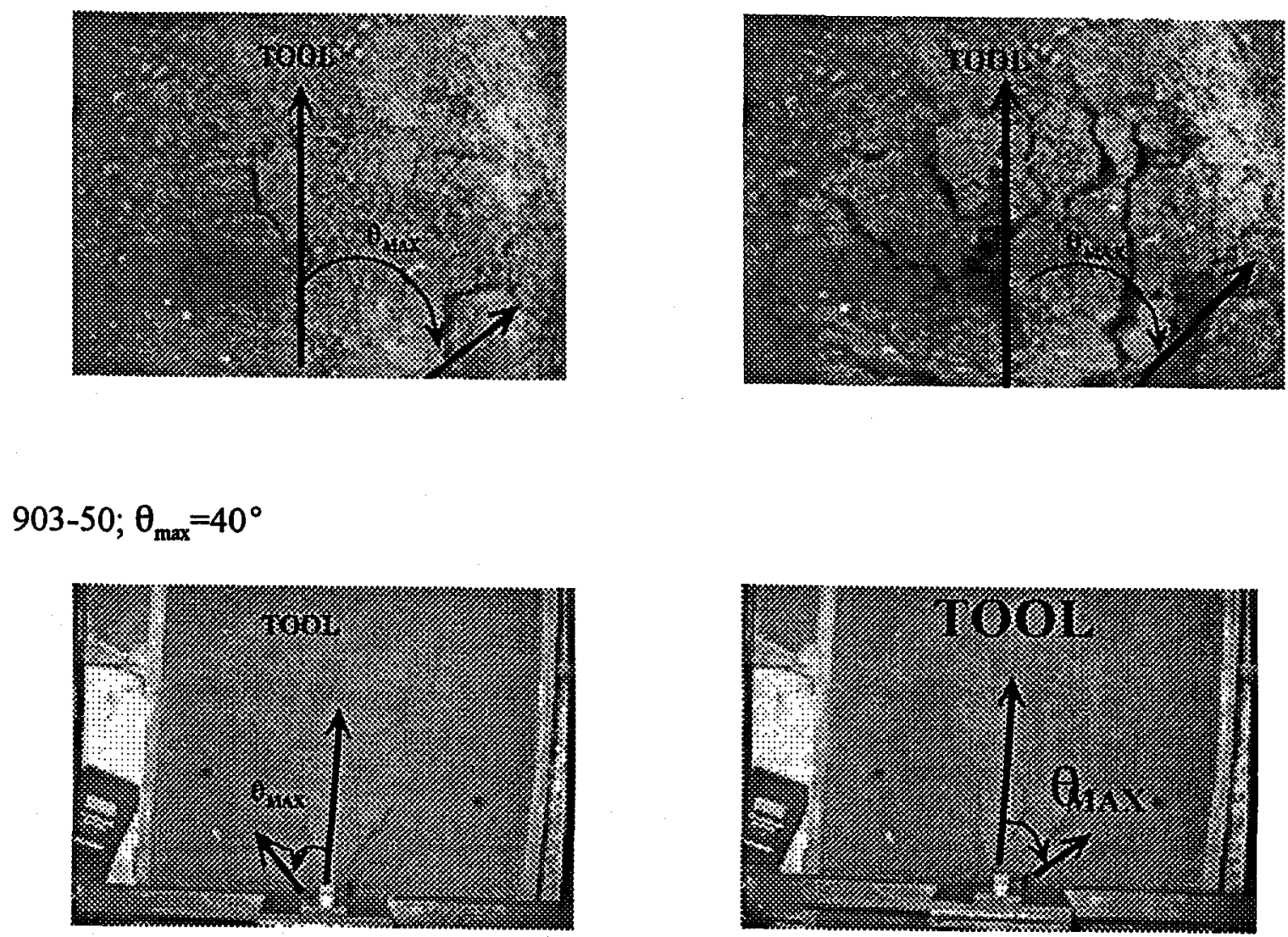
The maximum angle was measured directly from the photographs.

$901-100 ; \theta_{\max }=45^{\circ}$
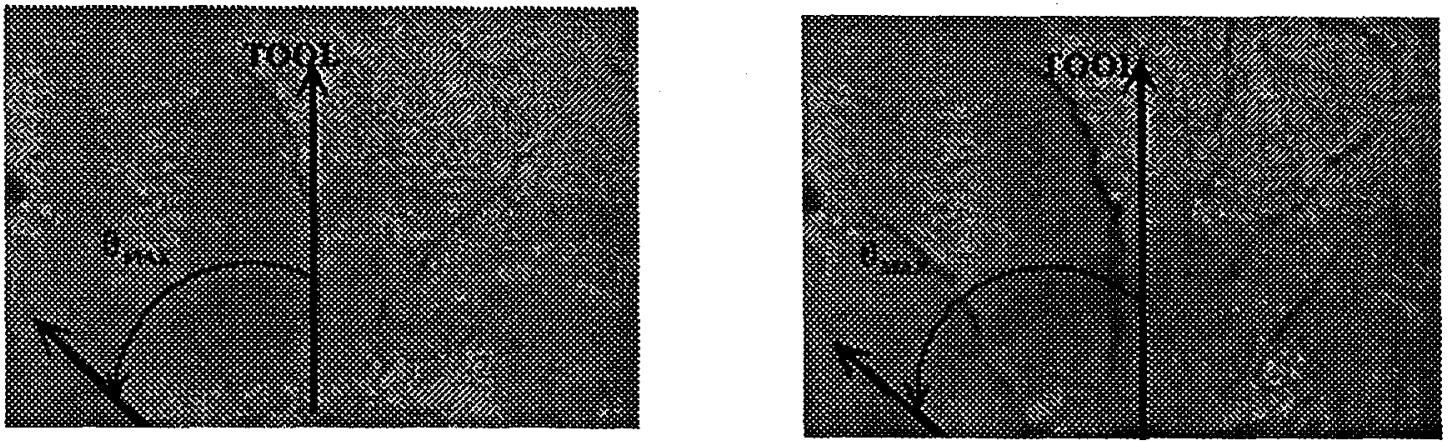

$902-100 ; \theta_{\max }=50^{\circ}$
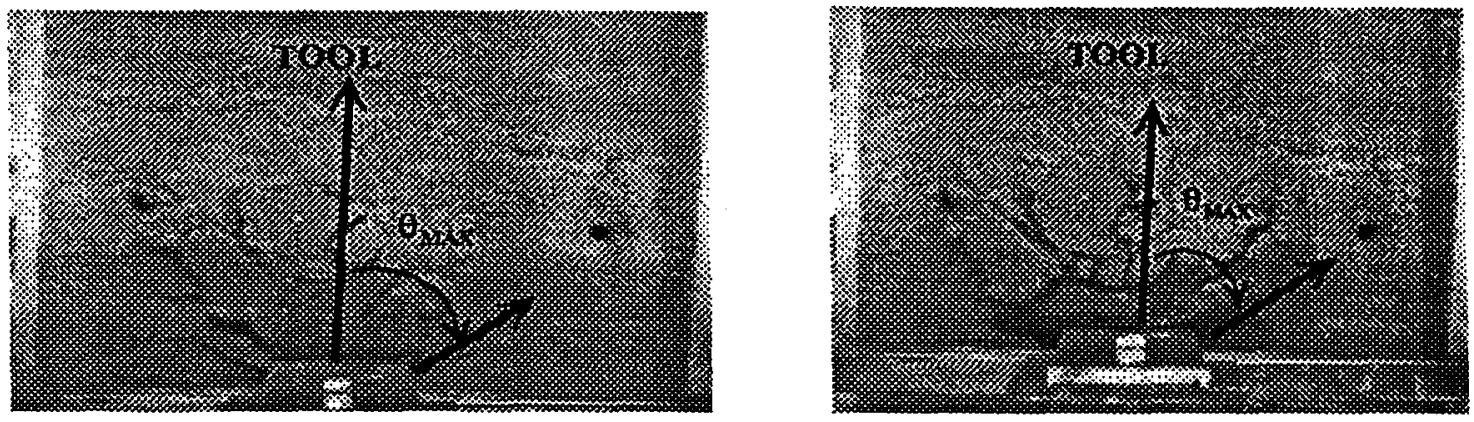

$903-100 ; \theta_{\max }=43^{\circ}$

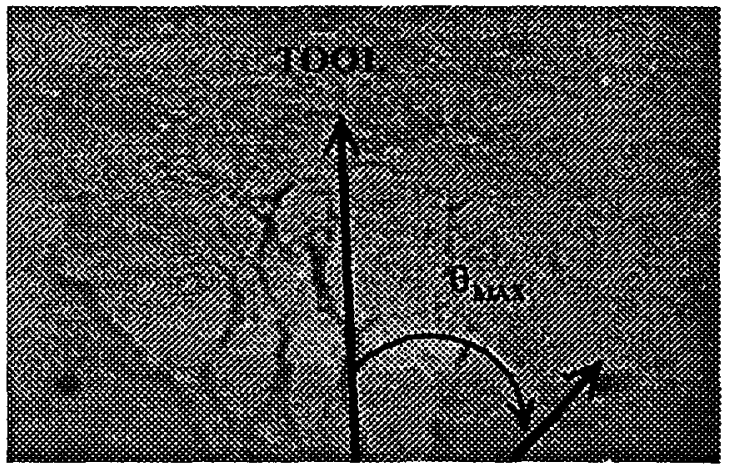

$-128-$ 


\section{APPENDIX C: \\ MINOR NORMAL STRESS CONTOURS AND TENSION FRACTURING DELIMITATION}


The figures on the left are maps of contours for each test. The figures on the right show the contour equal to the tensile strength (defining the maximum angle of fracturing). That line will define the tensile fracturing zone.

$301-50 ; \theta_{\max }=72^{\circ} ; \mathrm{T}=-0.38 \mathrm{kPa}$
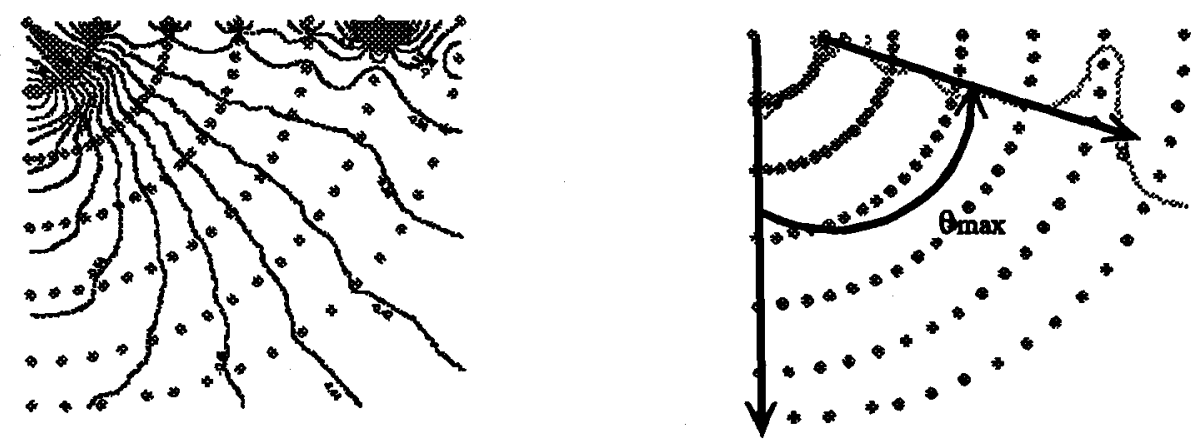

$302-50 ; \theta_{\max }=50^{\circ} ; \mathrm{T}=-0.45 \mathrm{kPa}$
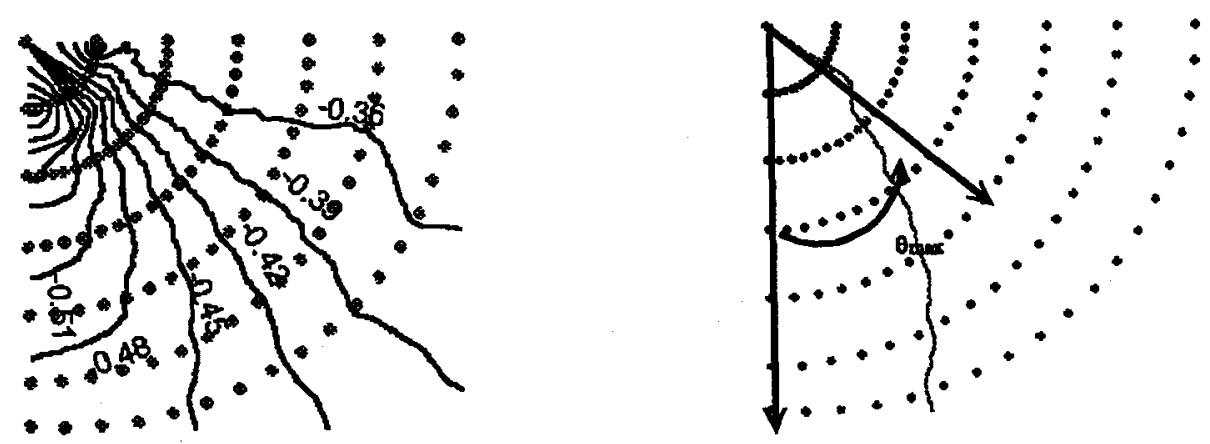

$303-50 ; \theta_{\max }=40^{\circ} ; \mathrm{T}=-0.48 \mathrm{kPa}$
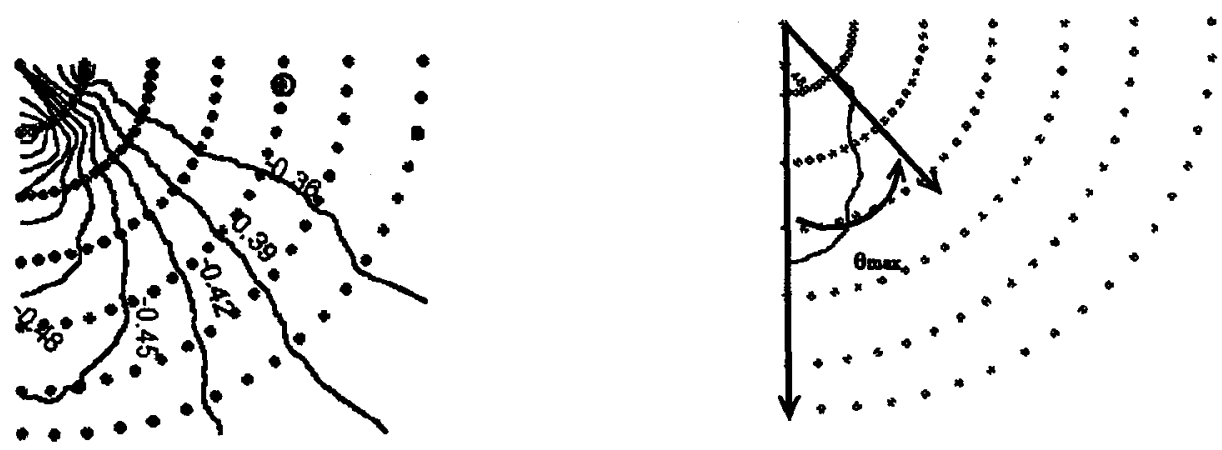
The figures on the left are maps of contours for each test. The figures on the right show the contour equal to the tensile strength (defining the maximum angle of fracturing). That line will define the tensile fracturing zone.

$301-100 ; \theta_{\max }=65^{\circ} ; \mathrm{T}=-0.38 \mathrm{kPa}$
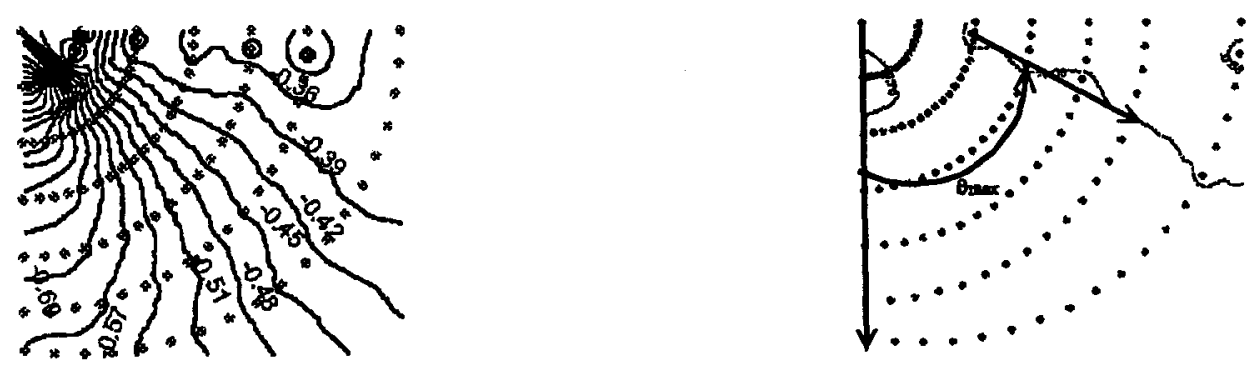

$302-100 ; \theta_{\max }=35^{\circ} ; \mathrm{T}=-0.45 \mathrm{kPa}$
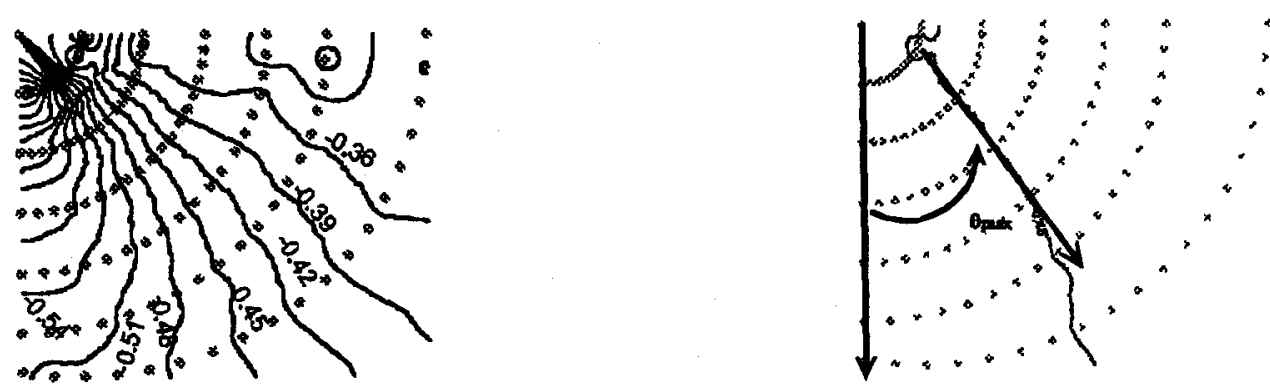

$303-100 ; \theta_{\max }=35^{\circ} ; \mathrm{T}=-0.48 \mathrm{kPa}$
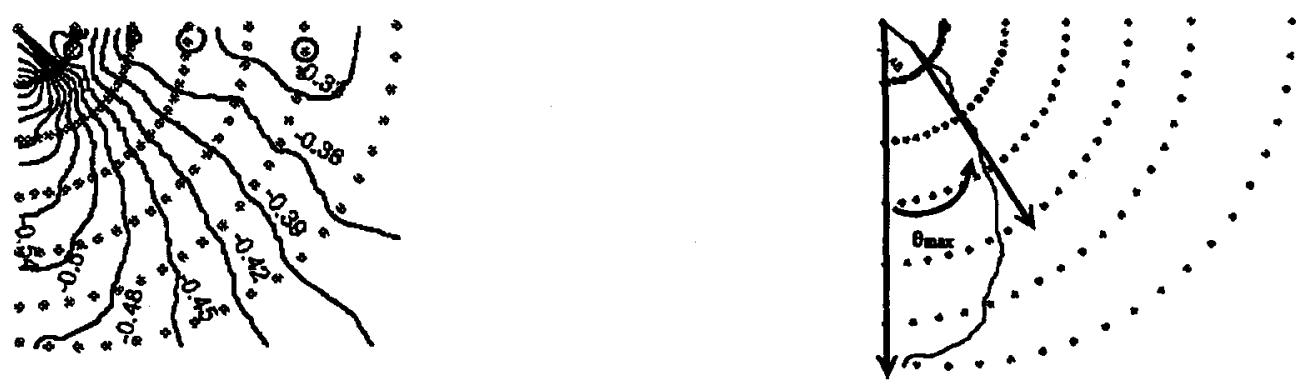
The figures on the left are maps of contours for each test. The figures on the right show the contour equal to the tensile strength (defining the maximum angle of fracturing). That line will define the tensile fracturing zone.

$601-50 ; \theta_{\max }=63^{\circ} ; \mathrm{T}=-0.38 \mathrm{kPa}$
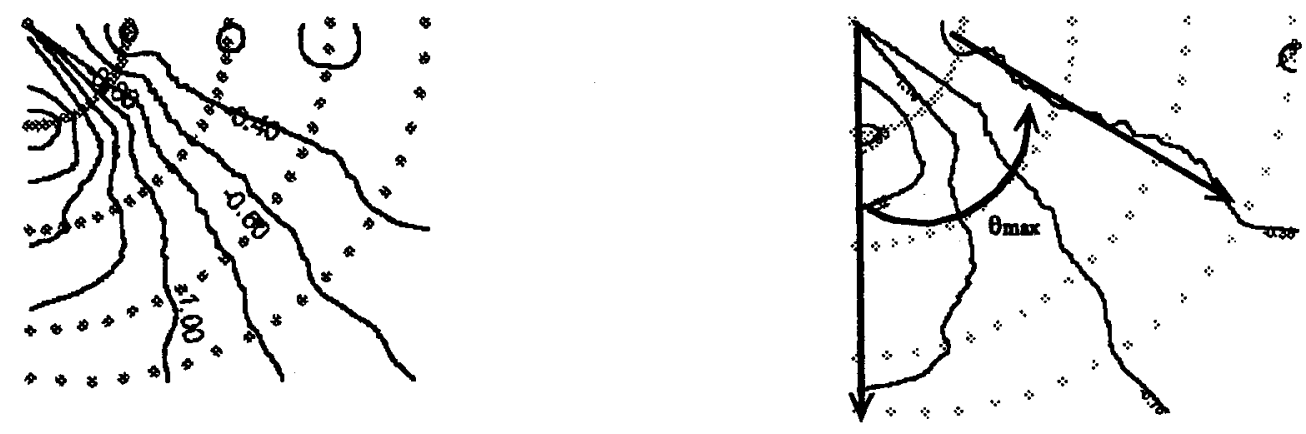

$602-50 ; \theta_{\max }=57^{\circ} ; \mathrm{T}=-0.45 \mathrm{kPa}$
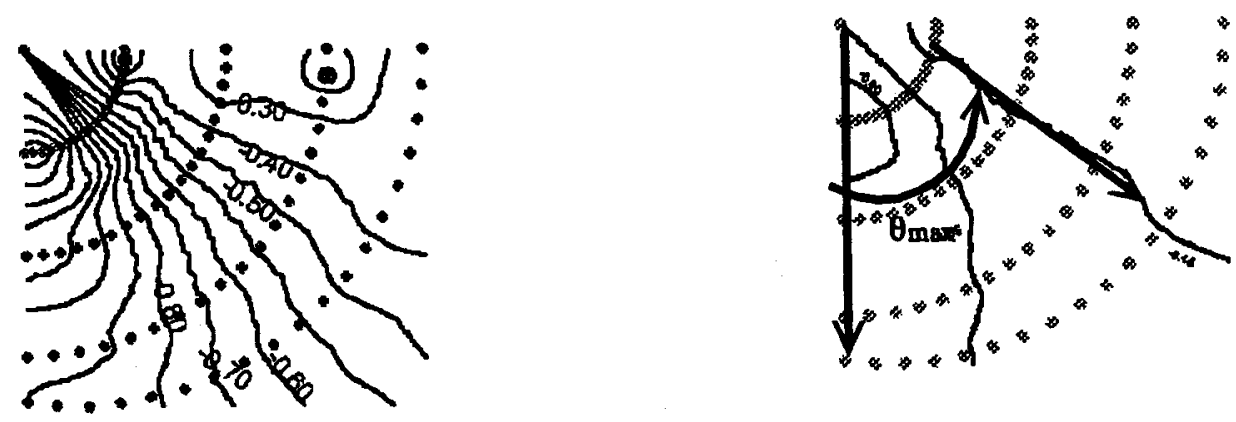

$603-50 ; \theta_{\max }=57^{\circ} ; \mathrm{T}=-0.48 \mathrm{kPa}$
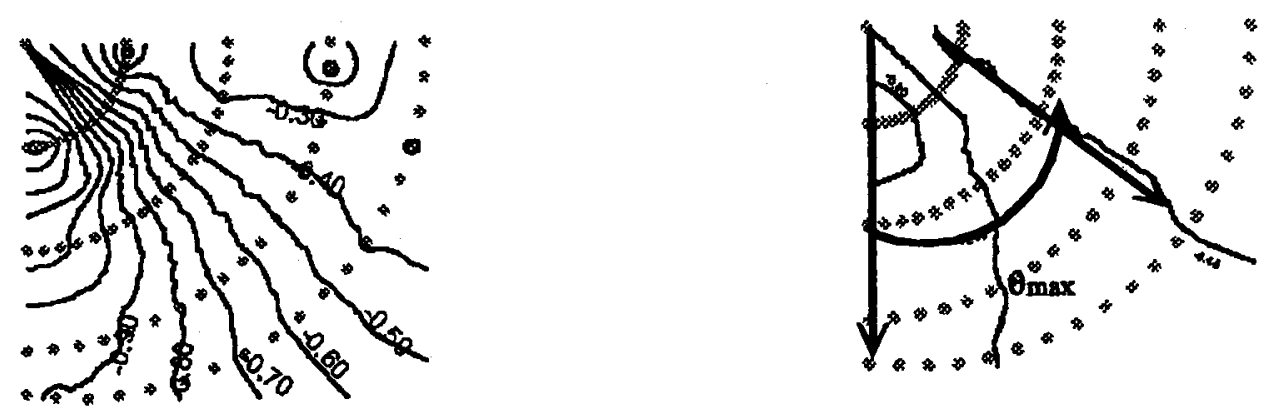
The figures on the left are maps of contours for each test. The figures on the right show the contour equal to the tensile strength (defining the maximum angle of fracturing). That line will define the tensile fracturing zone.

$601-100 ; \theta_{\max }=55^{\circ} ; \mathrm{T}=-0.38 \mathrm{kPa}$
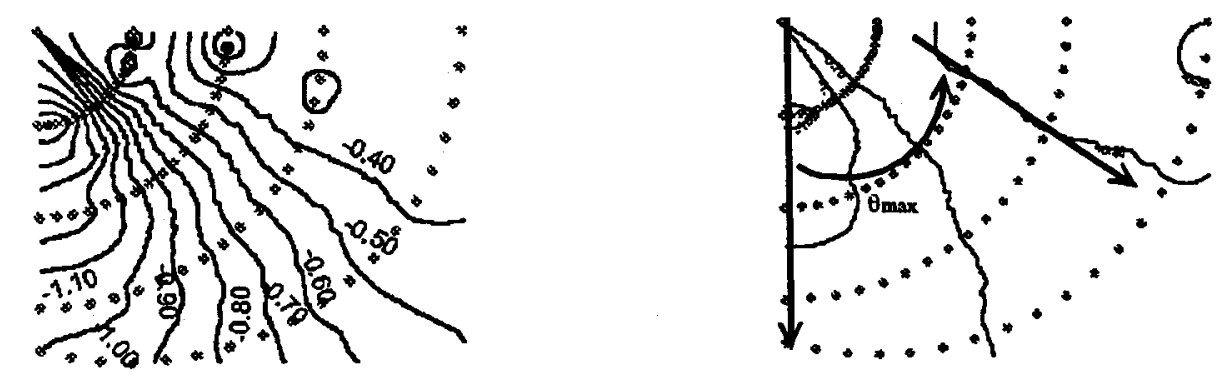

$602-100 ; \theta_{\max }=45^{\circ} ; \mathrm{T}=-0.45 \mathrm{kPa}$
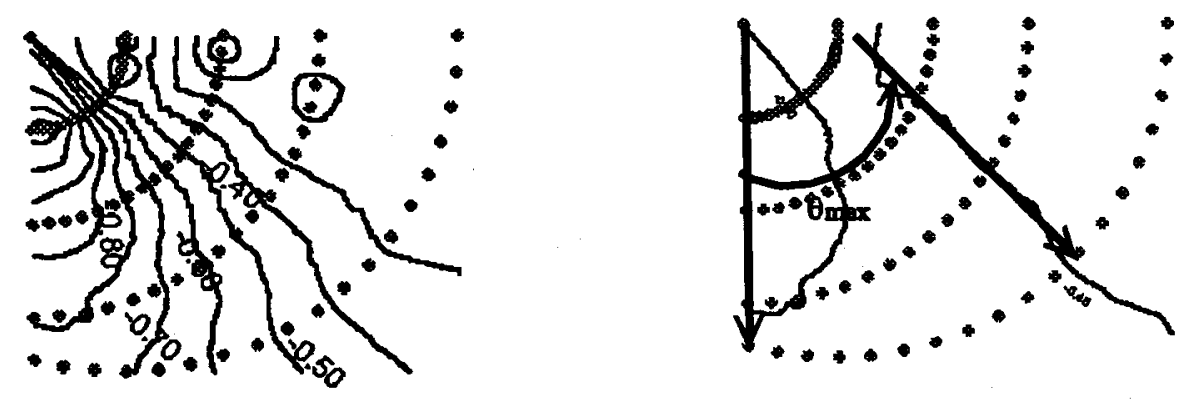

$603-100 ; \theta_{\max }=45^{\circ} ; \mathrm{T}=-0.48 \mathrm{kPa}$
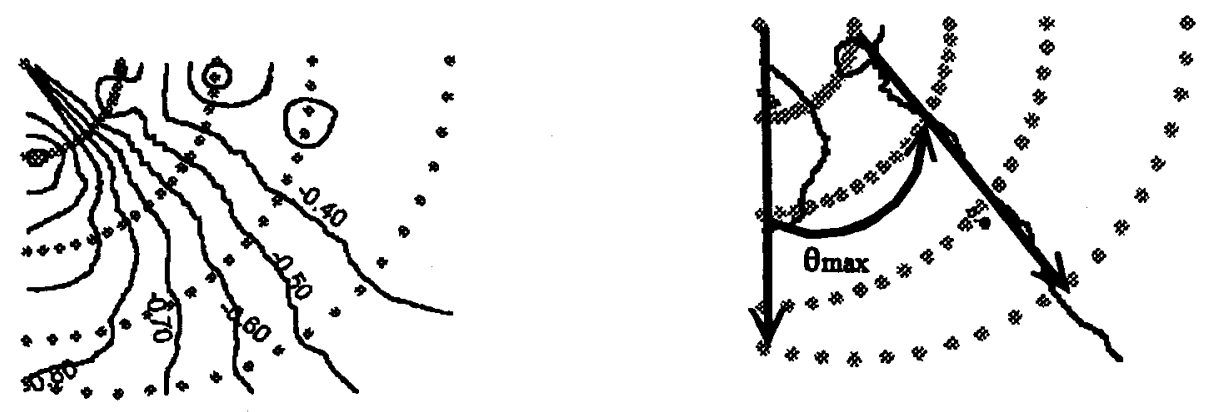
The figures on the left are maps of contours for each test. The figures on the right show the contour equal to the tensile strength (defining the maximum angle of fracturing). That line will define the tensile fracturing zone.

$$
901-50 ; \theta_{\max }=67^{\circ} ; \mathrm{T}=-0.38 \mathrm{kPa}
$$
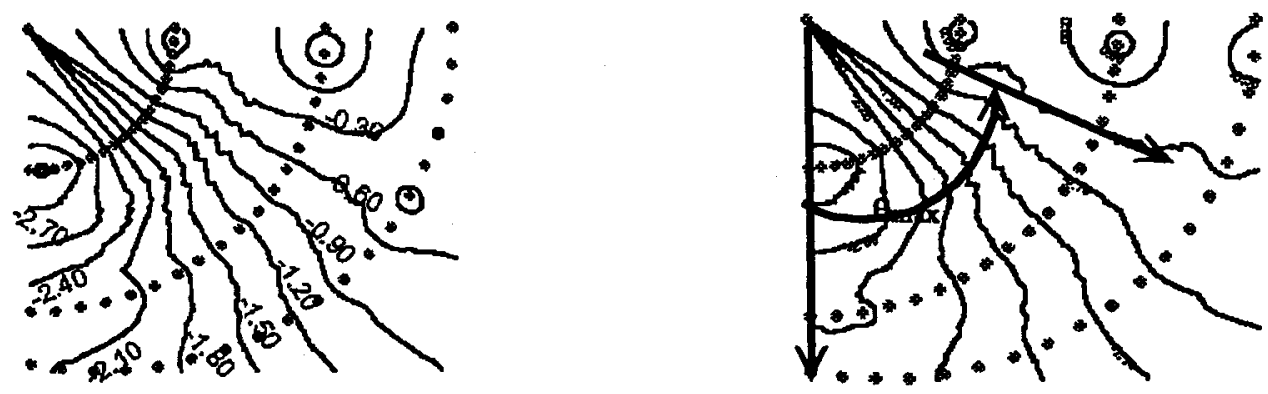

$902-50 ; \theta_{\max }=58^{\circ} ; \mathrm{T}=-0.45 \mathrm{kPa}$
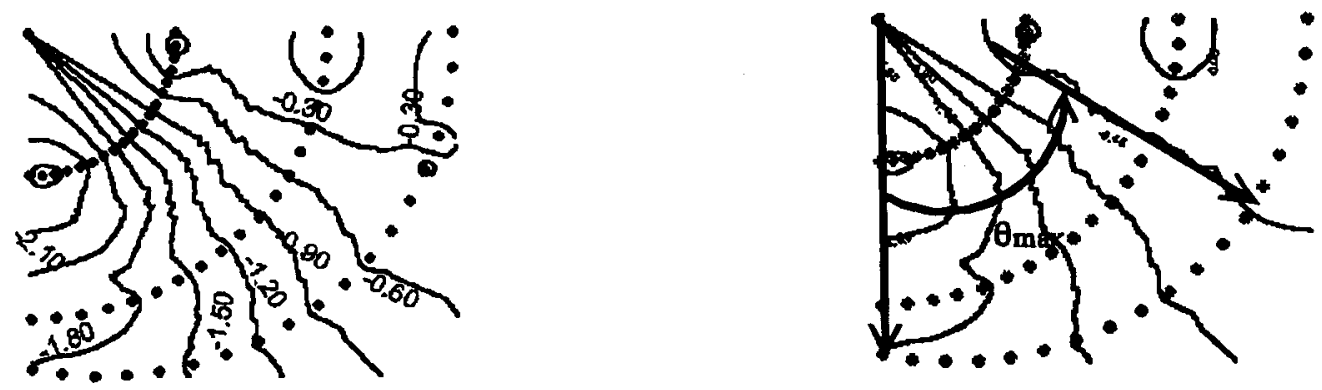

$903-50 ; \theta_{\max }=55^{\circ} ; \mathrm{T}=-0.48 \mathrm{kPa}$
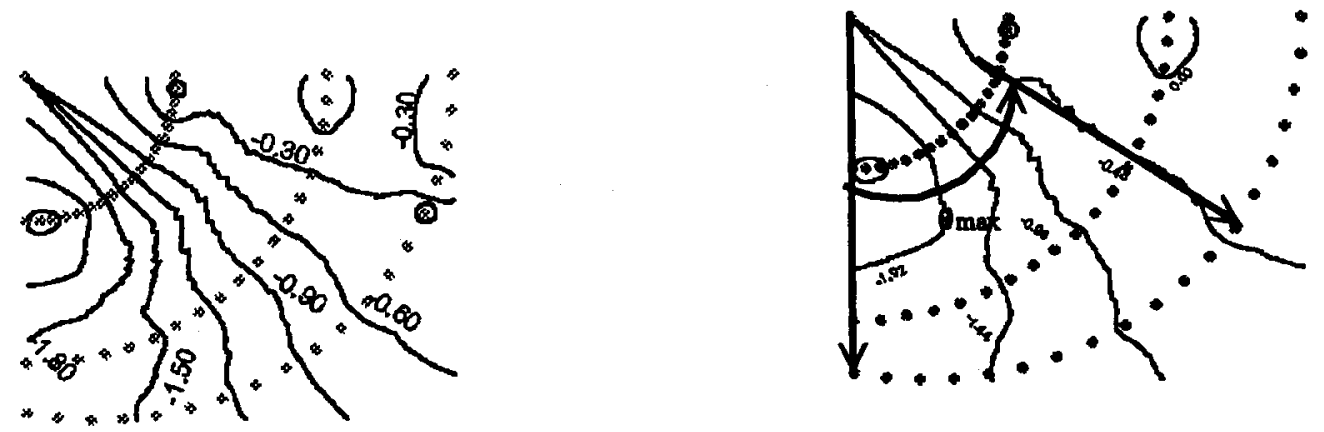
The figures on the left are maps of contours for each test. The figures on the right show the contour equal to the tensile strength (defining the maximum angle of fracturing). That line will define the tensile fracturing zone.

$901-100 ; \theta_{\max }=58^{\circ} ; \mathrm{T}=-0.38 \mathrm{kPa}$

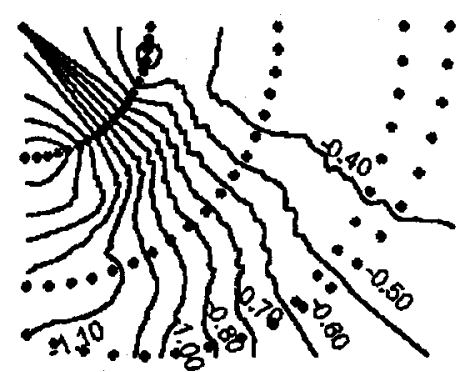

$902-100 ; \theta_{\max }=47^{\circ} ; \mathrm{T}=-0.45 \mathrm{kPa}$

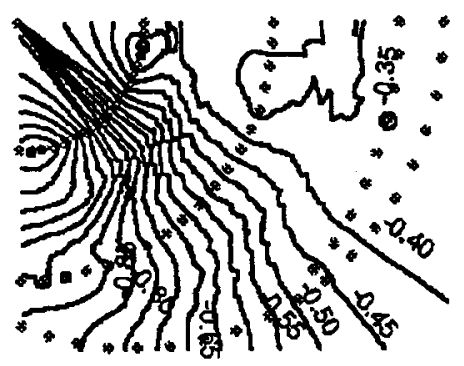

$903-100 ; \theta_{\max }=40^{\circ} ; \mathrm{T}=-0.48 \mathrm{kPa}$

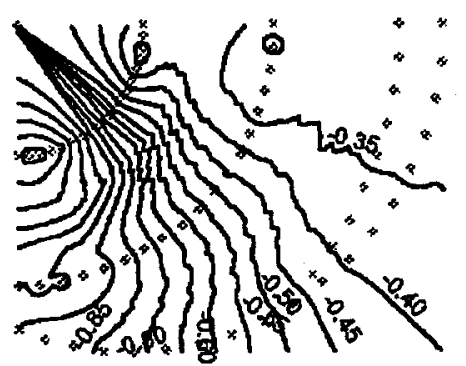

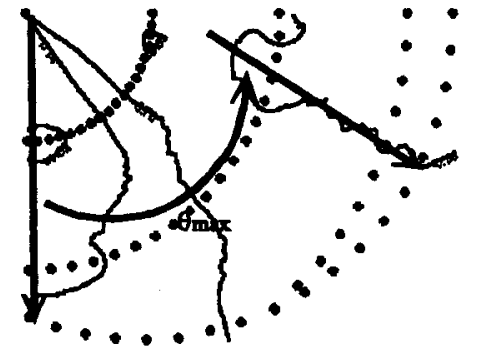
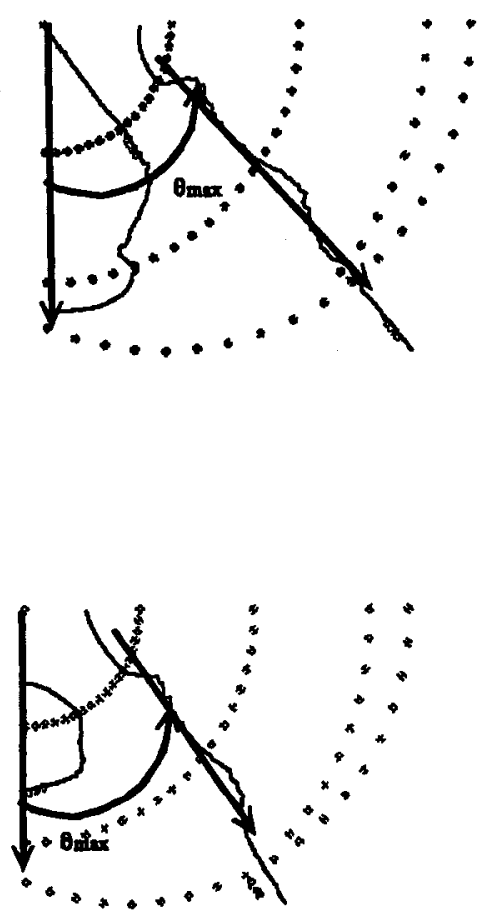